\title{
Methods for Collection and Processing of Surface-Water and Bed-Material Samples for Physical and Chemical Analyses
}

By Janice R. Ward and C. Albert Harr, Editors

U.S. GEOLOGICAL SURVEY

Open-File Report 90-140 


\section{DEPARTMENT OF THE INTERIOR \\ MANUEL LUJAN, JR., Secretary}

U.S. GEOLOGICAL SURVEY

Dallas L. Peck, Director

For additional information write to:

Chief, Office of Water Quality U.S. Geological Survey 412 National Center Reston, Virginia 22092
Copies of this report can be purchased from:

U.S. Geological Survey Books and Open-File Reports Federal Center, Building 810 Box 25425 Denver, Colorado 80225 
CONTRIBUTORS

U.S. Geological Survey contributors to this report include the following:

Robert C. Averett

Wesley L. Bradford

Linda J. Britton

C. Albert Harr
Daniel C. Hahl

Robert A. Krieger

Robert F. Middleburg

Jerry D. Stoner

John T. Turk 


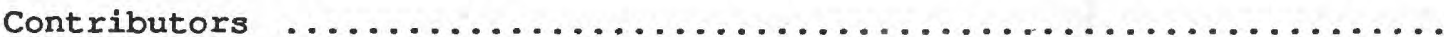

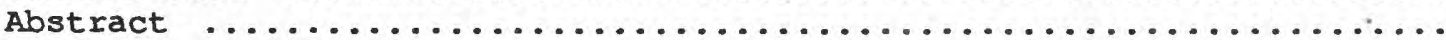

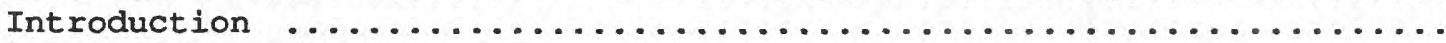

Sample collection

Streams

Representative sampling

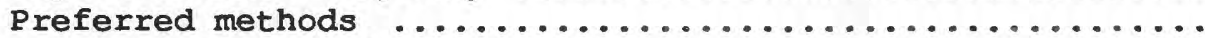

Single-vertical method

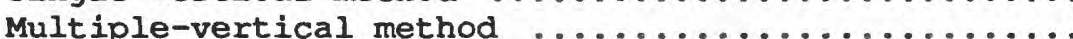

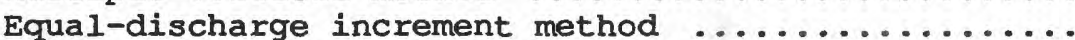

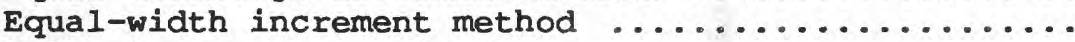

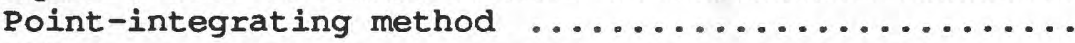

Equipment

Isokinetic samplers - principles and use ..........

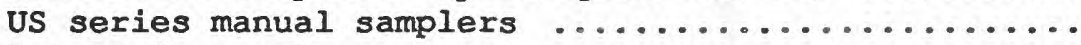

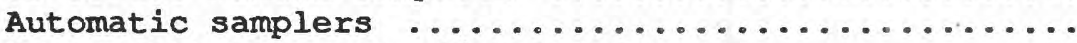

Open-mouth water-sampling bottles ...............

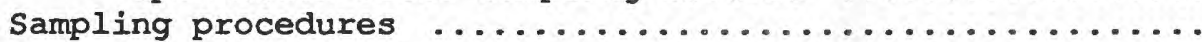

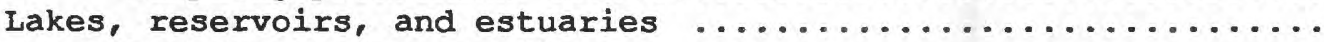

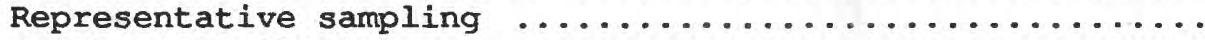

Preferred methods $\ldots \ldots \ldots \ldots \ldots \ldots \ldots \ldots \ldots \ldots \ldots \ldots \ldots$

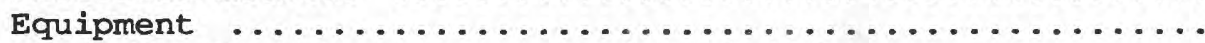

Van-Dorn type water-sampling bottles ............

Kemmerer type water-sampling bottles .............

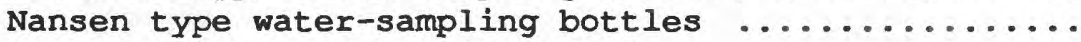

Open-mouth water-sampling bottles ...............

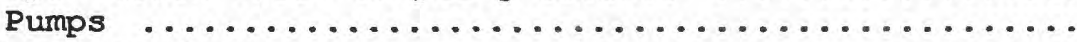

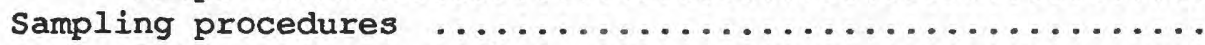

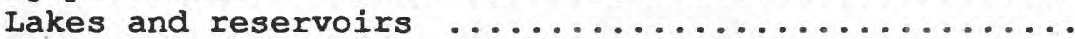

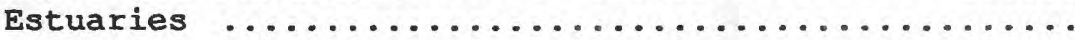

Bed materials

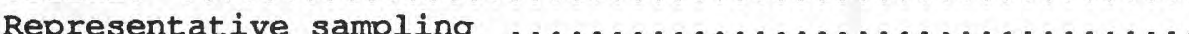

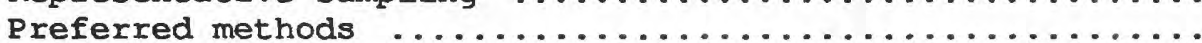

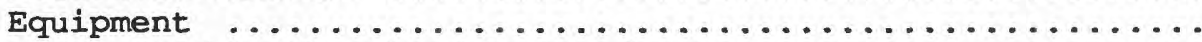

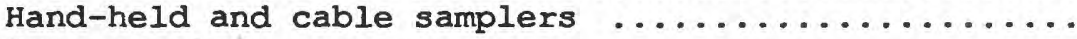

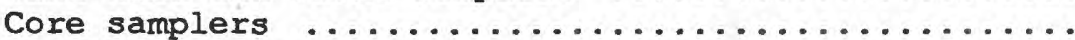

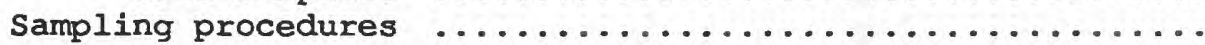

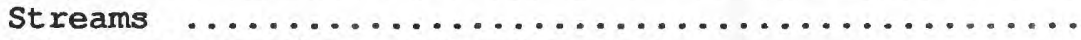

Lakes, reservoirs, and estuaries $\ldots \ldots \ldots \ldots \ldots \ldots \ldots$

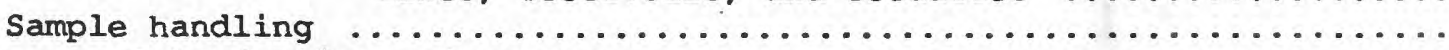

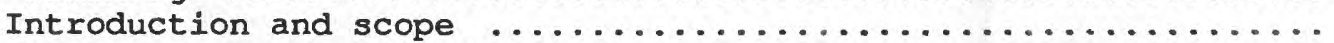

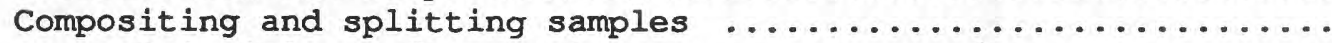

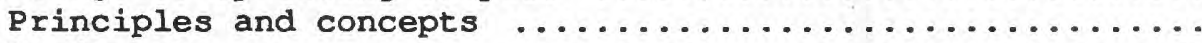

Equipment

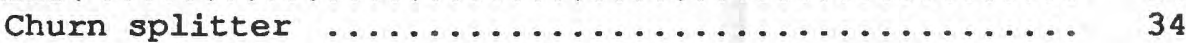

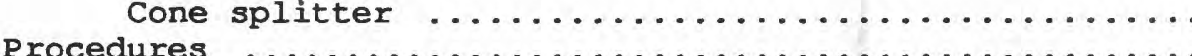

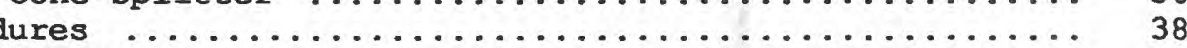

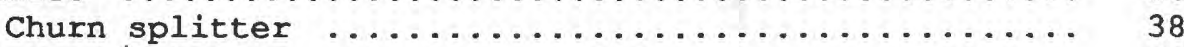

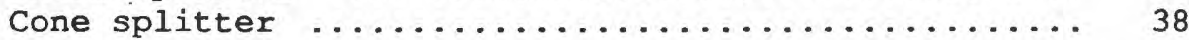


Filtration of water-sediment samples $\ldots \ldots \ldots \ldots \ldots \ldots \ldots \ldots \ldots$

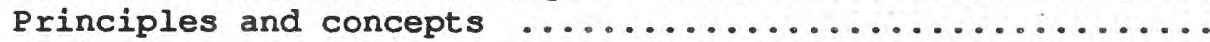

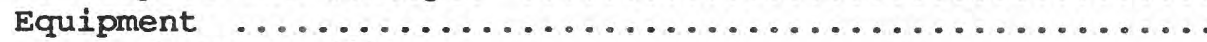

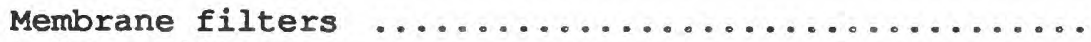

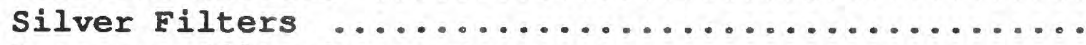

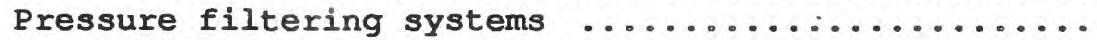

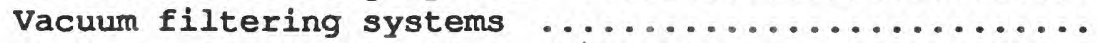

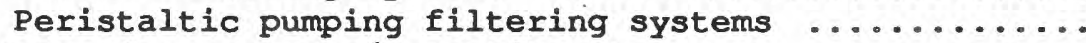
Procedures for groups of constituents ............... Major inorganic constituents and nutrients .......

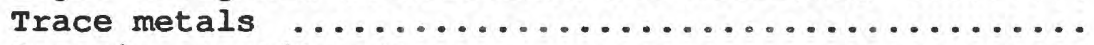

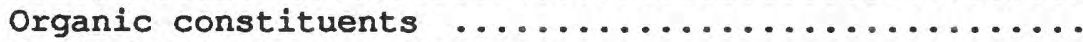

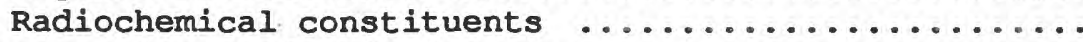

Storage, preservation, and shipping of water samples .........

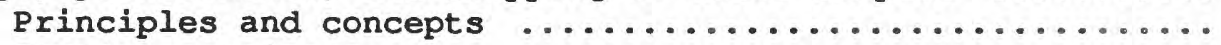
Sample containers

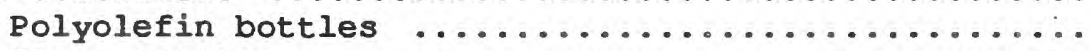

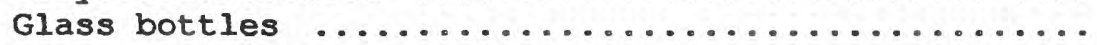

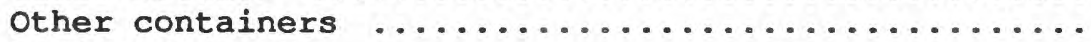

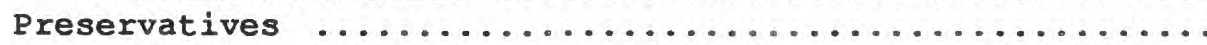

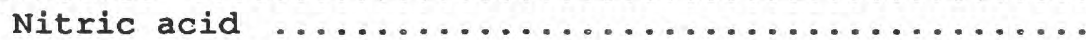

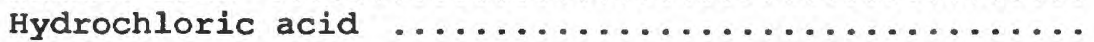

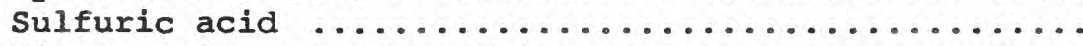

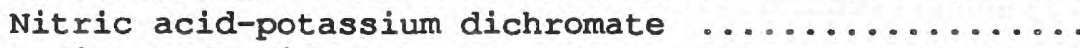

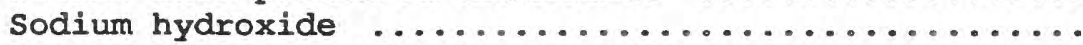

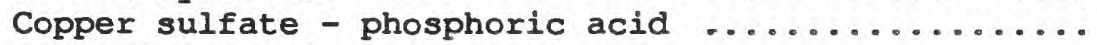

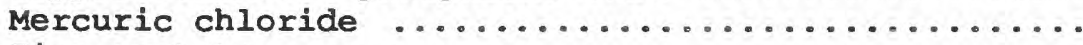

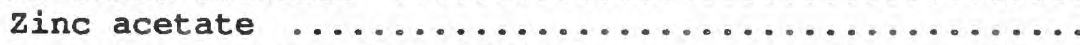

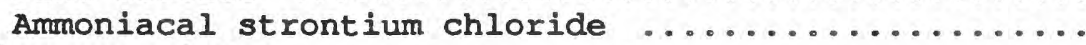

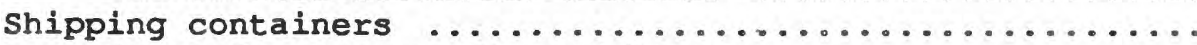

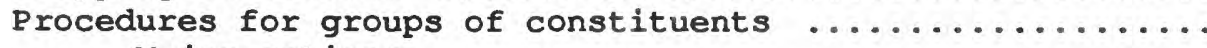

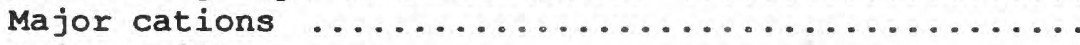

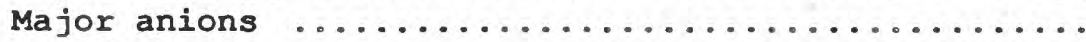

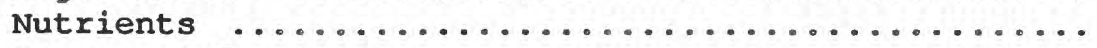

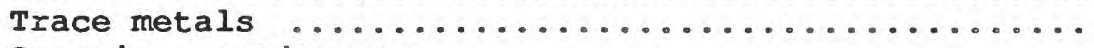

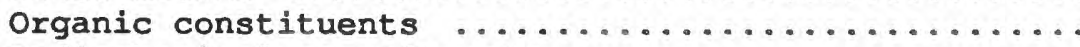

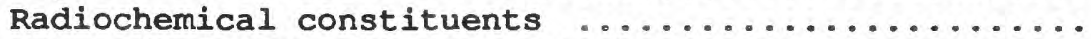

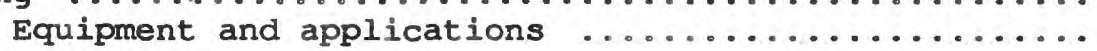

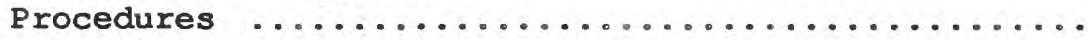

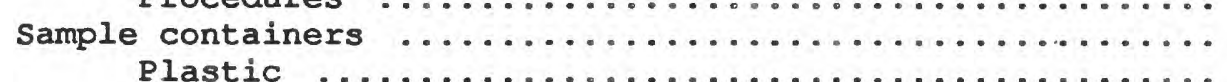

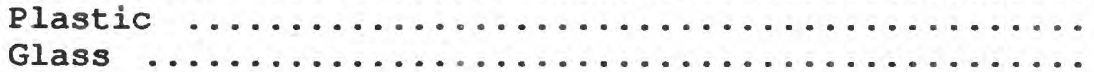

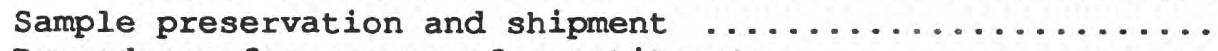

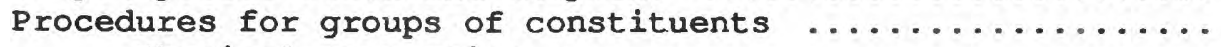

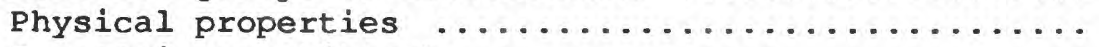

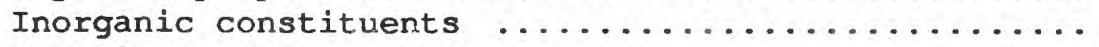


1. Sampled and unsampled zones in a stream sampling vertical with respect to velocity of flow and sediment

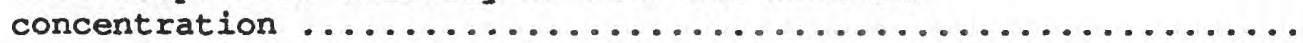

2. The distribution of stream velocity and concentration of a constituent in a stream cross section ................

3. Relation between intake velocity and sample concentration for isokinetic and non-isokinetic sampling for particles greater than 0.062 millimeters ................

4. The single-vertical sampling method .....................

5. Nomograph to determine the number of sampling verticals required to obtain results within an acceptable relative standard error based on the percentage of sand in the sample and the mean velocity squared

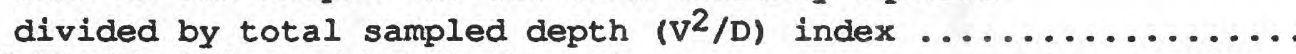

6. Weighted bottle and bottle basket .......................... 14

7. Van-Dorn type water-sampling bottle (alpha horizontal

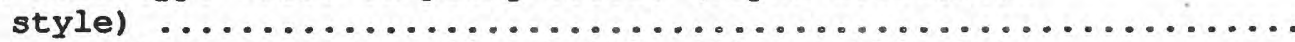

8. Kemmerex-type water-sampling bottle (A) metallic tube

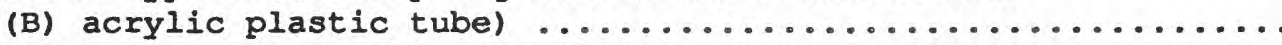

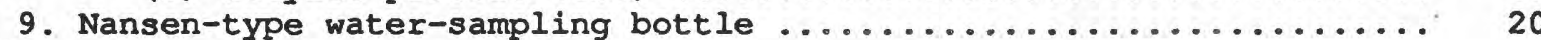

10. Bed-material core samplers: (A) standard $\mathrm{K}-\mathrm{B}$ core,

(B) Wildco hand-core, (C) heavy-duty $\mathrm{K}-\mathrm{B}$ core, and

(D) Davis-Doyle self-tripping core samplers ...............

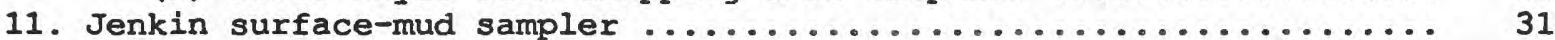

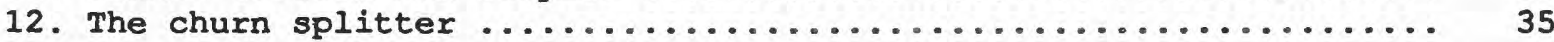

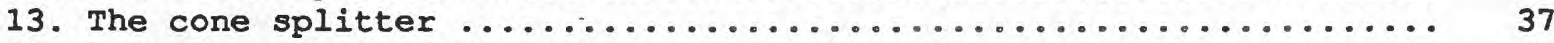

14. Relative sizes of water-borne particles .................... 39

15. Photomicrograph of surface of 0.45 micrometer

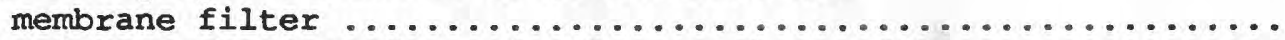

16. Photomicrograph of surface of silver membrane filter .......... 44

17. A gas-pressure filtration system ....................... 46

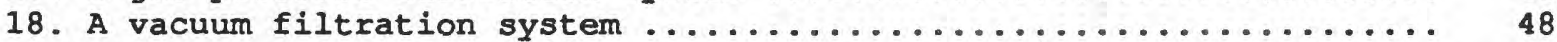

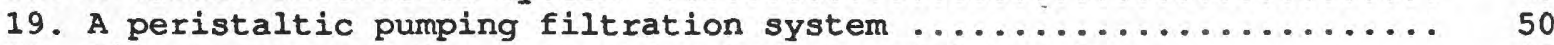

20. Sieves approved for processing bed-material samples .......... 65

\section{TABLES}

1. Sampler designations and characteristics ...................

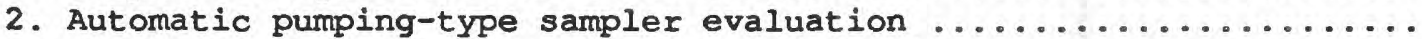

3. Classification of sediments by particle size .................

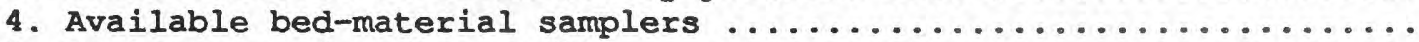

5. Resistance of membrane filters to common reagents ............. 


\begin{tabular}{|c|c|c|}
\hline & Length & \\
\hline \multirow[t]{2}{*}{$\begin{array}{l}\text { inch }(i n .) \\
\text { foot }(f t)\end{array}$} & $\begin{array}{l}25.4 \\
0.3048\end{array}$ & $\begin{array}{l}\text { millimeter (mm) } \\
\text { meter (m) }\end{array}$ \\
\hline & Area & \\
\hline \multirow[t]{2}{*}{$\begin{array}{l}\text { square inch }\left(\mathrm{in}^{2}\right) \\
\text { square foot }\left(\mathrm{ft}^{2}\right)\end{array}$} & $\begin{array}{l}6.452 \\
929.0\end{array}$ & $\begin{array}{l}\text { square centimeter }\left(\mathrm{cm}^{2}\right) \\
\text { square centimeter }\left(\mathrm{cm}^{2}\right)\end{array}$ \\
\hline & Volume & \\
\hline \multirow[t]{2}{*}{$\begin{array}{l}\text { U.S. liquid pint (pt) } \\
\text { U.S. liquid quart (qt) } \\
\text { U.S. liquid gallon (gal) } \\
\text { U.S. liquid gallon (gal) } \\
\text { U.S. liquid gallon (gal) } \\
\text { cubic foot ( } \mathrm{ft}^{3} \text { ) }\end{array}$} & $\begin{array}{c}0.4732 \\
0.9464 \\
3.785 \\
3,785 \\
0.003785 \\
28,320\end{array}$ & $\begin{array}{l}\text { liter }(\mathrm{I}) \\
\text { liter }(\mathrm{I}) \\
\text { liter }(\mathrm{L}) \\
\text { milliliter }(\mathrm{mL}) \\
\text { cubic meter }\left(\mathrm{m}^{3}\right) \\
\text { cubic centimeter }\left(\mathrm{cm}^{3}\right)\end{array}$ \\
\hline & Flow & \\
\hline \multirow[t]{2}{*}{$\begin{array}{l}\text { foot per second (ft/s) } \\
\text { cubic foot per second }\left(\mathrm{ft}^{3} / \mathrm{s}\right)\end{array}$} & $\begin{array}{l}0.3048 \\
0.02832\end{array}$ & $\begin{array}{l}\text { meter per second }(\mathrm{m} / \mathrm{s}) \\
\text { cubic meter per second }\left(\mathrm{m}^{3} / \mathrm{s}\right)\end{array}$ \\
\hline & Mass & \\
\hline \multirow[t]{2}{*}{$\begin{array}{l}\text { ounce, avoirdupois (oz) } \\
\text { ounce, avoirdupois }(\mathrm{oz}) \\
\text { pound, avoirdupois (lb) } \\
\text { ton, short }\end{array}$} & $\begin{array}{l}28.35 \\
28.350 \\
453.6 \\
0.9072\end{array}$ & $\begin{array}{l}\operatorname{gram}(\mathrm{g}) \\
\text { militigram (mg) } \\
\text { gram (g) } \\
\text { megagram (Mg) }\end{array}$ \\
\hline & Temperature & \\
\hline degree Fahrenheit $\left({ }^{\circ} \mathrm{F}\right)$ & ${ }^{\circ} \mathrm{C}=5 / 9 \quad\left({ }^{\circ} \mathrm{F}-32\right)$ & degree Celsius $\left({ }^{\circ} \mathrm{C}\right)$ \\
\hline
\end{tabular}


UNIT. CONVERSION

Multiply inch-pound unit

By

To obtain metric unit

\section{Pressure}

pound per square inch $\left(1 \mathrm{~b} / \mathrm{in}^{2}\right)$

6.895 kilopascal (kPa)

Concentration (Mass/Volumel

parts per million (ppm)*

ounces per quart (oz/qt)

pounds per cubic foot, $\left(1 \mathrm{~b} / \mathrm{ft}^{3}\right)$
1.0

29,960

16,020 milligrams per liter ( $\mathrm{mg} / \mathrm{L}$ ) milligrams per liter (mg/L) grams per cubic meter $\left(\mathrm{g} / \mathrm{m}^{3}\right)$

* This conversion is true for

$$
\mathrm{mg} / \mathrm{L}=\mathrm{c}(\mathrm{ppm})=\mathrm{C}\left[\frac{\text { Weight of sediment } \times 10^{6}}{\text { Weight of water-sediment mixture }}\right]
$$

when the ratio of weight of sediment to weight of water-sediment mixture is between 0 and 8,000 . If this ratio is greater than 8,000 , the investigator is referred to U.S. Geological Survey, Water Resources Division, Quality of Water Branch Technical Memorandum No. 72.10, tables 1 and 2, for the correct conversion factor to be used in the formula. 


\title{
METHODS FOR COLLECTION AND PROCESSING OF SURFACE- WATER AND BED-MATERIAI SAMPLES FOR PHYSICAI AND CHEMICAL ANALYSES
}

\author{
by \\ Janice R. Ward and C. Albert Harr, Editors
}

\begin{abstract}
Many Federal, State, and local agencies and the private sector can make best use of water-quality data if data-collection and analysis techniques are standardized. This manual describes the methods used by the U.S. Geological Survey for the collection and processing of surface-water and bed-material samples for the determination of their chemical and physical characteristics. It complements the report entitled "Field Methods for Measurement of Fluvial Sediment" by T. K. Edwards and G. D. Glysson (U.S. Geological Survey Open-File Report 86-531, 118 p., 1988), and those procedures and equipment described in that publication are referenced rather than repeated in this one. This manual describes equipment and procedures used for sample handing, and the containers and reagents used for the storage, preservation, and shipment of samples.
\end{abstract}

\section{INTRODUCTION}

The purpose of this manual is to document and describe the procedures used by the U.S. Geological Survey for the collection and processing of water-sediment ${ }^{1}$ samples from surface water and of material from the beds of surface-water bodies for physical and/or chemical analyses. Procedures for the collection and processing of samples for biological analysis are described in the U.S. Geological Survey Open-File Report 88-190 (Britton and Greeson, eds.. 1988). Detailed discussion of field methods and equipment for measuring fluvial sediment is given in the U.S. Geological Survey Open-File Report 86-531 (Edwards and Glysson, 1988).

\section{SAMPLE COLLECTION}

Water-sediment samples are collected and analyzed to determine the chemical composition and the biological and physical characteristics of a water body; to determine its suitability for domestic, industrial, and agricultural uses; to aid in understanding the geochemical and hydrologic relations; and to evaluate human influences on these systems. An essential phase of the data-collection process, and one that is of primary importance to the accuracy of the final result, is obtaining representative samples for analysis. Errors introduced by sampling can be the most significant in the entire data-collection process. The degree to which a single sample can be considered representative of a large water body depends on several factors, which include the homogeneity of the water body sampled, the number of points sampled, the size of the individual samples, and the manner in which samples are collected.

\footnotetext{
${ }^{1}$ Used throughout this report, the term refers to water and/or a mixture of water and suspended sediment:
} 
A stream or lake vertical, which is sampled using the depth-or pointintegrated samplers discussed later, is shown in figure 1 . The vertical is divided into a sampled zone and an unsampled zone, whose depths are determined by the design of the sampler. The unsampled zone generally carries a higher concentration and larger particles of sediment than the sampled zone. sediment transported in this zone consists of both bedload and suspendedsediment load, whereas sediment transported in the sampled zone is almost entirely suspended-sediment load. Only the sampled zone will be addressed in this report.

\section{Streams}

\section{Representative Sampling}

The need for each sample, or set of samples taken nearly simultaneously, to represent the chemical composition and the biological and physical characteristics of the whole flow of a stream at the sampling point at an instant, and the need for enough samples distributed in time or space to define the changes that occur in the water passing the sampling point or along a stream course, need to be considered for representative sampling of

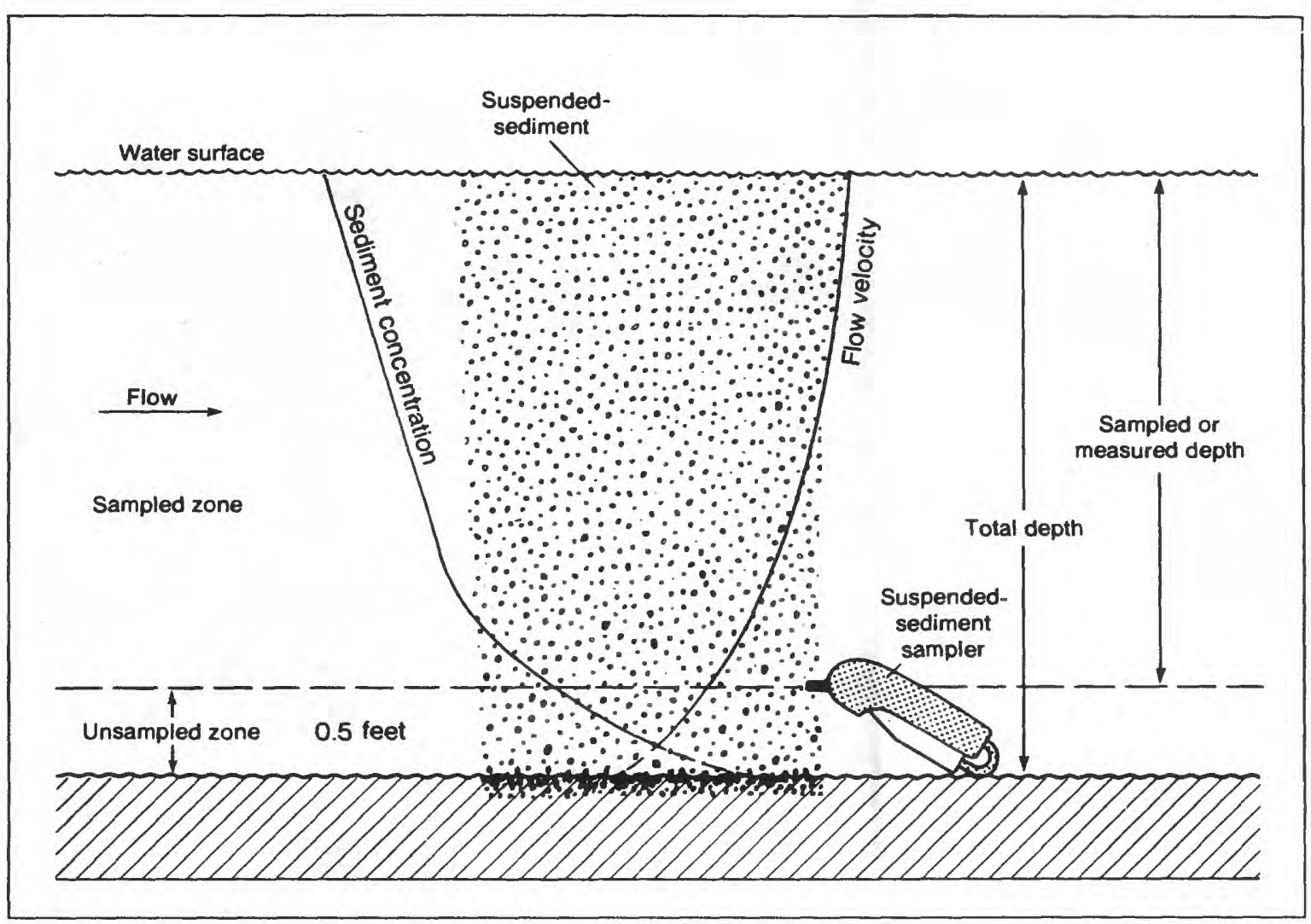

(Not to scale)

Figure 1. Sampled and unsampled zones in a stream sampling vertical with respect to velocity of flow and sediment concentration. 
flowing waters. If the properties and conditions of a stream and the water in it were completely homogeneous, the collection of representative samples would be a simple task: However, because most streams are not homogeneous, the representativeness of samples depends on the equipment and collection method used.

Each sampling site needs to be examined and sampled in a manner that minimizes its disadvantages and maximizes its advantages. Physical factors, such as the amount of turbulence, velocity gradients, and proximity of inflows, partially determine the homogeneity of a stream at a cross section (fig. 2). Below the confluence of streams there can be a distinct separation due to differences in the concentration of dissolved solids, suspended sediment, or water temperature. The difficulties these features present in obtaining a sample representative of the flow past a point can be minimized by careful selection of the sampling-cross section. Theoretically, a sample representative of the mean composition can be obtained by combining depthintegrated samples of equal volume taken at points in the cross section representing segments of equal flow (Hem, 1970, 1985).

To obtain samples representative of the water-sediment mixture, the samplex needs to be filled isokinetically; that is, water approaching the sampler does not change in velocity or direction as it enters the intake. Thus, the concentration of sediment in the water-sediment mixture in the sampler and its concentration in the stream are equal (fig. 3a). If the velocity in the nozzle is less than the stream velocity in the vicinity of the sampler, the concentration of sediment in the water-sediment mixture in the sampler will be greater than its concentration in the stream (fig. $3 \mathrm{~b}$ ). Conversely, if the velocity in the nozzle is greater than the stream velocity

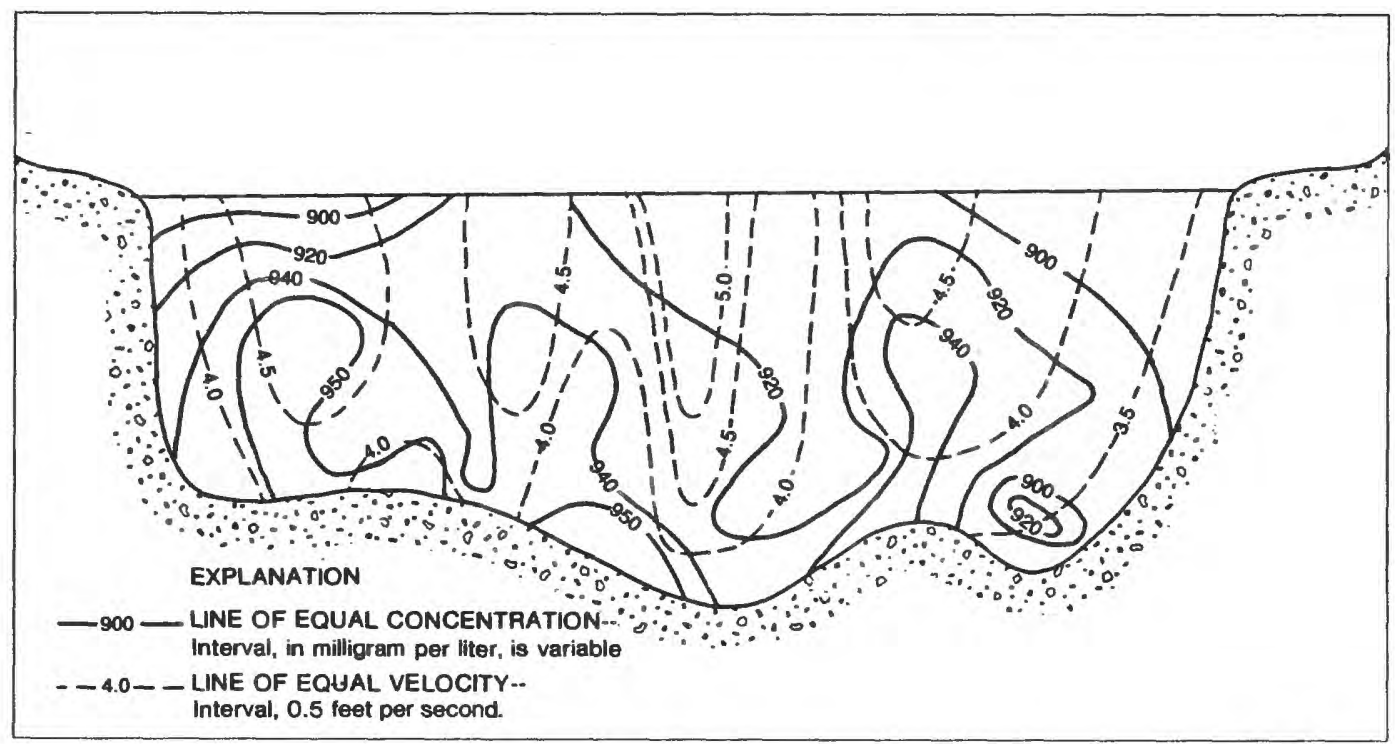

(Not to scale)

Figure 2. The distribution of stream velocity and concentration of a constituent in a stream cross section. 


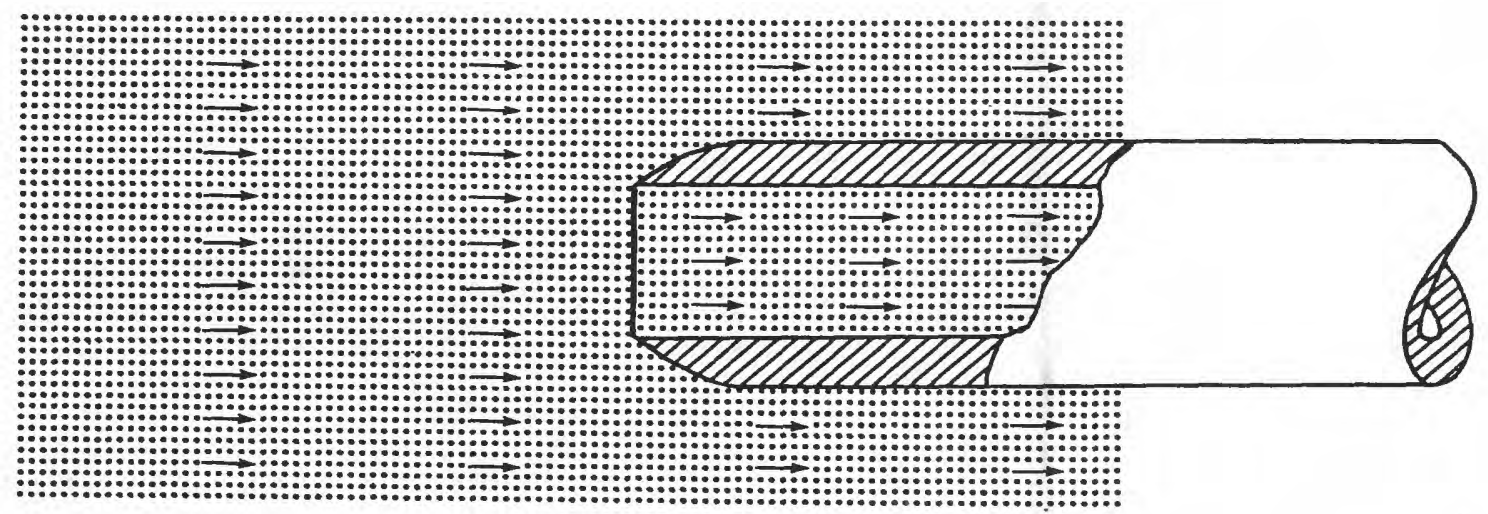

$V s=V i ; C s=C i$

Isokinetic sampling

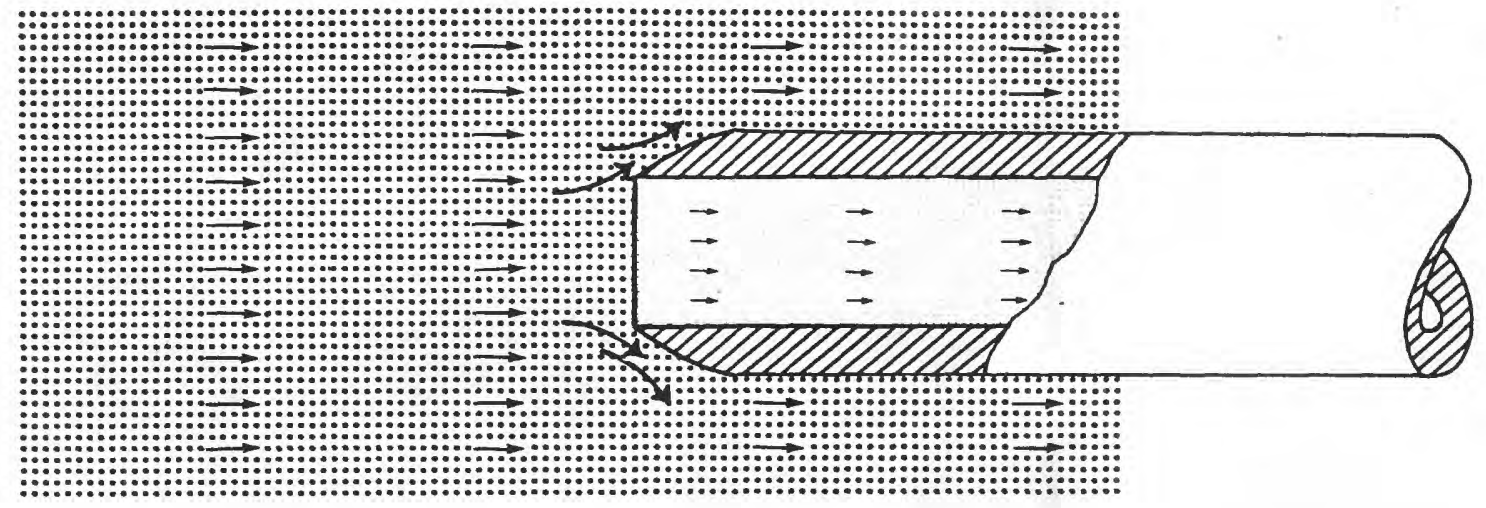

$V_{s}>V_{i} ; C s<C i \quad$ Non-isokinetic sampling

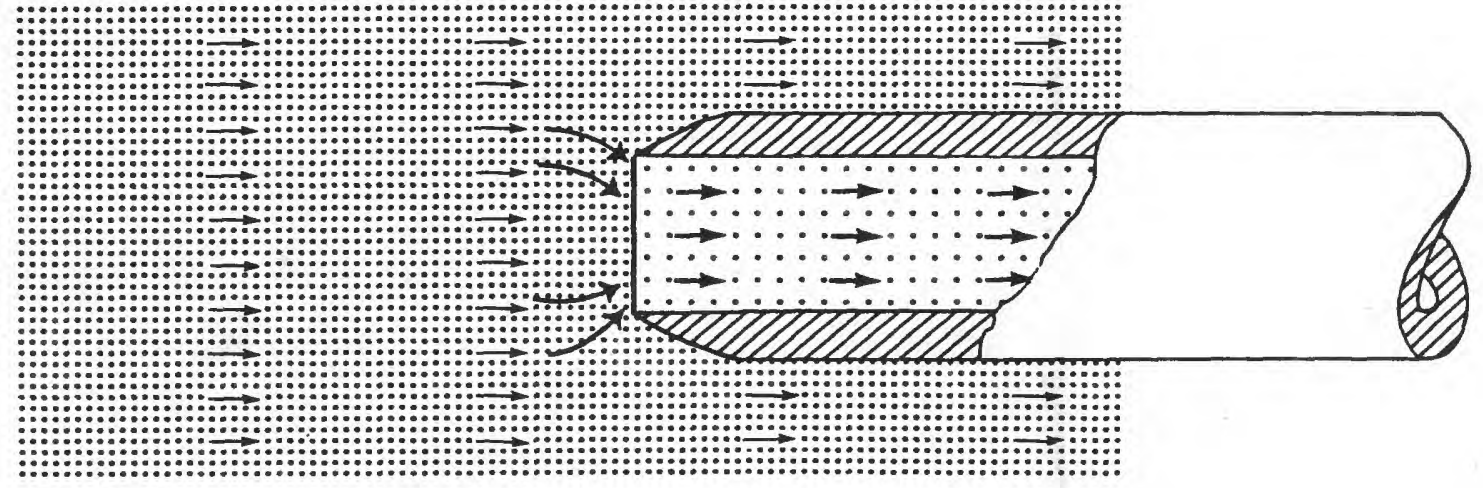

$V_{s}<V_{i} ; \mathrm{Cs}>\mathrm{Ci} \quad$ Non-isokinetic sampling

Figure 3. Relation between intake velocity and sample concentration for isokinetic and non-isokinetic sampling for particles greater than 0.62 millimeters. $\left(V_{s}\right.$, velocity in stream; $V_{i}$, velocity in nozzle; $\mathrm{C}_{\mathrm{s}}$, concentration in stream; $\mathrm{C}_{1}$, concentration in nozzle.) 
in the vicinity of the sampler, the concentration of sediment in the watersediment mixture in the sampler will be less than its concentration in the stream (fig. $3 \mathrm{c}$ ). The magnitude of sampling error associated with these velocity differences increases with extent of departure from the isokineticvelocity ratio and the particle size of suspended sediment. The magnitude of sampling error increases more rapidly with subnormal intake rates than with correspondingly supernormal rates.

The curvature of the flow pattern or any of its stream lines resulting from changes in velocity or direction or by disturbances due to the sampler will segregate suspended sediment from the water. The alteration of the concentration of suspended-sediment and sorbed constituents in the watersediment mixture in the filament of flow entering the sampler also contributes to sampling error.

\section{Preferred Methods}

Samplers and sampling methods need to be designed so that they yield samples that accurately represent the water-quality characteristics of a stream at a given time and location. Five different sampling methods based on the use of isokinetic samplers are described below.

\section{Single-Vertical Method}

Uniform water-quality and streamflow conditions at many sampling sites will permit the collection of a representative depth-integrated sample by the single-vertical sampling method.

\section{1--Application}

The single-vertical sampling method is used to obtain a representative sample in the vertical being sampled at the precise time the sample is collected. It generally can be used in small streams where the streambed is stable; the water discharge is distributed uniformly in the cross section; and the water temperature, specific conductance, $\mathrm{pH}$, and the dissolved-oxygen and suspended-sediment concentrations in the cross section do not deviate by more than five percent. Use of this method at various water discharges requires that cross-section uniformity be checked throughout the range of water discharges to be sampled. This method commonly is used at locations where a fixed (box) sampler is attached to a bridge or other structure for an observer to collect water-sediment samples for the determination of suspended-sediment concentration.

\section{2--Description}

When this method is used to collect a representative sample from small. streams, the position of the single vertical in the cross section is selected after field reconnaissance and measurement of water temperature, specific. conductance, $\mathrm{pH}$, and the dissolved-oxygen and suspended-sediment concentrations. A depth-integrating sampler is lowered to the bottom and raised through the water column at a uniform transit rate not to exceed 0.4 of the mean stream velocity; the minimum rate needs to be such that the round trip does not result in an overfilled sample container. A detailed discussion of transit rates can be found in Edwards and Glysson (1988). The method is illustrated in figure 4. 


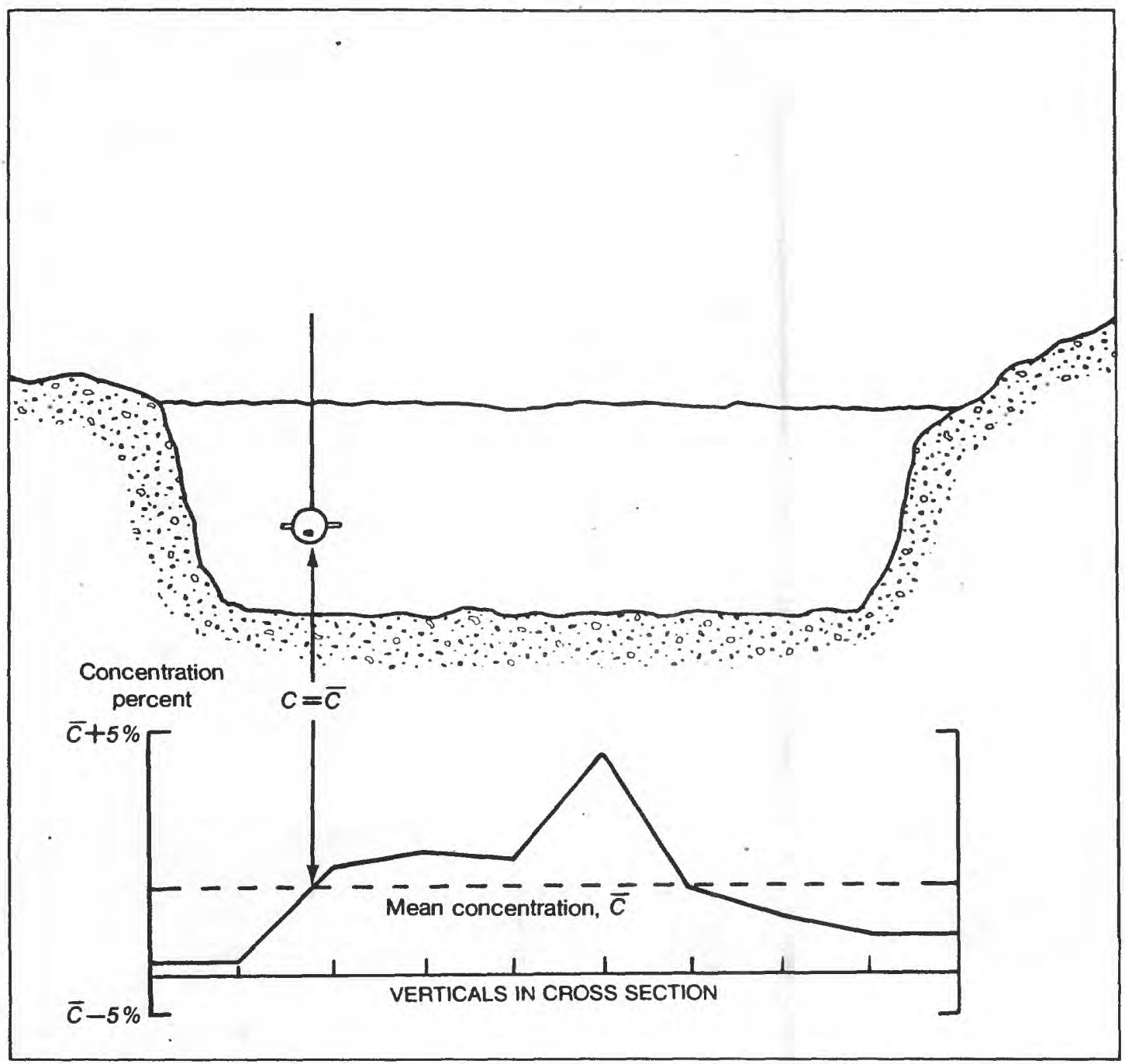

(Not to scale)

Figure 4. The single-vertical sampling method. (Depth-integrated sample is collected at flow weighted mean concentration vertical.)

A few considerations of variations in sample collection for different stream velocities are noted below. If stream velocity is low enough so that no sand is suspended $(<2.0 \mathrm{ft} / \mathrm{s})$, distribution of silt and clay is generally uniform from the stream surface to the bottom (Guy, 1970, p. 15). In this case, the transit rate of the sampler is not critical. For velocities higher than $2.0 \mathrm{ft} / \mathrm{s}$, transit rates need to be constant to obtain a representative sample. For high velocities $(>10 \mathrm{ft} / \mathrm{s})$, care needs to be taken when sampling to avoid any debris in the stream that may either damage the sampler or injure the field person. In cases of extreme velocity or heavy debris, it may only be possible to collect a surface or dip sample.

\section{Multiple-Vertical Method}

The multiple-vertical sampling method is the collection of several single-vertical samples in a cross section where the distribution of chemical constituents, suspended-sediment, and bed roughness vary markedly with dis- 
tance across the stream and with time (Simons and Richardson, 1966; Guy, Simons, and Richardson, 1966).

The Geological Survey uses two basic methods to define the location of multiple verticals: the equal-discharge- and equal-width-increment methods.

Equal-Discharge-Increment Method

The EDI (equal-discharge-increment) sampling method, formerly known as the centroids-of-equal-discharge-increments method (Edwards and Glysson, 1988) provides a transect sample whose concentration is discharge weighted both vertically and laterally. The sample volume at each section is kept constant by varying the transit rate.

$$
\text { 1--Application }
$$

The EDI method is used most often in streams that have stable channels and whose discharge ratings change very little during the year. It requires that the lateral distribution of water discharge be known or measured prior to sampling. It is preferable to not use this method for sandbed streams because flow distribution can change radically while the discharge measurement or sample is being taken. The EDI method can save time and labor over the EWI (equal-width-increment) method (discussed below), especially on larger streams because fewer sampling verticals are required (Hubbell and others, 1956). This method is also better than the EWI method in streams with rapidly changing stages because of the shorter sampling time required.

On the basis of the $\mathrm{V}^{2} / \mathrm{D}$ index (defined in fig. 5) concepts of variability, P. R. Jordan (written commun., 1968) used data from Hubbell and others (1956) to prepare a nomograph (fig. 5) that indicates the number of sampling verticals required for a desired maximum acceptable relative standard error (sampling error) based on the percentage of sand and the $V^{2} / D$ index. In the example illustrated by figure 5, the acceptable relative standard error is 15 percent, the sample is 100 -percent sand, the $\mathrm{V}^{2} / \mathrm{D}$ index is 2.0 , and the required number of verticals is seven. Notice that if the sediment were 50 -percent sand, the same results could be obtained with three verticals; or, if seven verticals were used with 50 -percent sand, the relative standard error would be about 8 percent.

$$
\text { 2--Description }
$$

1988.

A detailed description of this method is given by Edwards and Glysson,

\section{Equal-Width Increment Method}

The EWI sampling method, formerly known as the ETR (equal-transitrate) method (Edwards and Glysson, 1988) provides a transect sample whose concentration is discharge-weighted both vertically and laterally and whose volume is proportional to the water discharge in the sampled zone.

$$
\text { 1--Epplication }
$$

The EWI method commonly is used in shallow and/or sandbed streams where the distribution of water discharge in the cross section is not stable. An advantage of the EWI method is that knowledge of the lateral distribution 


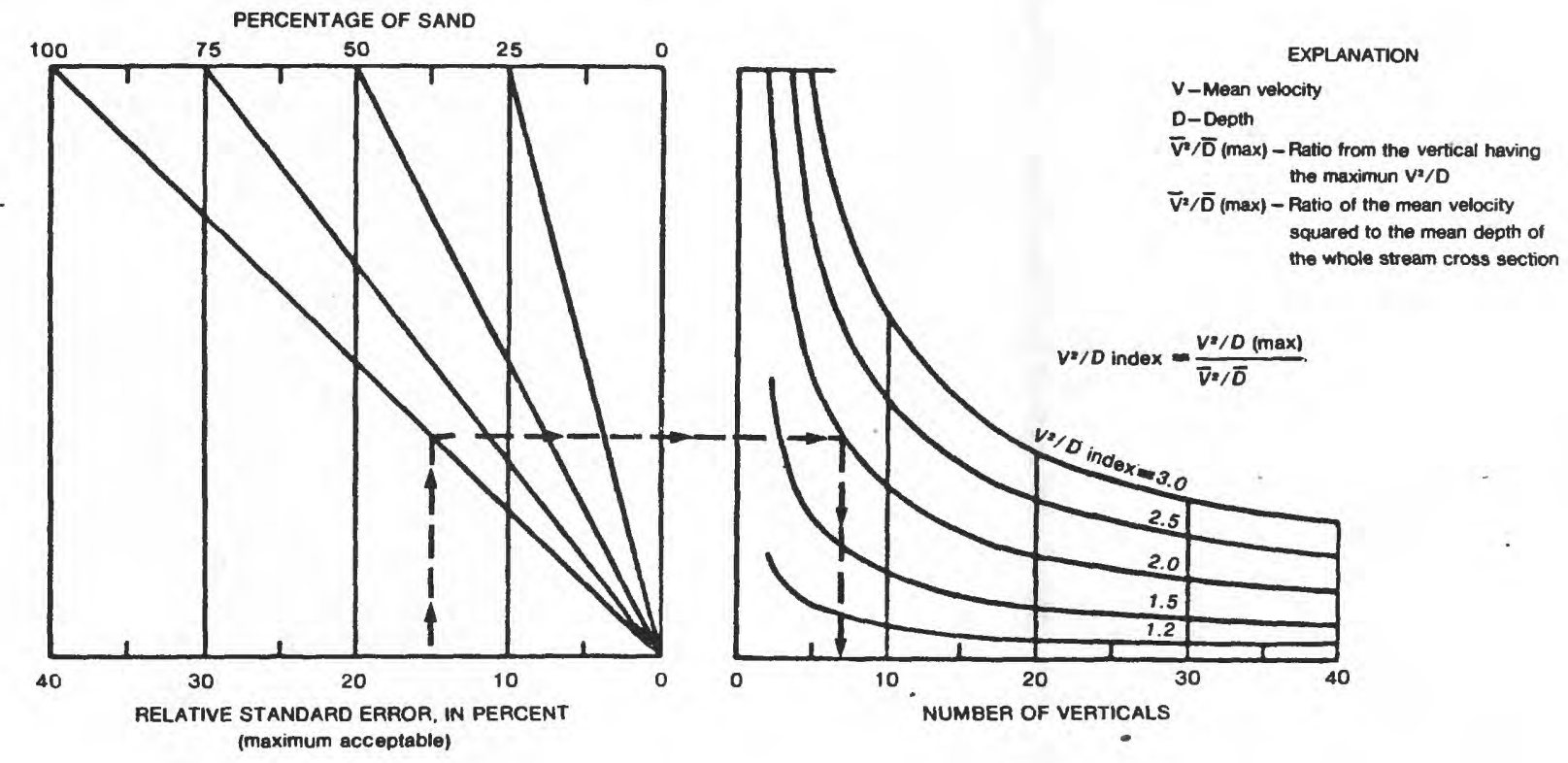

Figure 5. Nomograph to determine the number of sampling verticals required to obtain results within an acceptable relative standard error based on the percentage of sand in the sample and the $V^{2} / D$ index. (Best results are obtained when $V$ is between 2 and 5 and $D$ is greater than 1.5 feet.)

of discharge is not required. However, it is sometimes difficult to maintain the same vertical transit rate at all verticals; more verticals need to be sampled than with the equal-discharge increment method; and wherever the flow is not perpendicular to the transect, the width increment between sampling verticals needs to be adjusted by the sine of the angle between. the flow lines and the transect. The number of sampling verticals required depends on the distribution of concentration and streamflow in the cross sections as well as the desired relative standard error. Generally 10 to 20 verticals will provide an accurate mean discharge-weighted concentration of constituents.

\section{2.--Description} 1988.

A detailed description of this method is given in Edwards and Glysson,

\section{Boint-Integrating Method}

The point-integrating sampling method provides a water-sediment sample from a fixed point in a vertical. 


\section{1--Application}

The point-integrating sampling method is used to collect water-sediment samples from one or several points in a vertical to define vertical distribution in a stream, lake, reservoir, or estuary.

\section{2--Description}

A detailed detailed description of this method is given in Edwards and Glysson, 1988 .

\section{Equipment}

Many samplers are available for the purpose of collecting water and suspended-sediment samples. Most perform well under the conditions for which they were designed, but no single sampler is capable of collecting a correct sample under all conditions. A detailed discussion of the equipment used by the Geological Survey for the collection of water and suspended-sediment samples from streams for chemical and physical analysis is given in Edwards and Glysson, 1988.

\section{Isokinetic Samplers-Principles and Use}

Three criteria for the design of integrating-type samplers need to be met for an isokinetic sampler (Subcommittee on Sedimentation, Federal InterAgency River Basin Committee, 1952). These criteria are: (a) the sampler needs to fill at a rate such that the velocity in the nozzle at the point of intake and local stream velocity are equal; (b) the intake nozzle needs to point into the stream parallel to the lines of flow and project sufficiently far in front of the sampler body so that stream lines are not altered by the sampler body; and (c) the sampler needs to have a separate intake and air exhaust to permit smooth sampling. Additional design criteria require that: (a) the sampler has a removable sample container; (b) it permits sampling close to the streambed; (c) it needs to be streamlined and heavy enough to eliminate excessive downstream drag; (d) it has a rudder and lateral vanes to orient the sampler parallel to the flow if suspended by cable; and (e) it is of simple and sturdy construction.

Isokinetic samplers are either depth-integrating or point-integrating. Depth-integrating samplers can be used to collect water-sediment samples from depths of 8.86 to $19 \mathrm{ft}$, depending on nozzle and container sizes. Pointintegrating samplers can be used at depths of 51 to $180 \mathrm{ft}$. They also may be used for depth integration when the depth to be sampled exceeds $19 \mathrm{ft}$. Both types of samplers are designed for use in moving water.

\section{US Series Manual Samplers}

The US series of manual samplers designed, built, tested, and distributed by the Federal Inter-Agency Sedimentation Project are classified as either depth-integrating or point-integrating. A depth-integrating sampler is designed to collect a representative water-sediment sample from a stream vertical by matching the velocity of water entering the nozzle at the point of intake to the stream velocity and by moving through the vertical at a uniform rate. A point-integrating sampler is designed to collect a representative sample in the same way as a depth-integrating sampler, or at a single point in a vertical. 
The characteristics and uses of available samplers are presented in table 1. and discussed in detail in Edwards and Glysson, 1988. Most of the samplers are also available with epoxy-painted bodies and silicone-rubber gaskets, where appropriate, for the collection of samples for the determination of trace metals.

\section{Autoratic Samplers}

In addition to the manual samplers in table 1 , there are seven automatic samplers. They are designed for the collection of water-sediment samples at remote, or not easily accessible, sites where conventional sampling is not practical, or for flashy or intermittent streams where personnel might not be able to be present during sampling. There are two nonpowered samplers; US U-59 (or SS-59) and U-73, and five powered, pumping samplers; US PS-69, US CS-77, US PS-82, Manning ${ }^{2}$ S-4050, and ISCO 1680. A detailed discussion of these samplers is given in Edwards and Glysson, 1988.

The U-59 and U-73 samplers are similar to point samplers because they are used to collect a single sample at a single point in the stream vertical. Samples generally are collected near the surface and either near the streamkank or a pier or abutment where it is easy to fasten the sampler in place. Depth-integrated samples generally are not obtained. Intake velocity also generally does not match stream velocity, so that the sample might not even be representative of the point at which it was collected. These samplers were designed mainly for sediment studies and have not been widely used in water-quality studies.

of the five generally available automatic pumping samplers, the US PS -69 is probably the most widely known and used by Geological Survey personnel. All pumping samplers have the following basic characteristics: (1) a pump to draw a suspended-sediment sample from the streamflow and, in some cases, to provide a back-flush to clear the sampler plumbing before or after each sampling cycle; (2) a sample container unit to hold sample bottles in position for filling; (3) a sample distribution system to divert a pumped sample to the correct bottle; (4) an activation system that starts and stops the sampling cycle, either at some regular time interval or in response to a rise or fall in streamflow (gage height); and (5) an intake system through which samples are drawn from a point in the cross section. Some specific criteria of each of the samplers are summarized in table 2 .

Use of an automatic pumping sampler instead of conventional hand sampling can be as labor intensive and commonly more costly than hand sample collection. Installation requires careful selection of location, intake placement, and detailed background data to ensure meaningful pumped sample data. Numerous hand samples need to be collected to verify the representation of the automatic samples for both depth-integration and cross-section representation. This verification needs to be done for all constituents of concern. A detailed discussion of installation and data analyses concerns are given in Edwards and Glysson, 1988.

2 Reference to trade names, commercial products, manufacturers, or distributors in this manual is for identification purposes only and does not constitute endorsement by the U.S. Geological Survey. 


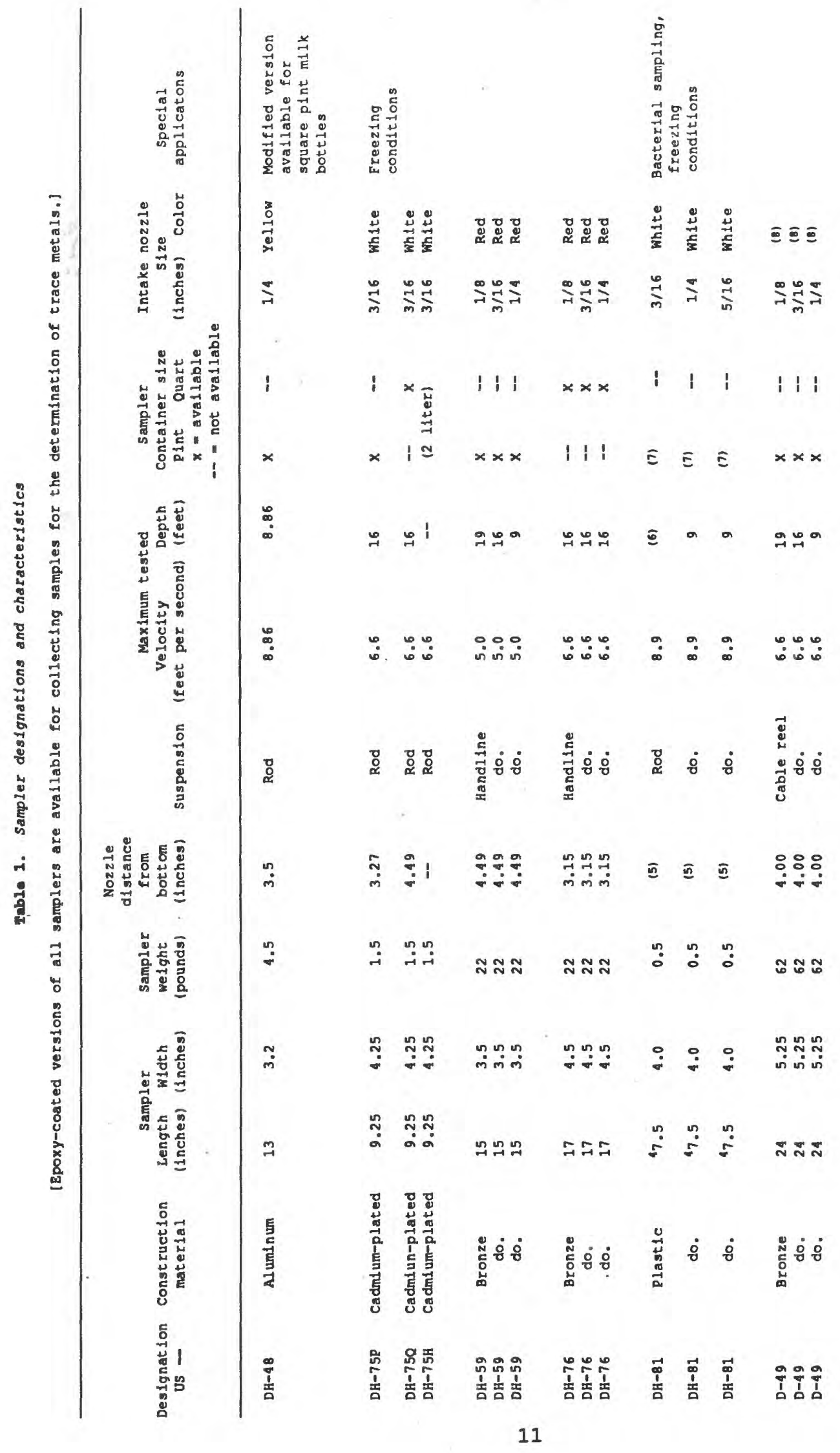




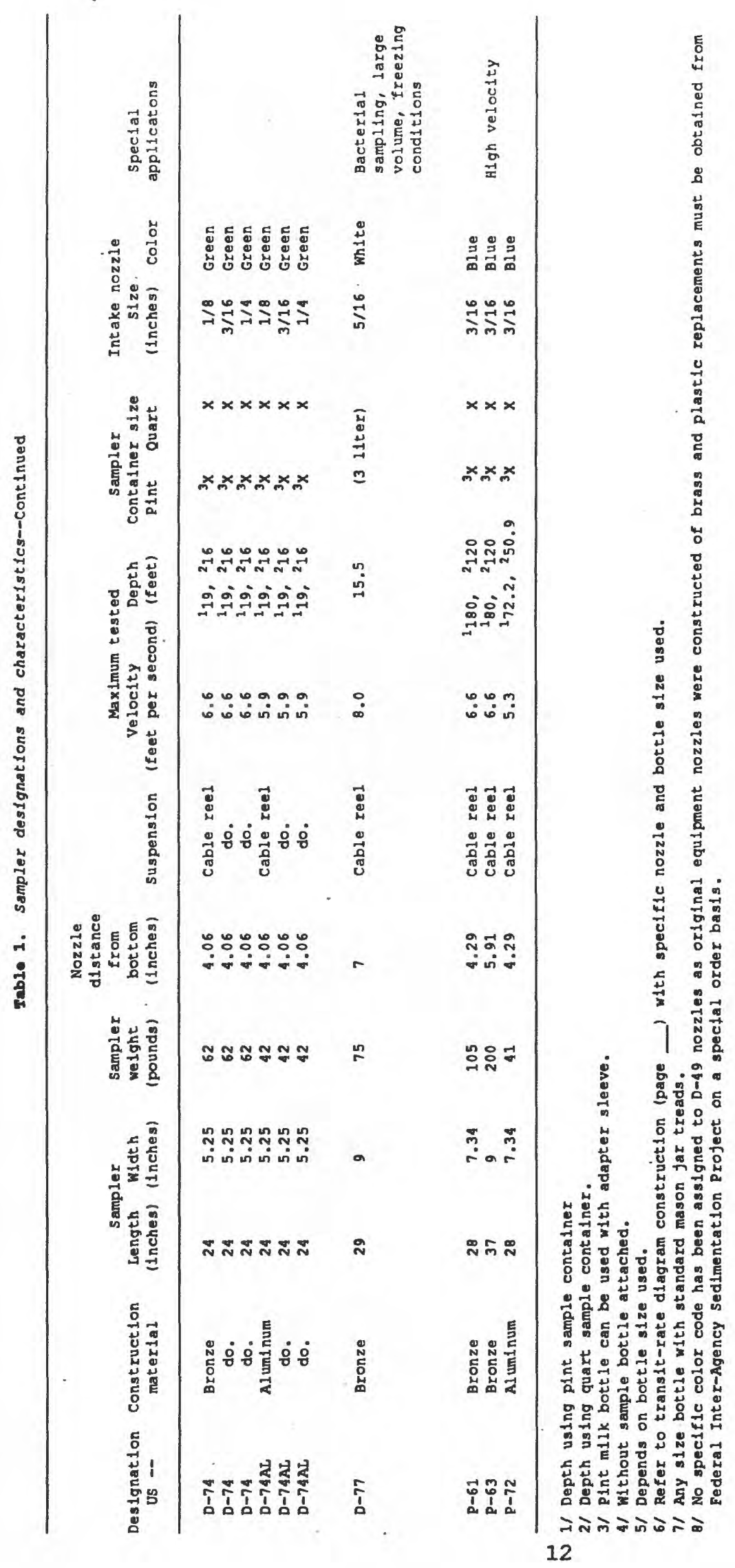


Table 2. Automatic pumping-type sampler evaluation

[A = US PS $-69 ; \mathrm{B}=$ US CS $-77 ; \mathrm{C}=$ US PS-82;

$D=$ Manning S-4050;E = ISCO 1680]

Evaluation criteria

criteria

1. Sample collection Isokinetic

2. Sediment concentration constant stream to sample container

3. Cross contamination prevented

${ }^{2} \mathrm{~A},{ }^{1} \mathrm{~B},{ }^{2} \mathrm{C}, \mathrm{D}$

4. Collects concentrations to 50,000 milligrams/ liter and particles to 0.25 millimeters

5. Sample volume $\geq 350$ milliliters

$A, B, C, D$

6. Intake diameter $3 / 4$ inch

${ }^{2} \mathrm{~A},{ }^{2 / 1}{ }_{B},{ }^{2} \mathrm{C},{ }^{2} \mathrm{D},{ }^{1} \mathrm{E}$

${ }^{3} \mathrm{~A},{ }^{3} \mathrm{~B},{ }^{3} \mathrm{C},{ }^{3} \mathrm{D},{ }^{3} \mathrm{E}$

7. Turbulent flow $(R=4,000)$ within sampler

A

8. Vertical pumping lift $\geq 35$ feet

${ }^{3} \mathrm{~A},{ }^{1} \mathrm{~B},{ }^{2} \mathrm{C},{ }^{3} \mathrm{D},{ }^{3} \mathrm{E}$

${ }^{1}{ }_{A},{ }^{1}{ }_{B},{ }^{1} \mathrm{C}$

9. Capable of collecting an adequate number of samples to accomplish the purpose of sampling

${ }^{3} \mathrm{~A},{ }^{3} \mathrm{~B},{ }^{3} \mathrm{C}, \mathrm{D}, \mathrm{E}$

10. Sampler protected against freezing, evaporation, and dust

${ }^{1} \mathrm{~A},{ }^{1} \mathrm{~B}, \mathrm{C},{ }^{1} \mathrm{D},{ }^{1} \mathrm{E}$

11. Sample container tray removable single unit

$A, D, E$

12. Sampling cycle activated by timer or stage change

$A, B, C, D, . E$

13. Capable of recording sample date and time

${ }^{1} \mathrm{~A}, \mathrm{~B},{ }^{1} \mathrm{C},{ }^{1} \mathrm{D},{ }^{1} \mathrm{E}$

14. Alternating current or direct current power capacity

${ }^{1} \mathrm{~A},{ }^{1} \mathrm{~B},{ }^{1} \mathrm{C},{ }^{1} \mathrm{D},{ }^{1} \mathrm{E}$

15. Sampler or principle components $\leq 100$ pounds

${ }^{1} \mathrm{~A},{ }^{1} \mathrm{~B},{ }^{3} \mathrm{C},{ }^{3} \mathrm{D},{ }^{3} \mathrm{E}$

${ }^{1} \mathrm{~A},{ }^{1} \mathrm{~B},{ }^{3} \mathrm{C},{ }^{3} \mathrm{D},{ }^{3} \mathrm{E}$

17. Required floor space $\leq 9$ square feet ( 3 by 3 feet)

${ }^{3} \mathrm{C},{ }^{3} \mathrm{D},{ }^{3} \mathrm{E}$

${ }_{1}^{1}$ Sampler requires modification to meet criteria.

${ }^{2}$ Sampler shows a reduction in capacity with particle sizes $\geq 0.250$ millimeters.

${ }^{3}$ Sampler exceeds criteria. 
Open-mouth bottles are the simplest samplers used for the collection of water samples. They generally consist of a glass or plastic bottle housed in a weighted support frame for submergence. Two types of open-mouth bottles, weighted bottles and bottle baskets, are described below.

Weighted bottles consist of an open-mouth glass or plastic bottle housed in a short length of pipe. The sample bottle is inserted into the pipe and secured underneath by a bolt which extends through the pipe at the bottom. The upper end is sewn with two "ears" drilled to accommodate a length of sash chain attached to a ring that slips over the neck of the bottle (fig. 6).

Bottle baskets are typically a frame made of strap iron (fig. 6) that supports the sample bottle. A lead or iron weight of sufficient size to overcome buoyancy is attached to the bottom of the basket to submerge the sampler. An open-mouth glass or plastic bottle is held in place by a ring, ring and chain, or loop of suspension line over its neck.

Open-mouth water-sampling bottles do not sample isokinetically, and collect only quasi-depth-integrated samples. The capacity of the samplers ranges from about 500 to $4,000 \mathrm{~mL}$. The sampling depth is controlled by the capacity of the bottle and the rate of filling. Relatively representative samples can be collected from streams when the suspended sediment is uniformly distributed in the vertical and the velocity is less than $2.0 \mathrm{ft} / \mathrm{s}$ (Edwards and Glysson, 1988). These bottles can also be used in shallow streams where there is not much variation in composition in the vertical.

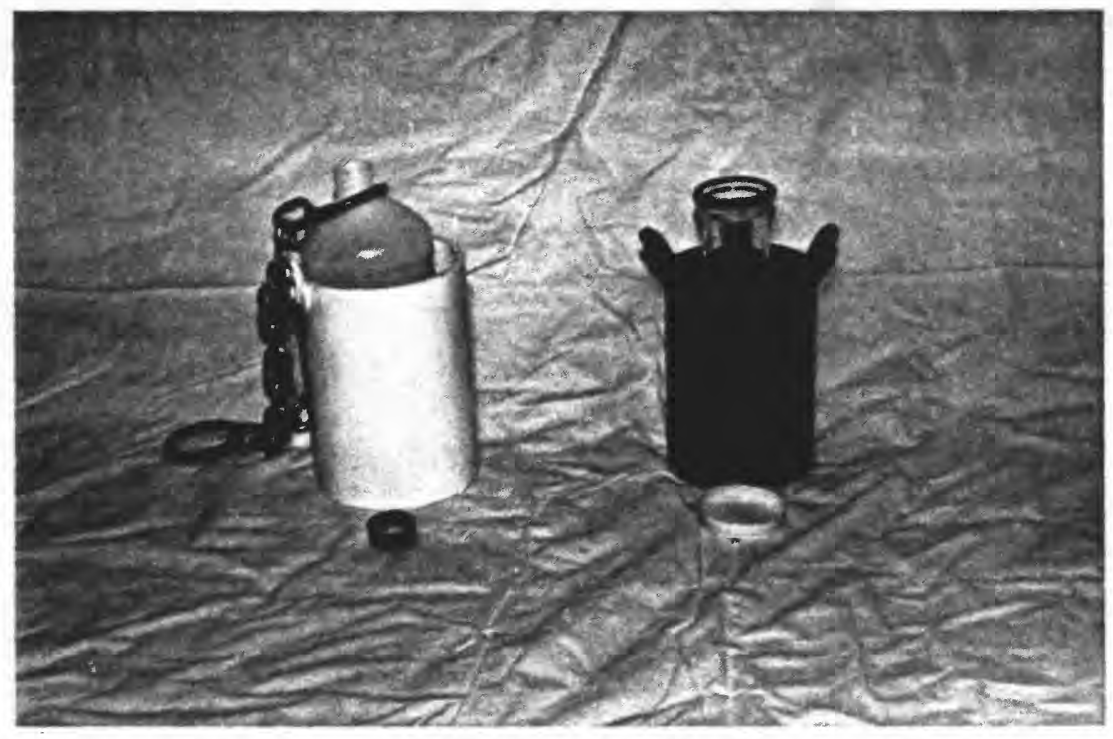

Figure 6 . Weighted bottle and bottle basket. 


\section{Sampling Procedures}

Sampling procedures for the collection of water-sediment samples from streams for analysis of water quality are the same as those required for analysis of fluvial sediment. A detailed description of procedures and equipment is given in Edwards and Glysson, 1988.

\section{Lakes, Reserroliss, and Estuaries}

Interest in refining the techniques for sampling lakes, reservoirs, and estuaries has grown because of increased interest in assessing their water-quality characteristics and in studying processes such as transport and eutrophication. As studies of these water bodies become more complex, sampling techniques for data collection require increased accuracy and consistency.

\section{Representative Sampling}

The probability that a single sample of a lake, reservoir, or estuary will be representative is slight. Even the concept of a representative sample has little utility. A single sample normally will be used only for reconnaissance purposes. Multiple samples describe three-dimensional variations in water-quality characteristics. In most investigations it is the three-dimensional variations that are of interest, and sampling programs normally are designed and conducted to meet that objective.

Three-dimensional variations in the water-quality characteristics of lakes and reservoirs result from the interaction of several interrelated physical, chemical, and biological processes. Physical processes include: (1) circulation patterns; (2) thermal, chemical, and density stratification; (3) morphometry of the lake or reservoir; (4) length of exposure to the sun and winds; (5) inflow and outflow patterns; (6) position and operation of outflow structures at dams; and (7) latitude of the lake or reservoir. Temperature probably is the major controlling factor for chemical and biological processes. These latter processes also are controlled by light penetration, dissolved-oxygen and nutrient concentration and biomass. Comprehensive discussions of these processes are given in texts on limnology, such as Hutchinson (1957).

Estuaries are dynamic systems, presenting a continually changing system that needs to be considered if successful sampling is to be accomplished. Estuaries may have large areas with low velocities that might be stratified; these areas generally are sampled like lakes and reservoirs. Near inlets and outlets where velocities can be much higher, sampling techniques for streams might be more appropriate. Freshwater inflow, circulation, and the tidal cycle affect estuarine water quality. The tide, which varies on daily, Iunar, and annual cycles, might have identical stages as many as four times daily, yet water-quality characteristics are likely to be different each time.

Probably the most important aspect of sampling lakes, reservoirs, and estuaries is the design of the sampling program. The objectives of the sampling program (whether a reconnaissance or comprehensive survey) and the hydrologic and physical characteristics of the water body govern the choice of the location and number of sampling sites. Two schemes, dispersed random sampling and transect sampling, are preferable for planning the distribution of sampling sites. Dispersed random sampling requires that samples be collected from sites scattered over the area and that conscious choice in the 
selection of sampling sites be rigorously excluded. Transect sampling requires that samples be taken randomly or at regular intervals along a predetermined line extending across the area concerned (Welch, 1948). The advantages of transect sampling are that the location and number of sampling sites are known and it may be easier to distribute sites over the area concerned while maintaining the requirements of random sampling.

\section{Preferred Methods}

Great care needs to be taken in the choice of methods whereby watersediment samples are collected from lakes, reservoirs, and estuaries because the samples need to be taken at a known depth and need to be brought to the surface in a strictly unmodified condition. Samples are most commonly collected using a water-sampling bottle or pump.

Sampling with water-sampling bottles meets the above sampling requirements if the equipment is in good condition and properly used. Advantages include the ability to sample thin stratum, simplicity, light weight, and modest cost. The principal disadvantage is that repeated trips to the selected depth are needed to obtain large quantities of sample.

Pumping requires the use of a suitable pump which, when fully primed, has no leaks or air spaces. The fundamental disadvantage of pumping is the likely failure to meet the requirement of sampling from one thin definitely known stratum because water moves radially from unknown distances into the pump. Although this may not be serious if small amounts of water are needed, it needs to be remembered that before samples are collected, the pumping system needs to be filled with water from the stratum selected. Pumps and intake lines can also be costly and difficult to handle. Some or all of these disadvantages can be eliminated by choice of equipment.

\section{Equipment}

Depth- and point-integrating samplers, described previously, are not suitable for collecting water-sediment samples from slow-moving waters such as lakes, reservoirs, and some areas of estuaries. Equipment for sampling these waters must collect a sample at an exactly known depth, and needs to deliver the sample to the surface intact and unchanged. The sampling equipment described below meet these general sampling requirements, if used and maintained properly.

\section{Van-Dorn Type Water-Sampling Bottles}

\section{1--Application}

Van-Dorn type water-sampling bottles are used to collect instantaneous point water-sediment samples from lakes, reservoirs, and some areas of estuaries. They also can be used to collect point samples from streams if the velocity is less than $1.5 \mathrm{ft} / \mathrm{s}$. The horizontal configuration watersampling bottle is best for sampling at shallow depths. Vertical configuration water-sampling bottles can be linked in series for simultaneous sampling at several depths. The bottles are available in several different materials, suitable for sampling all inorganic constituents, including trace metals, and halogenated hydrocarbons. 


\section{2--Description}

The Van-Dorn type water-sampling bottle (fig. 7) consists of an acrylic or PVC (polyvinyl chloride) plastic tube with end seals, a messengeroperated closing device, and spring-loaded drain valve for sample removal. Bottle capacity ranges from 2.2 to $30.2 \mathrm{~L}$. The $2.2 \mathrm{~L}$ bottle is $4.5 \mathrm{in}$. in diameter and is $13.8 \mathrm{in.}$ long; the $30.2 \mathrm{~L}$ sampler is $8.9 \mathrm{in}$. in diameter and is 43.0 in. long.

There are two styles of Van-Dorn water-sampling bottles. The alphastyle bottle has molded semirigid neoprene rubber end seals. The beta-style bottle has machined rigid neoprene rubber end seals; it is also available with rigid silicone rubber end seals and nonmetallic parts for collecting samples for determination of trace metals and halogenated hydrocarbons. Both styles of bottles are available in either vertical or horizontal configurations.

\section{Kermerer-Type Water-Sampling Bottles}

\section{1--Application}

Kemmerer-type water-sampling bottles are used to collect instantaneous point water-sediment samples from lakes, reservoirs, and some areas of estuaries. They can also be used to collect point samples from streams if the velocity is less than $1.5 \mathrm{ft} / \mathrm{s}$. The bottles can be used singly or in series to simultaneously collect samples at several depths. The bottles are available in several different materials, suitable for sampling all inorganic constituents, including trace metals, and halogenated hydrocarbons.

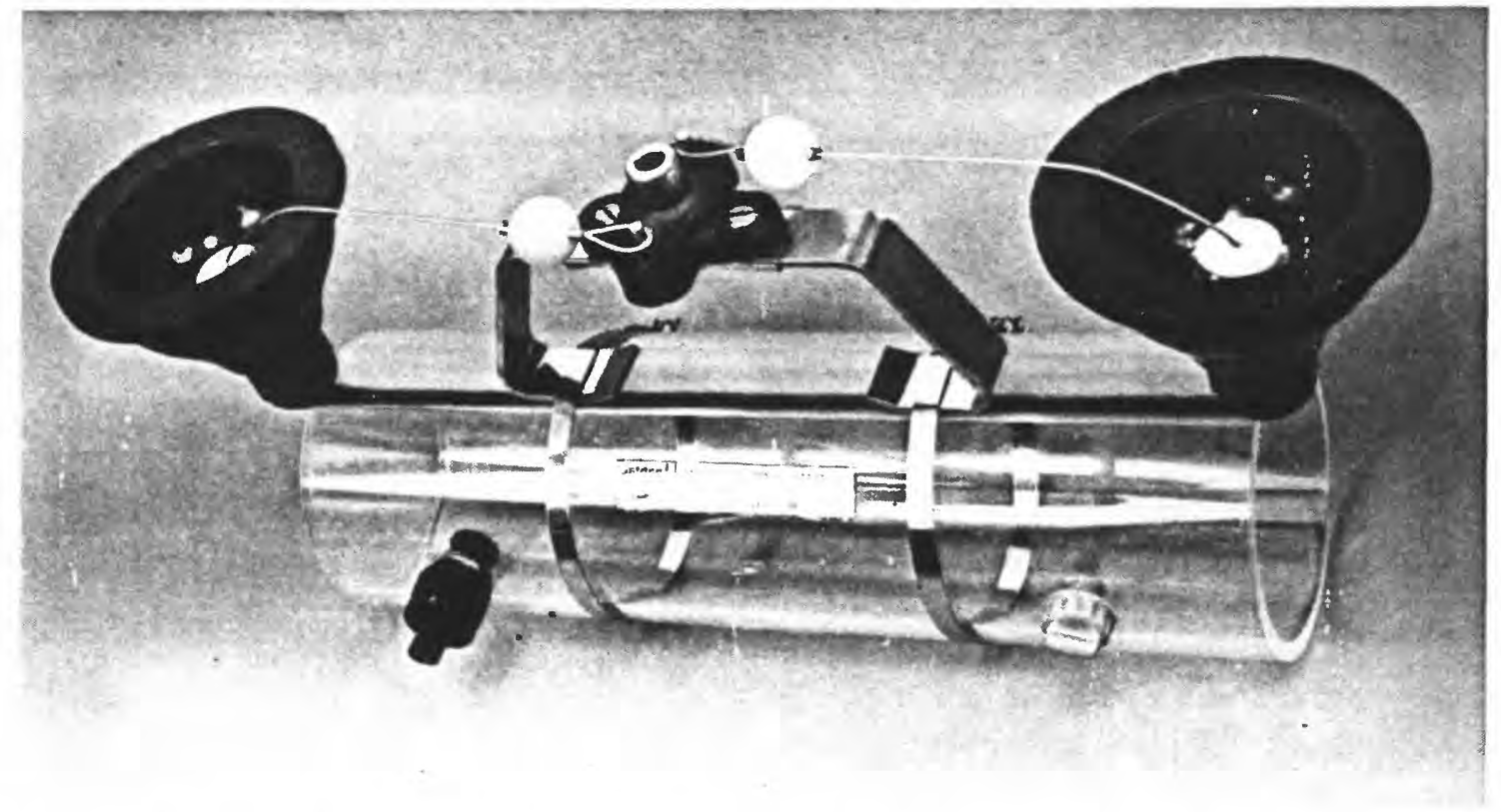

Figure 7. Van Dorn type water-sampling bottle (alpha horizontal style). (Photograph courtesy of Wildlife Supply Company.) 


\section{2--Description}

The Kemmerer-type water-sampling bottle (fig. 8) consists of a metallic or nonmetallic tube with end seals, a valve for sample removal, and a triggering device for closing. The brass or nickel-plated brass samplers range from 2.6 to $4.5 \mathrm{in}$. in diameter and from 16.8 to 45.5 in. in length. Capacity ranges from 0.4 to $8.2 \mathrm{~L}$. A hollow brass tube extends through the center and supports neoprene rubber seals at the top and bottom. The top of the inner tube is enlarged and engages with a tripping device when the bottle is open. There is a spring-loaded valve in the bottom seal for sample removal. The acrylic or PVC plastic bottles range from 3.0 to 6.6 in. in diameter and from 16.8 to $45.5 \mathrm{in}$. in length; capacity ranges from 0.4 to 16.2 L. Plastic bottles are available with PVC components and siliconerubber seals for the collection of samples for the determination of trace metals. A specially designed bottle is also available for the collection of samples for the determination of halogenated hydrocarbons.

\section{Nansen-Type Water-Sampling Bottles}

\section{1--Application}

The Nansen-type water-sampling bottle was designed primarily for oceanographic sampling, and is used most often in series. As many as 18 bottles can be attached to an oceanographic wire to collect nearly simultaneous point water-sediment samples at different depths. Because of the limited capacity of the Nansen bottle, several lowerings might be required to obtain sufficient sample volume for analysis. A Teflon-lined Nansen bottle is available for collecting samples for the determination of trace metals. The need to lubricate moving parts and seals in the bottle with penetrating oil and stopcock grease precludes its use for collecting samples for organic analysis. Each Nansen bottle is also fitted with a detachable deep-sea-reversing thermometer frame to hold a thermometer for measuring temperature at a given depth.

\section{2--Description}

The Nansen-type water-sampling bottle is a reversing-water bottle made of metal with a 1.25 L capacity (fig. 9). The bottle is fitted at both ends with tapered-plug valves, joined with a connecting rod. The lower end of the bottle is securely attached to an oceanographic wire with a clamp, and the upper end is hooked to the wire by a tripping mechanism.

open-Mouth. Watcr-Sampling Bottles

$$
\text { 1--Application }
$$

Depth-integrated water-sediment samples can be collected from lakes, reservoirs, and some areas of estuaries by using open-mouth water-sampling bottles. As the bottle is lowered through a vertical, the rate of filling can be controlled by a one-hole rubber stopper. The depth that can be sampled is controlled by the size of bottle and the rate of filling. Point water-sediment samples can also be collected by fitting a solid stopper in the sample bottle, which can be removed by an attached line at the selected depth. 

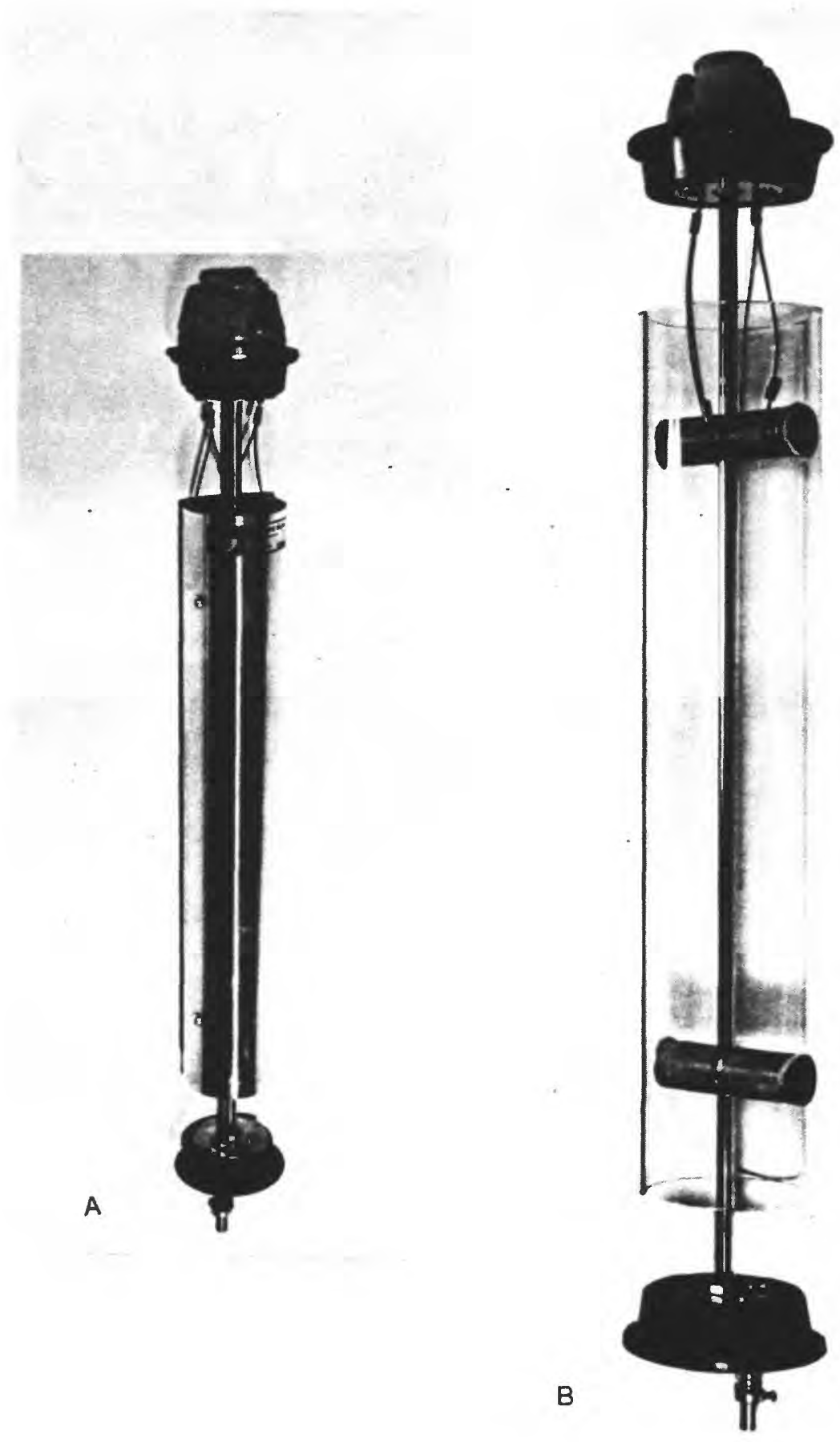

Figure 8. Kemmerer-type water-sampling bottles: (A) Metallic tube, (B) acrylic plastic tube. (Photograph coutesy of Wildlife Supply Company.) 


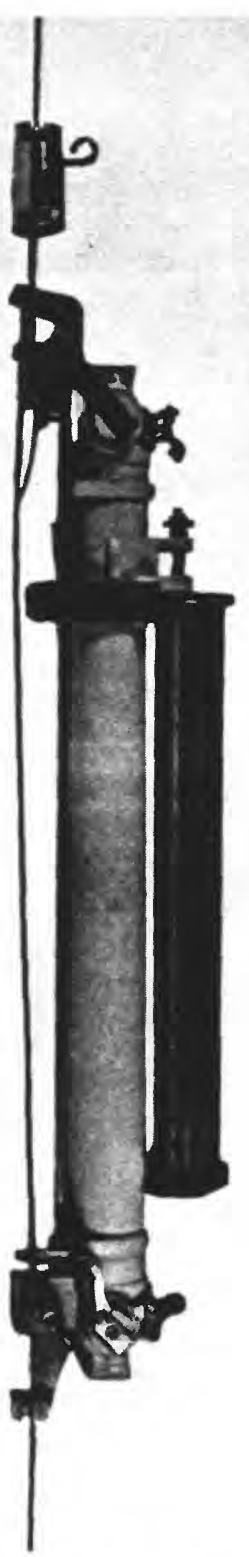

Figure 9. Nansen-type water-sampling bottle. (Photograph courtesy of Wildlife Supply Company.)

\section{2--Description}

Two types of open-mouth water-sampling bottles have been described previously and shown in figure 6 . Bottles of various capacities can be made as needed. 
Pumps

\section{1--Application}

The ability to collect large volume point water-sediment samples from lakes, reservoirs, and estuaries is the principal advantage of using pumps. Pumps can also be used to collect time-integrated samples from estuaries during tidal cycles. The use of pumps is restricted by the availability of power, length of intake or discharge line, and size of vessel required for the sampling operation. In addition, it is difficult to collect samples from a narrow stratum because water moves into the end of the intake line from all directions, and the radial distance that the sample is pulled from at the end of the intake is unknown. When taking a series of samples, water already filling the pump and intake line needs to be evacuated and replaced by water from the new sampling depth. This generally entails pumping a considerable quantity of water. It is uncertain how much of this water has come from other strata (Welch, 1948, p. 201).

\section{2--Description}

Suction-lift pumps (centrifugal and peristaltic) and positivesubmergence pumps (submersible) are commonly used for sampling lakes, reservoirs, and estuaries. Suction lift pumps do not apply any force directly on the water. Iift is accomplished by developing a negative-pressure head (less than atmospheric pressure) at the pump intake. Atmospheric pressure on the water surface or higher pressure below the water surface forces water into the intake and pump. Positive submergence pumps have a pump unit submerged in the water below the pumping level. A positive-pressure head (greater than atmospheric pressure) forces water into the intake. Detailed discussion of these pumps is given below.

\section{Sampling Procedures}

Lakes and Reservcirs

\section{1--Application}

Water-sediment samples are most commonly collected in lakes and reservoirs by pumping or by discrete or point sampling with water-sampling bottles. The location and number of sampling sites depends on the objectives of the study and the hydrologic and physical characteristics of the lake or reservoir.

Each lake or reservoir is unique and has its own set of conditions for which a sampling program needs to be based. In small lakes or reservoirs with regular shore lines and uniform bottom configuration, a single site near the middle or in the deepest area may be sufficient to describe the distribution and abundance of constituents. In large, diversified lakes and reservoirs a single site is not adequate. Because each individual lake or reservoir may require a different design of the sampling program, no standard set of rules for locating sampling sites can be made that apply in all situations. However, consider selecting sites: (1) at or near inflows and. outflows; (2) in the deepest area or at each submerged depression; (3) in partly enclosed bays and coves; (4) in extensive shallow areas; (5) in the vicinity of lee and windward shores; (6) behind large islands and peninsulas; and (7) in the vicinity of marsh or swamp shores. In addition, consider selecting sites along significantly placed transects or at randomly selected positions scattered over all open water. 


\section{2--Preferred Methods}

There is no single preferred method for collecting water-sediment samples from lakes and reservoirs; the one selected depends on the application. Pumping has the advantage of producing a large volume of sample. The principal disadvantage is the difficulty of obtaining a sample from a thin stratum of the water column. Other disadvantages include the need for an external power source, weight, and difficulty in handling. Discrete sampling with water-sampling bottles has the advantage of being able to sample thin stratum. The principal disadvantage is the relatively small volume of sample collected, which might require repeated sampling.

$$
\text { 3--Equipment }
$$

The equipment selected for obtaining water-sediment samples from lakes and reservoirs depends on the application. Van-Dorn and Kemmerer-type watersampling bottles of sufficient capacity for the volume requirements of the analysis to be made are most commonly used. The horizontal style Van-Dorn type bottle is preferred because of its ability to sample thin strata. If trace metals are to be determined, an all plastic trace-metal version of the bottle needs to be used.

Peristaltic pumps, similar to those used for peristaltic-pumping filtration systems (see discussion of filtration of water samples below) also are preferable for sampling. These pumps have low-power requirements; can be used to obtain samples for the determination of trace metals; do not require heavy auxilliary equipment, such as hoists and hose reels; and reduce the difficulty of sampling thin strata. Boats of sufficient capacity for equipment and personnel are needed as sampling platforms. Small centrifugal and submersible pumps can also be used to collect larger volumes of sample.

\section{4--Procedures}

After the location of sampling sites has been selected, measurements of depth, water temperature, specific conductance, dissolved-oxygen concentration, and $\mathrm{pH}$ need to be made at each vertical to guide the selection of sampling depth. Measurement of the depth of light penetration also might be needed. These measurements determine the position and depth of the epilimnion, metalimnion or thermocline, and hypolimnion, and whether the bottom of the lake or reservoir is oxic or anoxic.

The availability of multi-parameter instrumentation for simultaneous measurement of these physiochemical properties has greatly simplified the task. The instruments need to be calibrated according to standard procedures and the measurements made with care. At each depth in the vertical, do not record measurements until the instrument has had sufficient time to equilibrate.

Once sampling depths are determined, sample with Van-Dorn or Kemmerertype water-sampling bottles as follows: (1) check the bottle to make sure it is not damaged and lay out the supporting line free of knots; (2) cock the end valves in the open position and slowly lower the bottle to the sampling depth (it has been shown that movement of the bottle through the water column causes slight disturbances, but they are not serious if. care is taken); (3) release the messenger to trip the closing mechanism; (4) ratse the filled bottle to the surface; and (5) drain the sample from the bottle and process for analysis. The procedure is repeated at each sampling depth in the 
vertical and for each sampling site. To hold the boat in position, particularly if a wind is blowing, both bow and stern anchors are to be used.

The procedure for sampling with pumps is similar to that with bottles. The weighted intake hose or submersible pump is lowered using a hoist to sampling depth and the pump is turned on. Water is pumped to clear the intake hose and insure that water from the sampling depth is being obtained. The sample is collected and processed for analysis. The procedure needs to be repeated at each sampling depth in the vertical and for each sampling site.

Estuaries

$$
\text { 1--Application }
$$

Most of the sampling problems and procedures associated with lakes and reservoirs also occur in estuaries. Design of a sampling strategy in an estuary need to consider: (1) short term, generally nonrepetitive water movement driven by inflow, tides of variable amplitude, and winds of variable velocity superimposed on a migrating saltwater-freshwater interface; and (2) transport and deposition of dissolved and suspended constituents from inland sources, coupled with similar transport and deposition from oceanic sources and the mixing of constituents, complicated by water movement, differences in ionic strength of freshwater and saltwater, and changes in $\mathrm{pH}$ and water temperature.

The usual objective in sampling estuaries is to obtain synoptic measurements of water-quality characteristics at some appropriate point in the tidal cycle, generally slack water at high or low tide. At high or low tide, water moves from point to point so that the water sampled at one point was at another point some time earlier. Vertical mixing by tidal action frequently is not sufficient to smooth out variations; thus the description of water-quality characteristics from data collected at high or low tide can easily be confused and spatially inaccurate.

Preferable sampling techniques in estuaries are to collect samples at single points, or discrete sampling, throughout the vertical. Regardless of which technique is used, the location of the sampling point in the vertical needs to be known so that the point can be related to other sampling points.

\section{2--Preferred Methods}

The preferred method of sampling an estuary depends on the hydrologic characteristics of the estuary and the objectives of the study; no single method is preferred.

$$
\text { 3--Equipment }
$$

The equipment needed for collecting water-sediment samples from estuaries is dependent on the application. Single-point samples can be collected with Van-Dorn or Kemmerer-type water-sampling bottles of sufficient capacity to satisfy analytical requirements. A number of nearly. simultaneous point samples throughout a vertical can be collected with Nansen-type bottles or a series of Van-Dorn or Kemmerer-type water-sampling bottles attached to an oceanographic line at predetermined intervals. Although Nansen-type bottles have limited capacity, they have the advantage, if equipped with reversing thermometers, of measuring the temperature of the sample at the instant of collection. Water-sampling bottles are relatively trouble free when used in saline waters because of their mechanical operation. 
Discrete samples can be collected at any depth with pumps. Pumps have the advantage of supplying any required sample volume. However, because of the size of the intake line, supporting cable, need for external power source, and the inability, in most cases, to use a reel to hold the intake line, the use of pumps, particularly in deep water, can be cumbersome. Also, because of problems associated with electrical equipment and saline water, it is preferable to not use submersible pumps. An adequate pump for use in small boats can be designed using a peristaltic pump capable of delivering a varying flow rate.

A variety of nonstandard samplers are available for sampling estuaries. Stevens, Lutz, and Hubbell (1980) designed a collapsible bag sampler capable of collecting depth-integrated samples from deep estuaries. There are no preferred nonstandard samplers.

\section{4--Procedures}

The procedures for collecting water-sediment samples from estuaries are similar to those used for lakes and reservoirs. Depth of sampling should be selected based on the objectives of the study and the vertical distribution of the water-quality characteristics to be determined. For example, in a salt-wedge estuary the wedge normally is uniform, requiring fewer samples in the vertical than the overriding layer which normally has large salinity gradients. In mixed estuaries sampling at the top, middle, and bottom may be adequate. However, there is no single technique for selection of sampling depth that is applicable to all estuaries and for all purposes. In most cases a vertical profile needs to be developed to describe the water-quality characteristics of an estuary. Vertical salinity gradients vary with freshwater inflow and tidal stage and may change rapidly; samples in the vertical should be collected simultaneously.

To collect simultaneous samples, the following general procedure is used regardless of the type of water-sampling bottle used: (1) sound the bottom to determine the depth; (2) select the sampling intervals based on criteria developed for the study; (3) reference sampling intervals to depth from the surface; (4) cock and attach a water-sampling bottle to the oceanographic cable at each interval; (5) place a messenger on the cable below the bottle and attach it to the tripping mechanism on the bottle--the bottom sampler needs no messenger; (6) repeat steps (4) and (5) until all bottles have been attached; (7) lower the cable until the top bottle is at the proper depth; (8) attach and drop a messenger to trip the top bottle--as this bottle is tripped, the messenger attached below it is released to trip the next bottle, and so on, until all have been tripped; and (9) retrieve the cable, detach each bottle, remove the sample, and process as required for analysis.

Sampling in estuaries can present significant safety hazards. Weather conditions such as fog, storms, or lightning and ship traffic can make sampling dangerous or impossible. Sampling schedules must be flexible enough to allow for adverse conditions.

\section{Bed materials}

Bed material is defined by the office of Water-Data Coordination National Handbook, Chap. 3, P. 3-5 as "the sediment mixture of which the bed is composed." This differs from bedload in that bedload is sediment that moves by sliding, rolling, or bounding along or near the streambed (Leopold, Wolman, and Miller, 1964). From this perspective, the streambed is composed 
of two elements, distinguished one from the other by particle size and reaction to stream velocity. The first element consists of particles frequently transported as part of the suspended load or bedload, but considered as bed material when at rest. The second element consists of particles and aggregates of particles which compose definite structures on the streambed and reside there indefinitely or at least for long periods of time. The size fractions comprising the second element may only be moved by the most extreme flow events during which streambed erosion and scour occur.

\section{Representative Sampling}

At any given time, a major fraction of the chemical load of a stream may be transported by suspended sediment which, when deposited on streambeds and flood plain, in lakes, and tidal reaches of rivers, provides a historical integration of water quality. Bed-material samples are collected to provide data on the particle size and mineralogy of deposited material; the stratigraphy and bedding patterns of deposits; the density and compaction of deposits; the amount and distribution of contaminants sorbed on sediment particles; the geochemical characteristics of deposited material; and the character and distribution of benthic organisms. The data derived from chemical analyses of bed material are significant as reconnaissance tools, in planning analytical schedules, in conducting short-term studies for deriving water-quality trends, and for identification of problem areas (Feltz, 1980).

The deposition of sediments depends on velocities and the duration of a set of hydrologic conditions in streams, lakes, or estuaries. The agents of transportation, (i.e. traction, suspension, and solution), are the same but vary in intensity. Hence, the amount and type of deposition differs from place to place. Sediment transport is dependent on current velocity and turbulence. As velocity increases, some sediments transported as bedload may be changed to suspended load and as the velocity decreases, from suspended load to bedload. Because these changes occur readily, separate consideration of bedload or suspended load transport of noncolloidal sediment is difficult. In contrast, transport of dissolved material is independent of velocity.

Sediment transport involves consideration of a stream's competency, capacity, and load (Gilbert, 1914). Competency, or the ability to transport sediments in terms of particle size, is dependent on many things, such as velocity and turbulence; varying by about the fifth power of the velocity. A stream has a competent slope for each channel variation and for each particle size of every specific gravity. Thus, other factors remaining equal, there is a competent velocity and a competent discharge for each dimension of sediment of a given specific gravity. Capacity, or the ability of a current to transport sediments in terms of quantity, is dependent on stream power, which is a function of velocity, turbulence, temperature of the water, stream discharge, channel geometry, sediment particle size and specific gravity, and the degree of mixing of the sediments. Load is the quantity of sediment transported.

Sediment transported as bedload is deposited as stream power decreases. Sediment transported as suspended-sediment load is deposited similarly in accordance with the competency and capacity. The distribution of particle sizes in deposited sediments depends to a certain extent on the amount of bedload and suspended-sediment load transported relative to the transport capacity of the stream and the extent to which the suspended load becomes a part of the bedload. In streams, every irregularity in channel geometry serves to alter velocity and turbulence resulting in differential sediment deposition. In standing water bodies, wave and current action may transport 
sediment back and forth over the same area, in contrast to downstream transport in streams, for long periods with coarser sediments deposited near shorelines or inflowing streams and finer sediments deposited in deeper portions of the water body.

Sediments are classified according to particle size (table 3 ). Because of the large surface areas and organic material associated with fine sands, silts, and clays, particle sizes of suspended sediment and bed material smaller than $2 \mathrm{~mm}$ often are the major transport mechanism and sink, respectively, for numerous chemical constituents.

Table 3. Classifications of sediments by particle size [mm, millimeter; $\mathrm{mm}^{2}$, square millimeter; >, greater than; <, less than]

\begin{tabular}{lccc} 
Class & $\begin{array}{c}\text { Particle } \\
\text { diameter } \\
(\mathrm{mm})\end{array}$ & $\begin{array}{c}\text { Number of particles } \\
\text { per kilogram }\end{array}$ & $\begin{array}{c}\text { Surface area } \\
\text { per kilogram } \\
\left(\mathrm{mm}^{2}\right)\end{array}$ \\
\hline Boulders & $>256$ & $<1$ & $>8,800$ \\
Cobbles & $256-64$ & $<1-3$ & $8,800-35,000$ \\
Gravel & $64-2.0$ & $3-90,000$ & $35,000-1.1 \times 10^{6}$ \\
Sand & $2.0-0.062$ & $90,000-3.0 \times 10^{9}$ & $1.1 \times 10^{6}-3.6 \times 10^{7}$ \\
Silt & $0.062-0.004$ & $3.0 \times 10^{9}-1.1 \times 10^{13}$ & $3.6 \times 10^{7}-5.6 \times 10^{8}$ \\
Clay. & $0.004-0.00024$ & $1.1 \times 10^{13}-4.6 \times 10^{16}$ & $5.6 \times 10^{8}-9.2 \times 10^{9}$
\end{tabular}

A detailed discussion of sediment transport and deposition is beyond the scope of this manual; the reader is referred to Twenhofel (1950), Guy (1970), Colby (1963), Leopold and Maddock (1953), and Culbertson and others (1967).

Because of the many variables in sediment transport and deposition, there is, at present, no good conceptual model of how to collect a representative sample of bed material in a cross section. In order for a random sampling in the cross section to yield a "mean sample" the distribution of biological, chemical, and physical characteristics must be normal, but so ideal a distribution is extremely unlikely.

\section{Preferred Methods}

To obtain satisfactory bed-material samples the equipment and procedures used must insure the enclosure of a volume of bed material and its isolation from currents while the sampler is lifted through the water column, preventing loss of fine-grained material. The ease by which the bed-material sample can be transferred to a suitable sample container is also important. In most circumstances, a number of samples should be collected at or near a cross section to provide a representative statistical characterization of the bed material. It may be possible to composite the samples to provide mean values for the characteristics being investigated, provided the material and its characteristics are uniform. Until such knowledge is available, it is recommended that individual samples not be composited for a single analysis. Results from individual analyses can be "composited" mathematically to yield 
average values. A more detailed discussion of methods is available in Edwards and Glysson, 1988.

\section{Equipment}

Samplers for collecting bed material can be either hand held or suspended from a cable. The samplers cannot physically collect bed material that is much larger than $16 \mathrm{~mm}$ (Edwards and Glysson, 1988). This limitation is probably not important chemically because most of the transport. is due to particles smaller than $2 \mathrm{~mm}$. Some of the samplers may also lose very fine sediments that may be present in the bed material, and this may be a very significant portion of the chemistry of the bed material.

\section{Hand-Held and Cable Samelers}

Table 4 summarizes available samplers for bed material and their basic characteristics. These samplers each have different advantages and disadvantages which should be considered before selecting a particular type for sampling bed material at a given location. In addition to the samplers in table 4, a new sampler (BM-84) has been developed for use in large, swift rivers (John Skinner, Federal Interagency Sedimentation Project, oral

commun.). A more detailed discussion of bed-material samplers can be found in Edwards and Glysson, 1988.

\section{Core Samplers}

Core or piston core samplers are used in streams, lakes, reservoirs, and estuaries to collect surface or core samples of bed materials ranging from soft mud to hard, compacted clay, sand, and gravel. The top portion of a core sample can represent the quality of surface bed material, or a larger portion of the core can be subdivided and analyzed in sections to look at historical quality of bed material. The size of sample collected depends on the size and depth of penetration of the sampler.

The specific core sampler needed for a particular site is dependent on the purpose of the sample and the physical characteristics at the site; there are no preferred core samplers. A large number of core samplers are available ranging from simple hand-pushed tubes for use in shallow water or by divers to explosive-driven and automatic surfacing models for oceanographic use. Some core samplers are available with automatic core catchers and plastic liners and Lexan nose pieces for collection of samples for the determination of trace metals. Several core samplers are shown in figure 10.

Most grab and core samplers are designed primarily for the collection of bed-material samples for benthic analysis and generally are not adequate for collecting undisturbed samples for chemical and mineralogical analyses from most lakes, reservoirs, and estuaries. They are particularly unsuited for collecting samples from the critical water-sediment interface where the bed material is loosely consolidated because the shock wave produced by the samplers is sufficient to blow away the top several millimeters or centimeters of sediment during sampling. A special water-sediment interface sampler, the Jenkin surface-mud sampler (Mortimer, 1964), shown in figure 11, and box corers (Reineck, 1963; Bouma and Marshal1, 1964) can be used to collect virtually undisturbed samples from the water-sediment interface. 


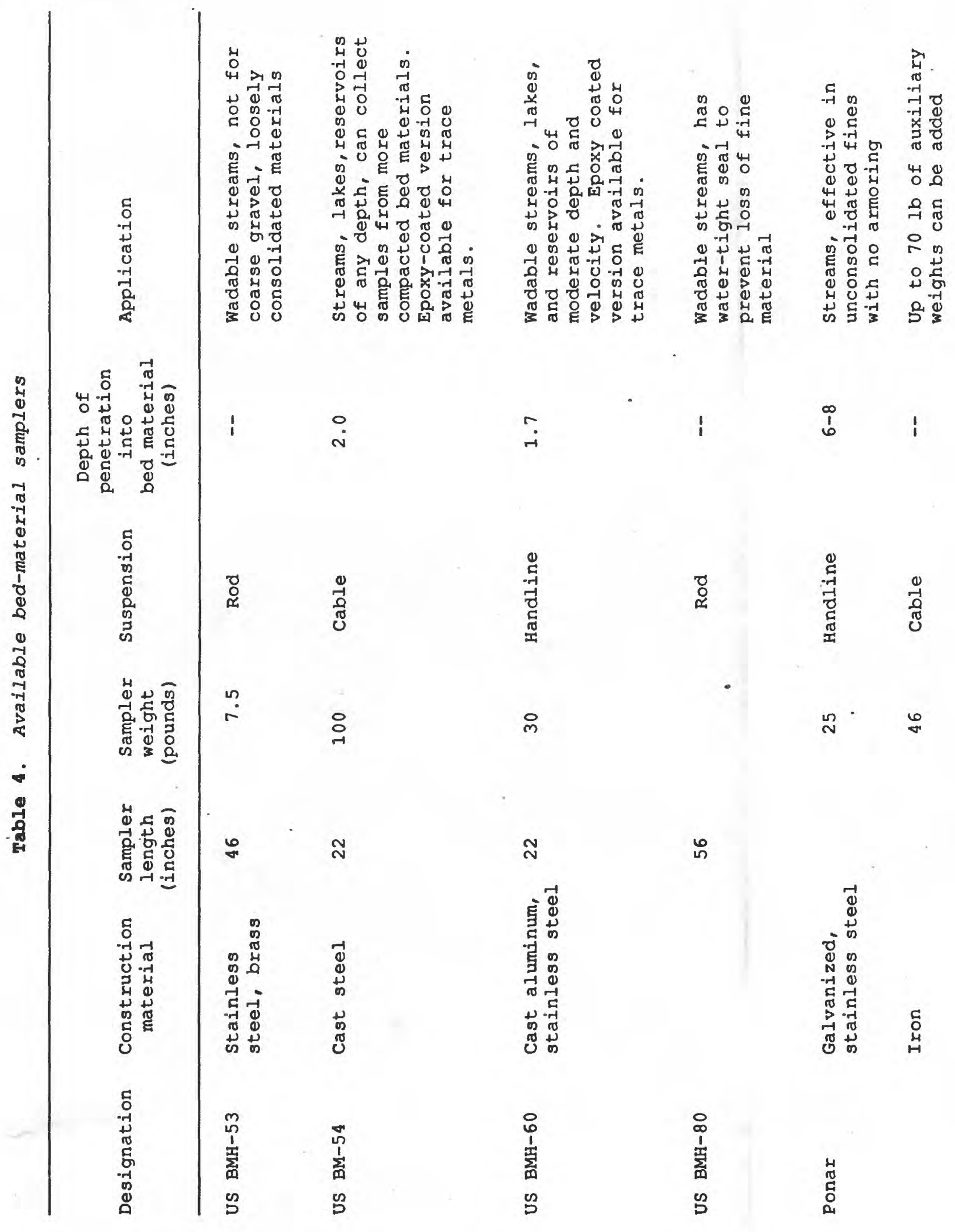




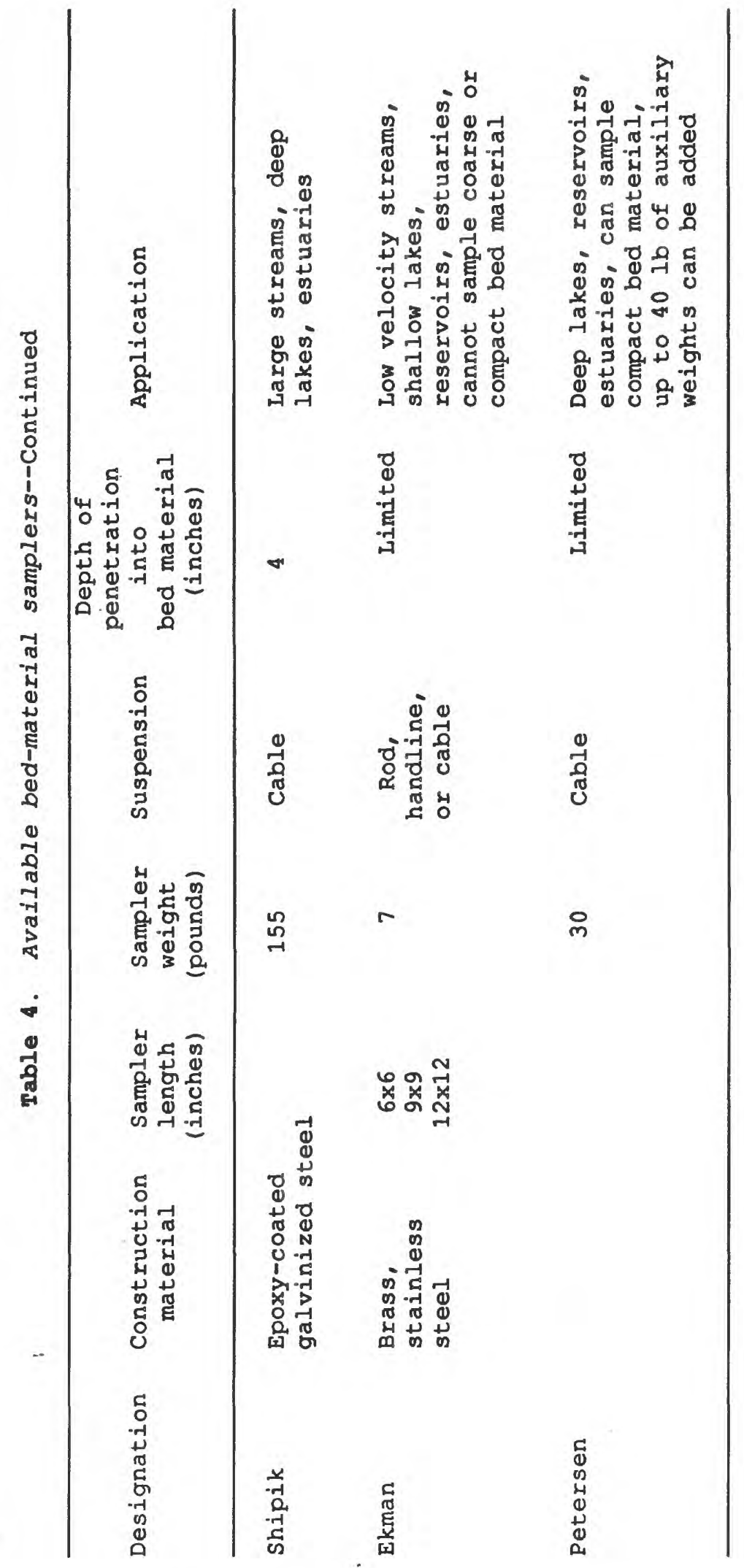




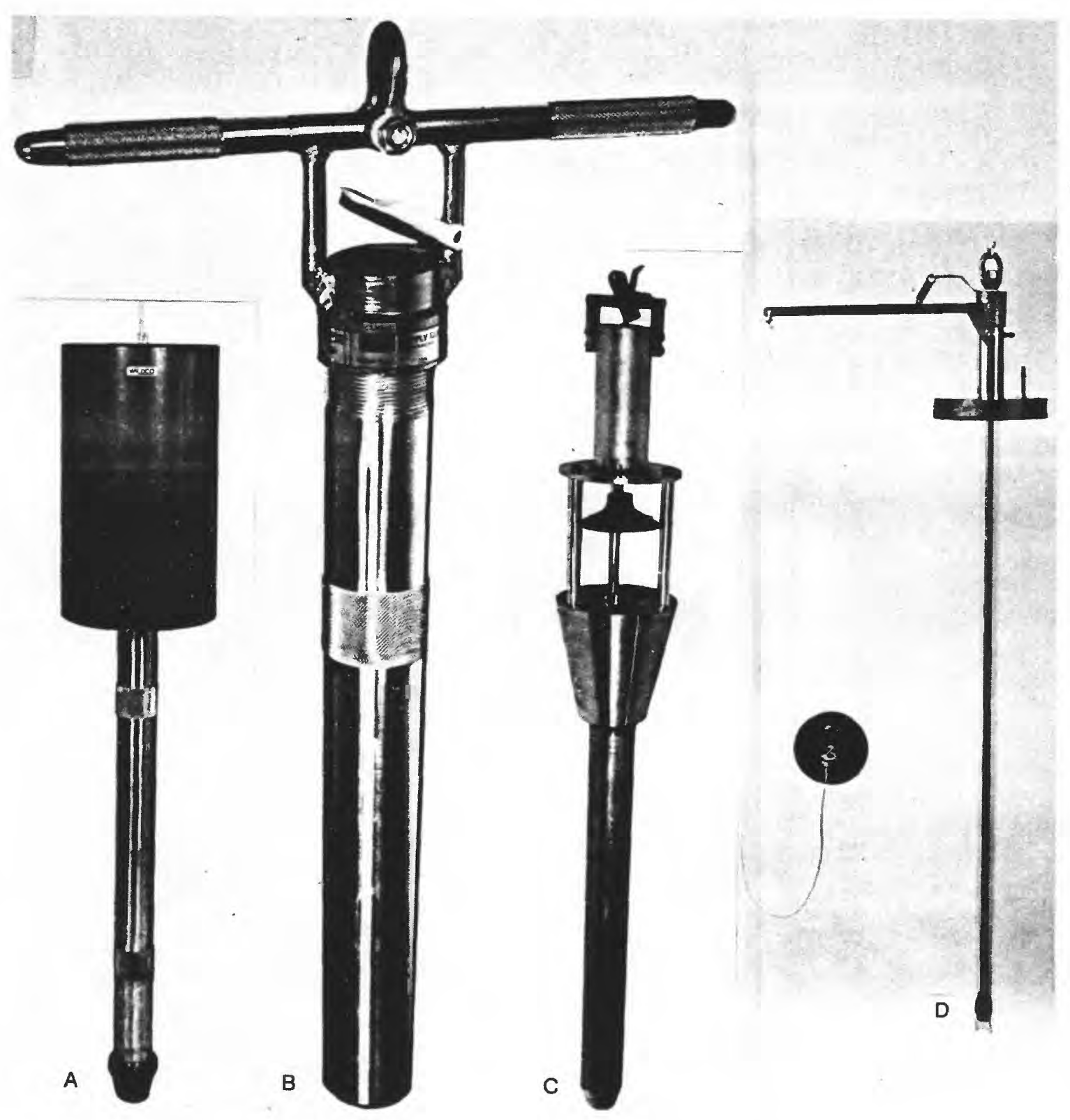

Figure 10. Bed-material core samplers: (A) standard K-B core, (B) Wildco hand core, (C) heavy-duty $\mathrm{K}-\mathrm{B}$ core, and (D) Davis-Doyle self-tripping core samplers. (Photograph courtesy of wildlife Supply Company.) 


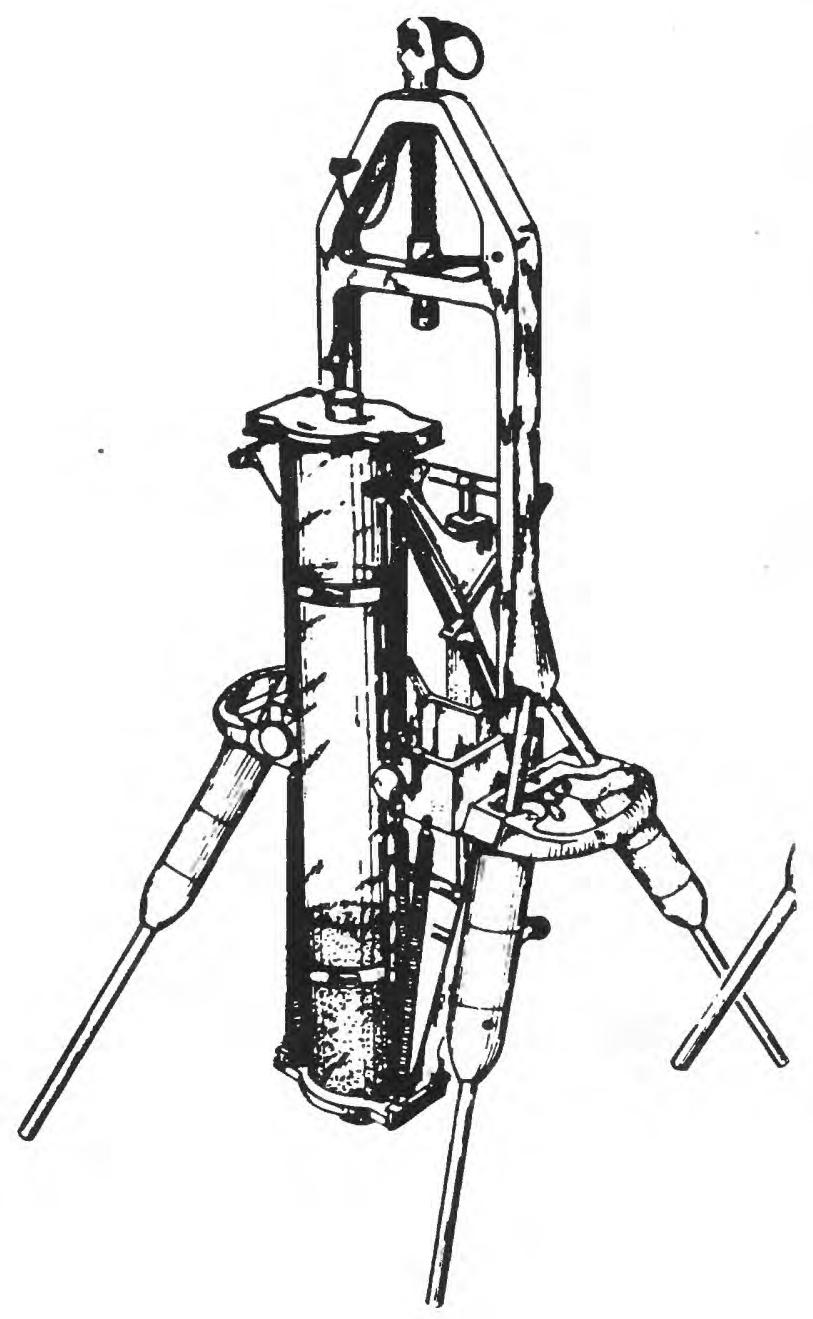

Figure 11. Jenkin surface-mud sampler. (By permission, Limnology and Oceanography and Mortimer, 1971.)

\section{Sampling Procedures}

Streams

\section{1--Application}

The procedures and equipment used to sample bed material in streams depend on stream depth and velocity, bed-material particle size and type of analysis to be performed. 


\section{2--Equipment}

The BMH-53 and BMH-80 samplers are the most practical to sample streams that can be waded and where the streambed consists of material finer than medium gravel (less than $16 \mathrm{~mm}$ in diameter). The BMH-60 sampler is preferred for sampling streams that are not wadable, but where depths are less than $10 \mathrm{ft}$ and velocities less than 2 to $3 \mathrm{ft} / \mathrm{s}$. The BM-54 sampler is used for sampling streams where the depths are greater than 10 ft and velocities greater than $3 \mathrm{ft} / \mathrm{s}$. The Shipek grab sampler can be used to collect samples from large streams where the bed material consists of clay, sand, and gravel. The Ekman, Petersen, and Ponar grab samplers are used infrequently, except in low velocities, because of the danger of loss of fine-grained materials.

\section{3--Preferred Methods}

Because the preferred method of collecting bed-material samples from streams varies with the character of the stream and size of the bed material, there are no standard methods. Where only one sample (composite) is to be collected annually at a site, it should be collected after an extended period of low flow typical of the stream (A. J. Horowitz and W. I. Bradford, U.S. Geological survey, written comm., 1982).

\section{4--Procedures}

Bed-material samples should be collected from wadable streams prior to making water-discharge measurements or collecting water-sediment samples to avoid disturbance of the streambed. Sampling equipment used to collect bedmaterial samples, especially those parts contacting the sample, need to be thoroughly cleaned before sampling. A detailed description of procedures to collect bed-material samples is given in Edwards and Glysson, 1988.

Lakes, Reservoirs, and Estuaries

$$
\text { 1--Application }
$$

The procedures and equipment selected for the collection of bedmaterial samples for chemical analysis from lakes, reservoirs, and estuaries depend on the objectives of the investigation, the depth of the water, the depth or thickness of the bed material, and the particle size and degree of consolidation of the bed material.

\section{2--Equipment}

Core samples collected from lakes, rivers and estuaries are generally collected to examine gross bed-material chemistry, historical profiles, and chemistry of the water-sediment interface. Core samplers equipped with plastic liners and nose pieces should be used to collect bed-material samples for the determination of trace metals. Provided suitable precautions are taken, the Shipek grab sampler can be used to sample relatively consolidated clay, sand, and gravel for gross chemical analysis. The BM-60 and BMH-54 bed-material samplers can be used to collect samples of coarser sediments from estuaries.

When data are required on the vertical distribution of trace metals, organic compounds, or other chemical constituents in lake, reservoir, or estuarine bed materials, the sampling needs to be done by coring. Again, provided suitable precautions are taken, core samples can be collected with 
samplers that do not depend on gravity for penetration. Because most core samplers lack positive seals to prevent the loss of fine-grained or loosely consolidated sediments as the sampler is withdrawn from the water, samplers with core retention devices need to be used. The Jenkin surface-mud sampler (Mortimer, 1964) and box corers (Reineck, 1963; Bouma and Marshall, 1964) can be used to collect virtually undisturbed samples for analysis at the watersediment interface.

\section{3--Preferred Methods}

Because the mode of deposition, particle-size distribution, and the chemical and mineralogic composition of bed materials vary greatly from place to place in lakes, reservoirs, and estuaries, and because of the diversity in the objectives of investigations, it is impractical to recommend any preferred methods. However, some general guidelines can be suggested. The method selected needs to consider: (1) the objectives of the investigation; (2) the variability in the particle-size distribution; (3) the variability in the chemical and mineralogic composition of the bed material; and (4) the degree of accuracy required. Regardless of the method, it is imperative that each sample taken be representative.

The principal methods suggested are based on limnological methods (Welch, 1948) and include Dispersed Random Sampling and Transect Sampling. Dispersed Random Sampling requires that samples be collected from points randomly scattered over the entire area, that conscious choice in the selection of sampling positions be rigorously excluded, and that the number of samples taken satisfy the precision requirements of the investigation. Transect Sampling requires that samples be taken randomly or at regular intervals along a predetermined line extending across the area concerned. The advantages of Transect Sampling are that the position and distribution of samples are known and it may be easier to distribute samples over the area concerned while maintaining the requirements of random sampling. Any substantial investigation will require several transects whose positions are determined by special features of the lake, reservoir, or estuary. There are no criteria for the number of samples required for representative sampling. One sample taken from the deepest part of a lake, for example, may be adequate to describe the trophic status, but obviously is not representative of the bed materials as a whole. At present, the decision on the number of samples to be collected probably should be discretionary, based on the investigators knowledge of the area concerned.

\section{4--Procedures}

Before collecting bed-material samples from lakes, reservoirs, or estuaries, the method of sampling and number of samples to be collected must be decided; the samplers used should be in working condition and clean; and accessory equipment and supplies should be on hand. Because most sampling will be from boațs, personnel must know how to operate them and the sampling equipment safely. The boat from which sampling is done should be held at the sampling position by navigational means; anchoring should be avoided to prevent disturbance of the bed material at the critical water-sediment interface. If anchoring becomes necessary, bow and stern anchors of a type appropriate to the bed material should be used. The anchor rope should be 7 to 10 times the water depth and sampling should be delayed until equilibrium conditions are re-established. For repetitive sampling of a lake, reservoir, or estuary it may be desirable to mark sampling positions with buoys, provided they do not interfere with navigation. 
The depth of water at each sampling position must be determined from a recent bathymetric map or by electronic depth meter. When the boat is at the sampling position the sampler, suspended by reel and cable, is lowered carefully and slowly through the water column to avoid setting up a shock wave to the bottom. The sampler is closed by releasing tension on the suspension cable, thus collecting the sample. The sampler is then raised, using the same care as when lowering to avoid sample loss. The sample is transferred quantitatively to a sample container for further processing. If the sampler fails to close completely, do not attempt to resample at that sampling position. The sampling is repeated at other sampling positions. Alternatively, samples can be collected by divers, however, diving must not be attempted unless personnel are experienced and proper equipment is available. Under no circumstances should a person dive alone.

\section{SAMPLE HANDLING}

\section{Introduction and scope}

The equipment and procedures approved for processing water, watersediment, and bed-material samples in the field and shipment to the National Water Quality Laboratory or contract laboratories are described in this section.

\section{Compositing and splitting samples}

\section{Principles and Concepts}

Water-sediment samples are composited when it is necessary to obtain a bulk mixture from several samples such as those collected by the EDI, EWI or other multivertical methods in a stream cross section. Subsamples from different depths of a lake or other bodies of water may also be composited. Unfortunately, preservation requirements and analytical methods seldom allow the submission of one sample in a single container to the laboratory for analysis. The composited sample is subdivided using a splitter, usually within a short time after collection, into a number of subsamples, each of which must be virtually equivalent in concentration of suspended and dissolved constituents. When contamination from the procedure is a threat, compositing is not appropriate and each multivertical sample may have to be preserved and analyzed independently.

\section{Equipment}

\section{Churn Splitter}

$$
\text { 1--Application }
$$

The churn splitter (fig. 12) is used for compositing water-sediment samples and for splitting the composite into a number of representative subsamples that are to be analyzed for "dissolved", "total", or "total recoverable" inorganic constituents. Large volume composite samples can be processed easily, allowing the withdrawal of different volumes of subsamples while maintaining the same basic chemical and physical characteristics of the original composite. However, when the churn splitter contains less than about 28 percent of its capacity, reliable subsamples cannot be withdrawn. Subsamples of the composite that are to be analyzed for "dissolved" inorganic constituents are processed after withdrawal of "total" or "total recoverable" subsamples. Because of partitioning of hydrophobic compounds the churn 


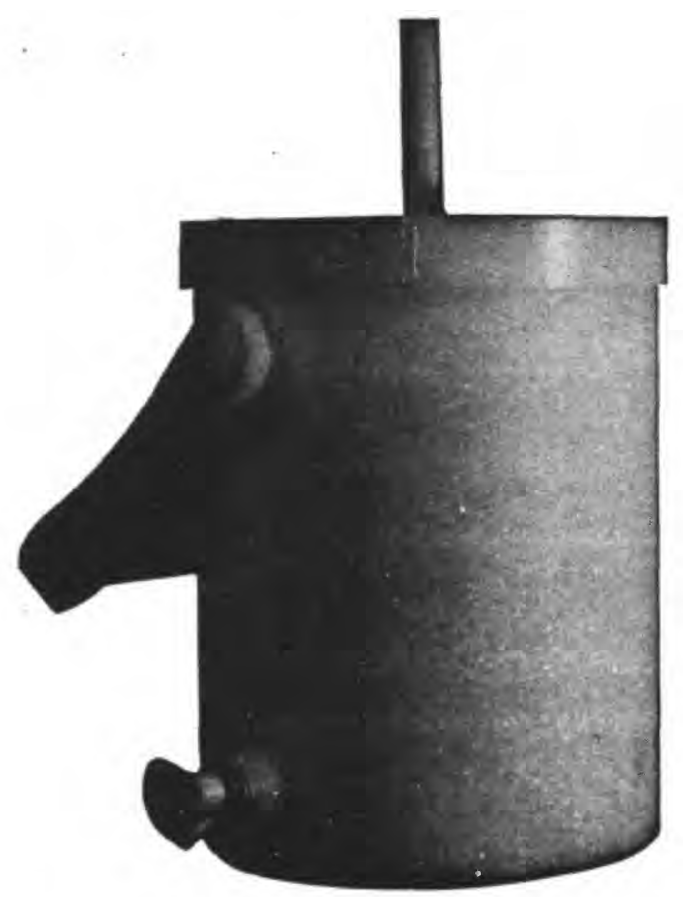

Figure 12. The churn splitter.

splitter should not be used for compositing or splitting water-sediment samples that are to be analyzed for organic constituents.

Suspended sediment coarser than $0.063 \mathrm{~mm}$ cannot be subsampled with an accuracy of less than about 10 to 15 percent. Therefore, if samples are collected in any vertical with a mean velocity of more than $2.0 \mathrm{ft} / \mathrm{sec}$, subsamples for total or total recoverable constituents cannot be composited in the churn splitter. A separate set of sections must be collected for each vertical in this case.

\section{2--Description}

The churn splitter (fig. 12) is made of molded and welded polyethylene plastic and consists of a straight-sided bucket with a folding handle, a cover, and a perforated-plate churning disc attached to a rod which extends through a hole in the cover. An internally tapered, push-button outlet valve is fitted through the lower side of the bucket. Both 8- and 14-L nominal capacity churn splitters are approved for use. A 4-I churn splitter is available from the manufacturer, but it is not approved because tests have shown that it does not produce reliable subsamples.

The bucket of the $8-\mathrm{L}$ churn splitter is $8.0-\mathrm{in}$. ID (inside diameter) and 10.75-in. deep; the 14-L unit is 10.25-in. ID and $12.25-\mathrm{in}$. deep. Wall thickness may vary between different churn splitters but is a minimum 0.25 in. A 0.25 by 0.38 -in. polyethylene $\mathrm{rib}$ is welded down the inside wall of the bucket to guide the churn during use. The outlet valve in both churn splitters is $0.31-i n$. ID and is tapered with the push-button seat at the apex so there is no space that would allow the accumulation of suspended sediment in the passage way. A close fitting cover prevents debris from falling in the bucket; a hole in the center of the cover accommodates the churn rod and also guides the churn during use. 
The churning disc is a circular polyethylene plate, 0.25 in. thick with a diameter of about 7.75-in. for the 8-L size and about 10.0-in. for the 14-L size. It is welded to a rod and supported by four baffles. The rod is $14.25 \mathrm{in}$. long and $0.75-\mathrm{in}$. ID and $17.75 \mathrm{in}$. long, and 1.0-in. ID, respectively, for the 8- and 14-L sizes. The disc is perforated with eight 1.3-in. holes arranged in a square pattern and eight semi-circular holes spaced equally around the circumference of the plate. A square notch in the disc engages with the vertical rib in the bucket. A $1.5-$ by $1.5-i n$. baffle is welded to the disc opposite the outlet-valve opening.

\section{3--Care and Maintenance}

The churn splitter is made of relatively thick polyethylene and can withstand some abuse, but reasonable care should be exercised to prevent damage. The unit should be protected from excessive heat which could cause deformation. The polypropylene spigot should be protected from accidental breakage.

Prior to taking the churn splitter into the field, it should be washed with a nonphosphate laboratory detergent and thoroughly rinsed with tap water followed by distilled or demineralized water. If the churn splitter will be used to collect trace metal samples, it should be soaked in a 5 percent solution of hydrochloric acid for about 4 hours, followed by the cleaning procedure described above. Putting the cover on the unit is usually sufficient to keep it clean, but storage in a clear plastic bag is recommended.

Cone splitter

\section{1--Application}

The cone splitter (fig. 13) was developed to reliably subsample watersediment samples smaller than the minimum required for proper operation of the smallest approved churn splitter. The cone splitter can be used for splitting water-sediment samples taken with automatic-pumping samplers for chemical and/or physical analysis. Subsamples from the cone splitter can also be composited into a single discharge-weighted sample. The cone splitter can split water-sediment samples as small as $250 \mathrm{~mL}$ into 10 subsamples, each being within 3 percent of equal volume and suspended-sediment concentration.

\section{2--Description}

The cone splitter is made of cast and machined acrylic resin and supported on a tripod stand. It consists of a 3.5-in. diameter by 7.0-in. high cast reservoir funnel with a $2-\mathrm{mm}$ mesh plastic screen at the bottom to retain debris that might interfere with the splitting process. The screen also reduces the vortex action of the water leaving the funnel and helps mix the sample. Below the reservoir funnel, a standpipe 1.0-in. in diameter by 3.75-in. long with a $0.35-i n$. bore with a $0.62-i n$. section tapered from $0.75-$ to $0.35-i n$. at the top directs the water in a steady stream into the splitting chamber. 


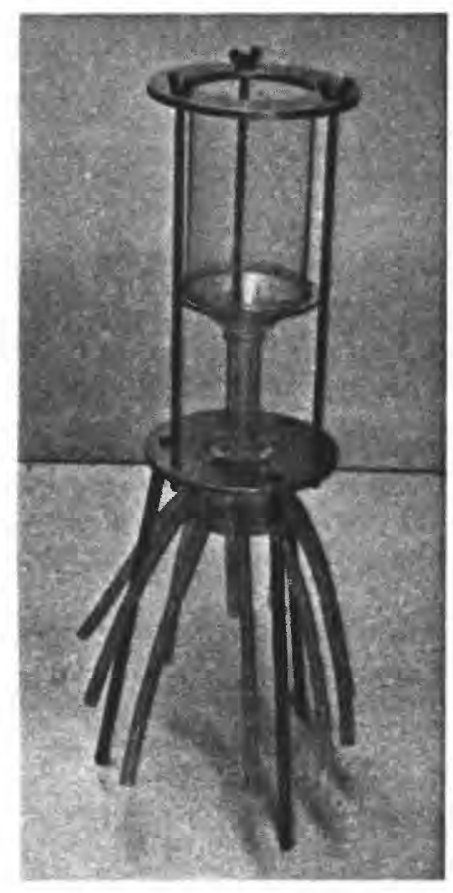

Figure 13. The cone splitter.

Ten 0.25 -in. exit ports are precisely drilled through one common point at an angle of 45 degrees from the vertical and spaced at 36-degree intervals around the circumference of the block to form the splitting chamber. There are no flat walls, benches, or surfaces inside the splitting chamber to retain debris or interfere with the splitting process. Ten silicone-rubber discharge tubes, $0.31-i n$. ID and about 8 -in. Iong are attached to the exit ports. These tubes must all be the same length for accurate splitting.

\section{3--Care and Maintenance}

Cone splitters are built to very close tolerances to produce accurate subsamples. Proper care, handling, and operation will produce reliable results for a considerable number of samples.

Cone splitters need to be cleaned before use. Disassemble the unit and wash the parts using a nonphosphate laboratory detergent and a soft bristle test-tube brush. Rinse thoroughly with tap water followed with distilled or demineralized water. If the cone splitter has been used to process water-sediment samples preserved with mercuric chloride, soak the parts in a 10-percent nitric acid solution for several minutes followed with tap water and distilled or demineralized water rinses. Reassemble the unit, store in a plastic bag and protect from physical damage between usages.

The cone splitter and interior of the cone splitting chamber need to be carefully inspected for damage. Units that show damage or wear are to be tested to verify their serviceability. Check discharge tubes frequently for proper length and cleanliness and replace as needed. 


\section{Procedures}

Churn splitter

Determine the total volume of water-sediment samples needed by summing the volumes of all subsample containers required for the analysis schedule. Allow an additional volume of about 10 percent for spillage and filter losses. If the water-sediment sample is to be subsampled for analysis of "total" or "total recoverable" constituents, collect an additional $4 \mathrm{I}$ of sample for the 14-L churn splitter, or $3 \mathrm{~L}$ for the $8-\mathrm{L}$ churn splitter, to obtain representative subsamples.

Collect representative water-sediment samples of the streamflow using the sampling methods described above. Collect $1 \mathrm{I}$ of sample at the first subsampling location to rinse the churn splitter before collecting the first sample. Quantitatively transfer each of the individual water-sediment samples collected into the churn splitter for compositing. Protect the churn splitter during freezing conditions to avoid formation of slush ice in the water-sediment mixture. When all of the individual water-sediment samples are in the churn splitter, place it on a support and place all of the labeled water-sediment subsample containers within easy reach.

Stir the composited water-sediment sample by raising and lowering the churning disc at a uniform rate of about 9 in. per second. The churning disc needs to touch the bottom of the tank and cover the entire depth of the sample without breaking the water surface on every stroke. High churning rates or breaking the water surface will entrain air in the water-sediment sample, which can change the concentration of dissolved gases, alkalinity, $\mathrm{pH}$, and other characteristics. Inadequate churning rates can result in nonrepresentative subsamples. After seirring for about 10 strokes, the first subsample is withdrawn by placing a sample container under the spout and depressing the valve to fill the container while continuing stirring. Withdraw the remainder of the subsamples in a similar manner. Stirring needs to be continuous throughout the withdrawal of subsamples. If a break in withdrawal is unavoidable, the previous stirring rate needs to be reestablished before continuing withdrawals.

Withdraw subsamples to be analyzed for "total" and "total recoverable" constituents first. Allow the remaining water-sediment sample to settle, and then withdraw samples for filtration. When compositing and splitting have been completed, the churn splitter needs to be rinsed with distilled or demineralized water and properly stored.

Cone splitter

Before using the cone splitter, field personnel need to inspect the unit. The cone-splitter housing and outlet parts should be smooth and symmetrical without any visible burrs or chips. Discharge tubes are to be the same length and securely attached to the outlet ports and extend into the subsample containers far enough to prevent spillage but not so far that the ends become submerged. The unit needs to be physically and chemically clean before use.

Place the required number of labeled subsample containers under discharge tubes. Discharge tubes can be combined to collect various combinations of the original water-sediment sample; however, when combining. discharge tubes there must be no back pressure resulting from restriction of flow. Shake or stir the water-sediment sample for 10 to 15 seconds. Rapidly 
invert the sample container over the reservoir funnel and pour the entire contents into the cone splitter. The stand pipe needs to be full for proper subsampling. After flow has stopped, tap the unit to dislodge any adhering droplets. Remove the desired subsamples and process as required. If necessary, any of the subsamples can be further split as described above.

Upon completion of the splitting, the cone splitter needs to be disassembled, thoroughly cleaned with nonphosphate detergent followed by tap water and distilled or demineralized water rinses, and reassembled for further use.

\section{Eiltration of Water Samples}

\section{Principles and Concepts}

Natural waters are multicomponent systems which can exist in all degrees of dispersion ranging from true solutions to macroscopic suspensions. True solutions are single-phase systems where atoms, molecules, or ions of the solutes, or dissolved substances, are distributed homogeneously throughout the solvent with no true surfaces of separation. Macroscopic suspensions are two-phase systems where discrete particles of suspended substances are distributed in the solvent with definite surfaces of separation. Between these extremes are the colloidal dispersions that are two-phase systems where the surfaces of separation are not clearly defined. The latter may be classified either as colloidal solutions or colloidal suspensions.

The relative size distribution of water-borne particles is shown in figure 14. Fluvial sediment that is normally in suspension in moving water ranges in size from 0.24 to about $500 \mu \mathrm{m}$; larger particles may be suspended in very turbulent flow. Colloidal dispersions range in size from 0.001 to $1.0 \mu \mathrm{m}$; coarse suspensions, composed of material other than mineralized sediment range from 1.0 to about $500 \mu \mathrm{m}$. The size of bacterial cells ranges from 0.2 to about $39 \mu \mathrm{m}$, and virus cells range from about 0.003 to about $0.06 \mu \mathrm{m}$. Algal cells have the greatest size distribution, ranging from $1.1 \mu \mathrm{m}$ to more than $100 \mathrm{ft}$.

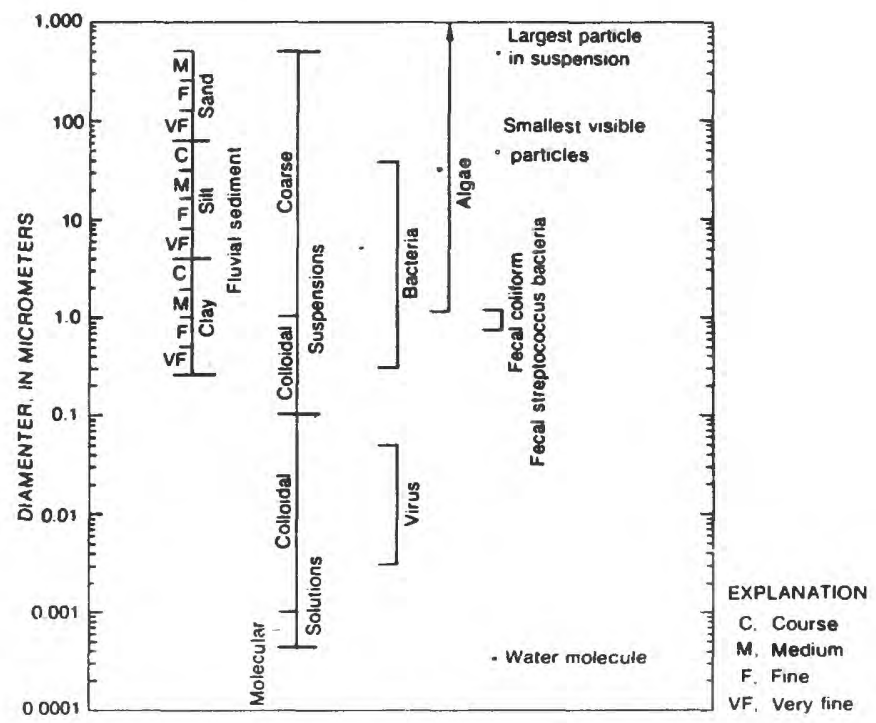

Figure 14. Relative sizes of water-borne particles. 
Except for very fine clay, most suspended sediment and bacteria, coarse suspensions, some colloidal suspensions and algae will be retained on a $0.45 \mu \mathrm{m}$ pore-size filter membrane. However, because a filter cake usually forms during filtration, some particles with a diameter of less than $0.45-\mu \mathrm{m}$ also may be retained. All of these particles, plus very fine clay and smaller bacteria will be retained on a $0.1 \mu \mathrm{m}$ pore-size filter membrane.

Constituents present in the filtrate, the fluid passing through a $0.45 \mu \mathrm{m}$ pore-size membrane filter, are defined as dissolved although it is apparent from figure 18 that most of the very fine clay-size sediment, colloidal suspensions, colloidal solutions, virus, and some bacteria also pass through the filter. The $0.45-\mu \mathrm{m}$ pore-size membrane filter was selected as the break between dissolved and suspended material by a Federal interagency committee principally because, at the time, it was the smallest poresize membrane filter that could be reliably manufactured. Although later technology has permitted reliable production of membrane filters with a pore size as small as $0.25 \mu \mathrm{m}$, the $0.45 \mu \mathrm{m}$ pore-size membrane filter remains the standard. Grim (1968) and Kennedy and others (1974), however, have shown that fine-grained particulates can pass through a $0.45-\mu \mathrm{m}$ pore-size membrane filter and can cause major errors in the apparent concentration of dissolved aluminum, iron, manganese, and titanium. Other elements enriched in very fine clay-size sediments, chelates, and complex ions may be similarly affected. Thus, it is recommended that for geochemical studies $0.1-\mu m$ poresize membrane filters be used; for general water-quality appraisals the $0.45-\mu m$ pore-size membrane filter is satisfactory.

\section{Equipment}

Membrane Filters

\section{1--Application}

The membrane filters commonly used for water analysis are made of cellulose triacetate, mixed cellulose esters, or polycarbonate polymers. These materials can be sterilized by autoclave or with ethylene oxide, but not with steam. Chemical compatibility to selected reagents is given in table 5 .

Because membrane filters are hydrophobic, they are treated with wetting agents during manufacture and must be rinsed with distilled or demineralized water followed by the water-sediment sample before any filtrate is collected for chemical analysis. For water-sediment samples with low concentrations of suspended material, the membrane filters can be rinsed with sample water. For water-sediment samples of medium to high concentrations of suspended material, or samples with high fine-grained concentrations, flush the filter first with distilled or demineralized water. Follow this with a flush of sample water to completely remove any remnant of the first flush. This will prevent plugging the filter with the sample flush before the actual sample is filtered. The total recommended volumes of rinse water for the 47-and 142-mm diameter membrane filters are about 30 and $400 \mathrm{~mL}$, respectively.

Membrane filters may generally be considered to be noncontaminating with respect to components present in higher than trace concentrations. Although Robertson (1968) and Spencer and Mannheim (1969) found significant 
Table 5. Resistance of membrane filters to common reagents

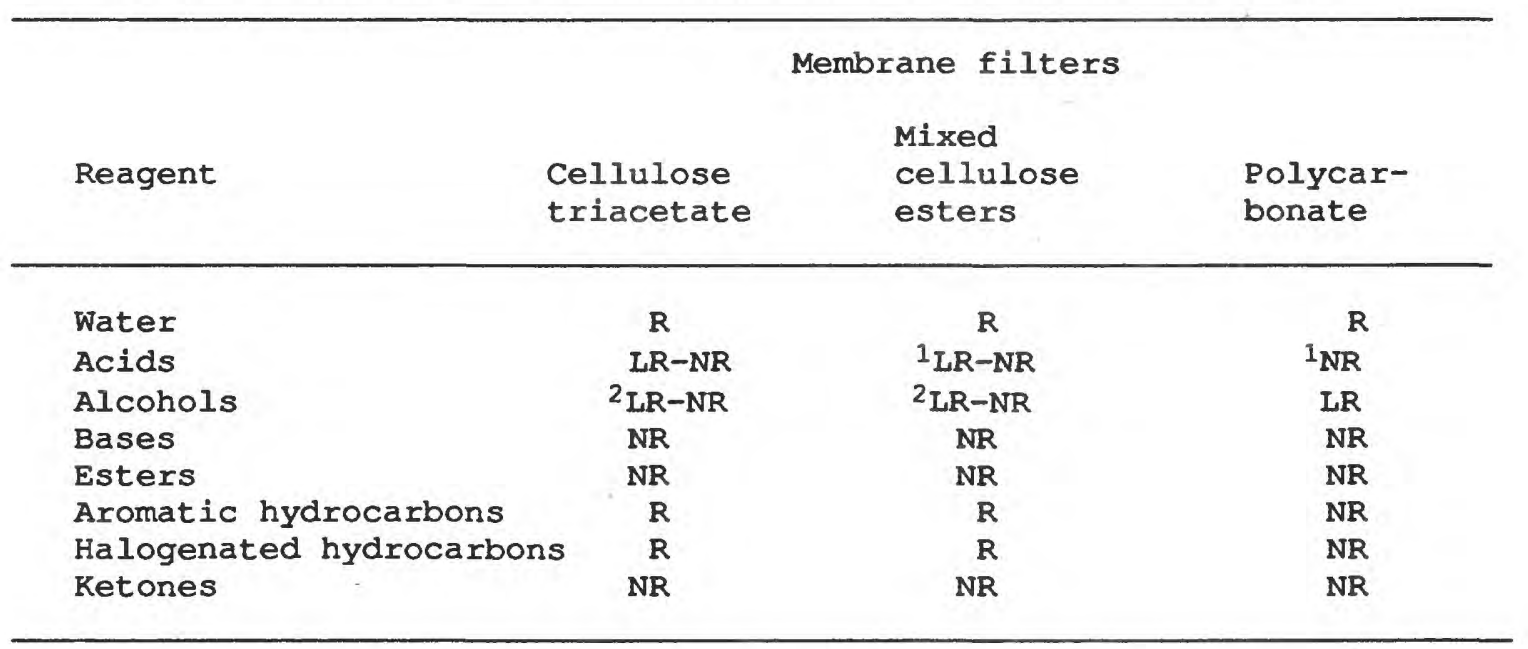

R Resistant after 48 hours exposure at 25 degrees Celsius

LR Limited resistance but may be suitable for short term, non-critical use

NR Not resistant

1/ Resistant to dilute or weak acids

2/ Resistant to amyl and isopropyl alcohols

concentrations of calcium,. magnesium, sodium, potassium, chromium, iron, and zinc in the ash of Millipore filters, the chemical composition of membrane filters is generally not important unless the filter and its contents are ashed or digested in strong acids. When analyzing for trace metals, minute quantities of contamination can cause very large percentage errors, and any possible source of contamination, including membrane filters, must be suspect. Trace metal analyses, therefore, should be considered as valid only when adequate blank analyses have been run to confirm the absence of contamination (A.J. Horowitz, U.S. Geological Survey, oral communication, 1988 ).

Plastic membrane filters are used to process water-sediment samples for chemical analysis for dissolved inorganic constituents including the major ions, trace metals, and nutrients. Plastic membrane filters should not to be used to process water-sediment samples for the determination of dissolved carbon or organic constituents.

$$
\text { 2--Description }
$$

Membrane filters are microporous films of biologically inert, expanded plastic polymers such as cellulose acetate or nitrate, regenerated cellulose, nylon, Teflon, polyvinyl chloride, polycarbonate copolymer, or acrylic copolymer. Membrane filters are approximately 60 to 80 percent void volume; the remainder consists of a single, solid plastic matrix with no fiber, binders, or fillers that can break loose to enter the fluid being filtered. Membrane filters are available in more than 20 pore sizes ranging from 0.025 to $14 \mu \mathrm{m}$ and in either sheet stock or precut discs 13 to $293 \mathrm{~mm}$ in diameter. The pore size is controlled to close tolerance during manufacture and ranges from plus or minus $0.003 \mu \mathrm{m}$ for the $0.025-\mu \mathrm{m}$ pore-size filter to plus or minus $3 \mu \mathrm{m}$ for the $14 \mu \mathrm{m}$ pore-size filter. 
Particles in a water-sediment sample equal to or greater in diameter than the pore size of the membrane filter will be retained on the membrane surface. Some of the particles smaller than the pore size of the filter will pass through, but some are also retained in the sponge-like internal structure (fig. 15). Flow rates through membrane filters are very high due to the high void volume.

\section{Silver Filters}

$$
\text { 1--Application }
$$

Silver membrane filters, commonly $47 \mathrm{~mm}$ in diameter and $0.45-\mu \mathrm{m}$ pore size, are used to process water-sediment samples for the determination of organic constituents. Field application is mostly for filtration of watersediment samples for the determination of dissolved and suspended organic carbon. Silver membrane filters are resistant to chemical attack by all fluids which do not attack metallic silver; cyanide solutions and nitric and sulfuric acids will dissolve the filters.

\section{2--Description}

Silver filters are made of metallic silver by a proprietary process which controls the size and orientation of the silver particles to produce a metallic membrane with close uniformity of pore size and high void volume. There are no fibers or particles to come loose to contaminate the filtrate. Silver filters are available in diameters ranging from 13 to $293 \mathrm{~mm}$ with absolute retention rates of from 0.2 to $5.0 \mu \mathrm{m}$ (fig. 16).

Rressure Filtering Systems

$$
\text { 1--Application }
$$

Pressure filtration systems use compressed air or an inert gas to force water through a filter. They can filter moderate volumes of watersediment samples that have low concentrations of suspended sediment.

Pressure filtration is used most commonly to process water-sediment samples for the determination of organic carbon.

Because of the danger of plastic filter holder assemblies exploding, gas pressure used should be less than $30 \mathrm{lb} / \mathrm{in} .{ }^{2}$; pressures greater than 15 to $20 \mathrm{lb} / \mathrm{in}^{2}$ have little effect on filtration once filters are clogged. Some types of algal cells rupture at pressures greater than $5 \mathrm{lb} / \mathrm{in} .{ }^{2}$, releasing cellular contents into the filtrate. However, many are able to withstand such pressures. In waters where the concentration of algae are low, rupture of the cells normally will not influence the chemical quality of the filtrate. Nevertheless, for water-sediment samples from lakes, reservoirs, and estuaries, the presence of ruptured algal cells should be assumed and their influence on the chemical quality of the water considered. 


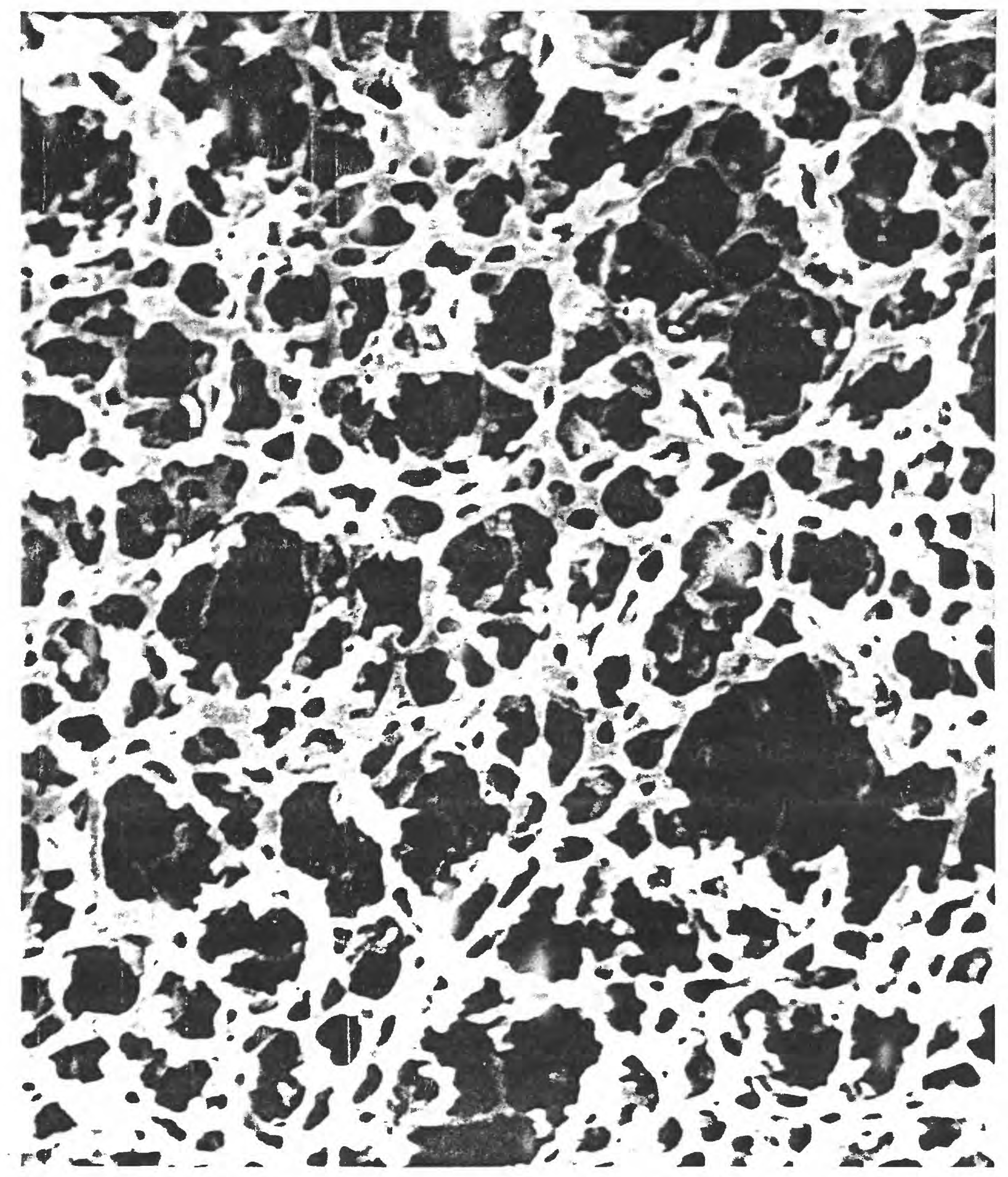

Figure 15. Surface of 0.45-micrometer membrane filter (7,000 times larger than normal). (Photograph courtesy of Gelman Sciences, Inc.) 


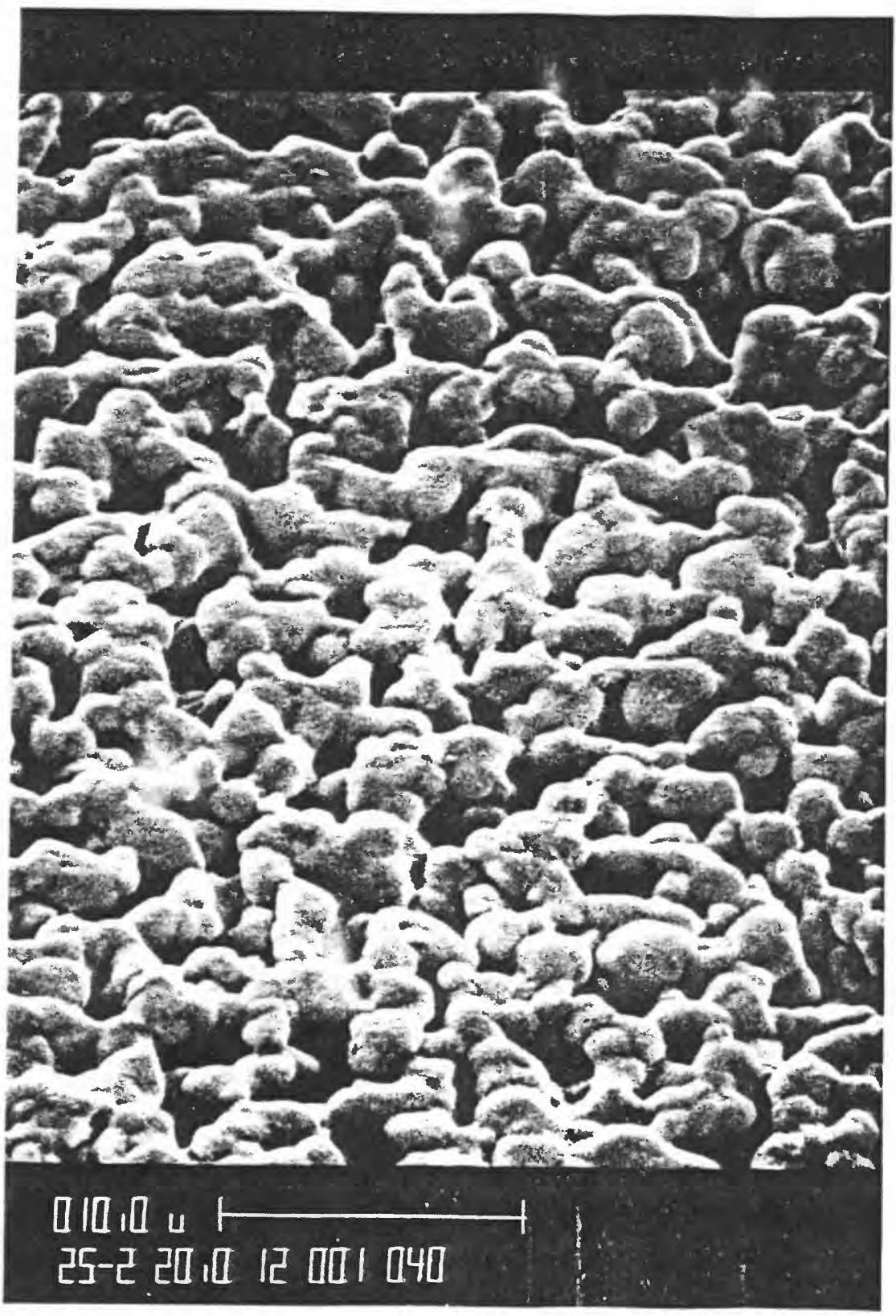

Figure 16. Silver membrane filter $(2,500$ times larger than normal). Photograph courtesy of Selas Corporation of America, Flotronics 
The preferred gas for pressure filtration systems is ultra-high purity, low-moisture content nitrogen similar to that used for bubble-gages. This grade of nitrogen gas is 99.995 percent pure and contains less than 0.005 percent oxygen, about 2.6 parts per million water, and less than 0.5 parts per trillion hydrocarbons as methane. It is satisfactory for filtering all types of water-sediment samples. Clean, compressed air can be used if the presence of oxygen will not adversely affect the sample. Air should not be used for filtering water-sediment samples with low dissolved-oxygen concentrations or with high concentrations of oxygen-demanding substances. Clean air can be pumped either by a peristaltic pump equipped with clean, dry tubing or by a hand-squeeze bulb. Tire pumps or air compressors should not be used because of the possibility of sample contamination from the oil and grease used for lubrication.

\section{2--Description}

The gas-pressure filtration system approved for use (fig. 17) consists of a type 303 stainless steel barrel 1.75-in. ID by 5.47-in. long, threaded at each end for caps. Immediately above the threads a groove accommodates a synthetic rubber o-ring for sealing. One cap is machined to hold a type 304 stainless-steel screen for supporting the membrane filter and is tapped for a 1/8-in. drain tube. The other cap is tapped for a 1/8-in. hose-nipple adapter for the 1/4-in. ID pressure hose. For convenience in attaching the pressure source to the filter unit quick-disconnect adapters may be used to replace the hose-nipple adapter. Teflon gaskets aid in sealing the filtration system. The capacity of the system is about $200 \mathrm{~mL}$. It can be used with 47-mm diameter plastic or metallic membrane filters and, if needed, $40-\mathrm{mm}$ diameter prefilters. Effective filter area is $96.2 \mathrm{~mm}^{2}$. The system can withstand pressures of $200 \mathrm{lb} / \mathrm{in} .^{2}$ and is autoclavable.

Plastic pressure filtration systems, such as the barrel- or reservoirtype filter (Skougstad and Scarboro, 1968) are not approved for use because of the danger of explosion.

\section{3--Care and Maintenance}

The pressure filtration system should be washed thoroughly with a nonphosphate laboratory detergent and rinsed with tap water followed with distilled or demineralized water to remove oil and grease. Inspect 0 -rings, Teflon gaskets, and the stainless-steel support screen prior to use and replace if damaged. The pressure hose and couplings should also be inspected before each use and replaced if worn or damaged. Protect the machined ends of the stainless-steel barrel from nicks, cuts, or dents for proper seating of the Teflon gaskets. Use only water to lubricate o-rings during assembly. The filtration system should be cleaned after use and reassembled and stored in a plastic bag between usages. Protect the filtration system and accessories from external damage when storing. 


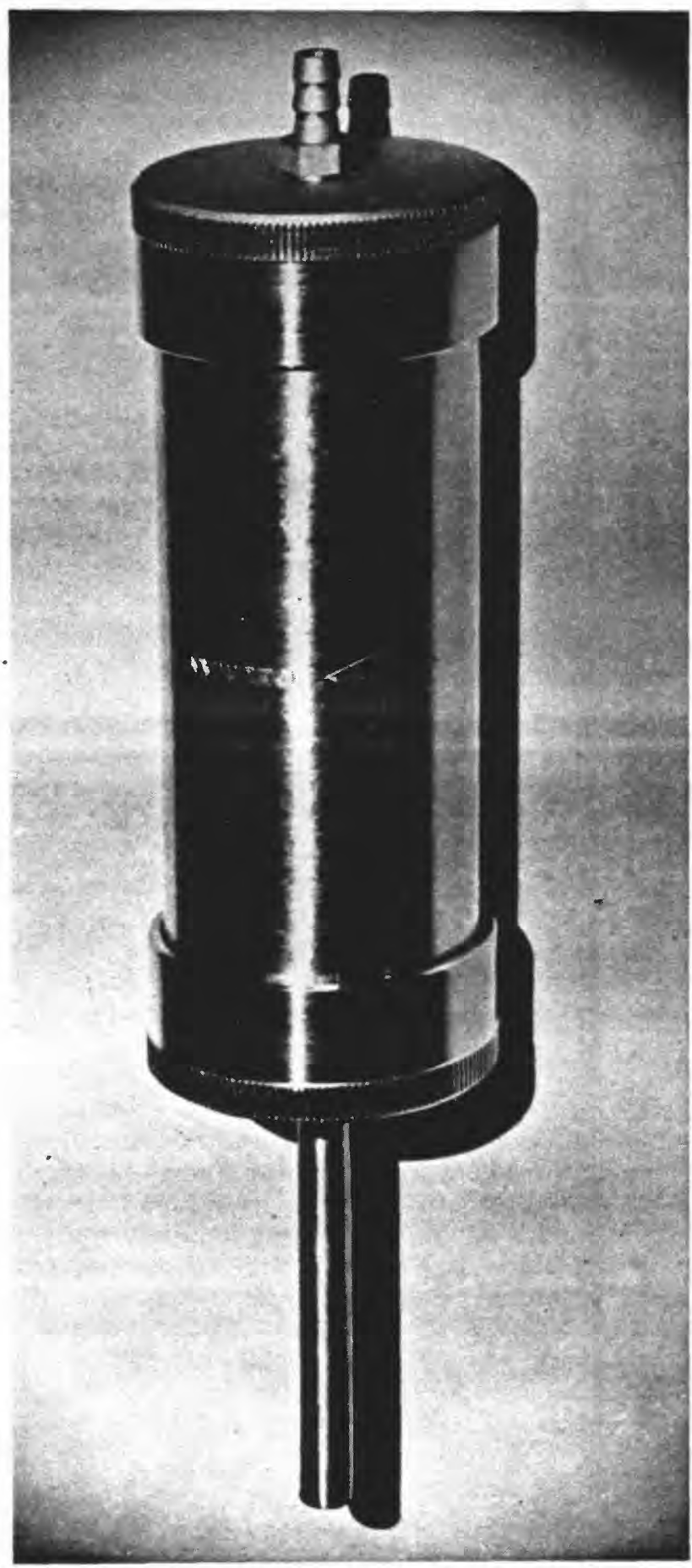

Figure 17. A gas-pressure filtration system. (Photograph courtesy of Gelman Sciences, Inc.) 
Vacuum Eiltering Systems

\section{1--Application}

Vacuum filtration systems, where atmospheric pressure forces water through a filter into an evacuated flask or other container, are seldom used for routine field filtration except for membrane microbiological procedures and for chlorophyll analysis (Greeson and others, 1977 and Greeson (ed.), 1979). Because of the relative ease of changing clogged filters, these systems may be used to filter large volumes of water-sediment samples with high concentrations of suspended sediment. Vacuum filtration systems are most useful for collecting suspended (filterable) material for subsequent analysis.

Special care must be taken to avoid contamination if vacuum filtration systems are used to collect the filtrate. Loss of dissolved gases, due to the negative pressure in the filter flask, during filtration is virtually impossible to avoid. Loss of carbon dioxide may significantly change the concentration of bicarbonate and carbonate, influence $\mathrm{pH}$, and alter carbonate equilibria (Garrells and Christ, 1965). Loss of oxygen may change the Eh (oxidation-reduction potential) of the sample.

A hand-vacuum pump may be used for small volumes of sample. An electric-vacuum pump or a modified intake manifold of an automotive engine may be used for larger volumes; when using the latter system a check valve should be installed in the vacuum line to prevent contamination of the filtrate by engine fumes.

\section{2--Description}

Typical vacuum filtration systems, like that shown in figure 18, generally consist of a two-part filter funnel (filter support assembly and a filter flask or other container capable of being evacuated) and a vacuum pump. Filter funnels and filter supports are made of borosilicate glass, polycarbonate, polysulfone, polyethylene plastic, or stainless steel. The capacity of filter funnels ranges from 50 to $1,000 \mathrm{~mL}$. Filter supports consist of fritted glass or plastic foam discs sealed in, or sintered in, woven metal screens placed in a tapered stem and inserted through a rubber stopper. The filter funnel and filter support are held together by a clamp; or by screw type, twist-lock, or magnetic couplings. Most assemblies are made to use 47-mm membrane filters and are autoclavable. Filter flasks usually are heavy-walled borosilicate glass of the type commonly used in chemical laboratories, or polycarbonate plastic.

\section{3--Care and Maintenance}

Vacuum filtration systems should be protected from breakage and chipping, particularly the mating surfaces of the filter funnels. The systems should be thoroughly cleaned before use with a nonphosphate laboratory detergent and rinsed with tap water followed by distilled or demineralized water. 


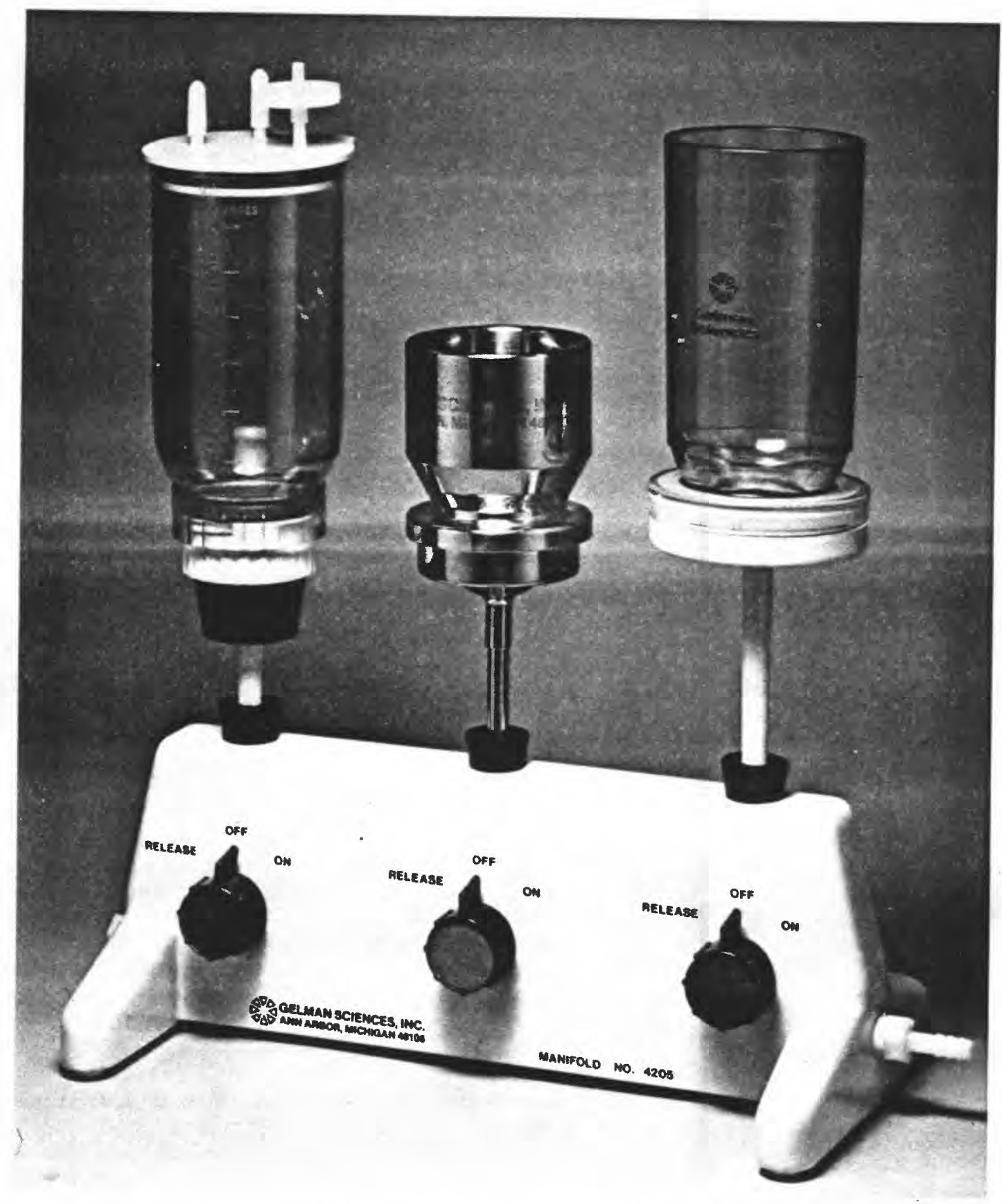

Figure 18. A vacuum filtration system. (Photograph courtesy of Gelman Sciences, Inc.) 
Reristaltic pumping Eiltering systems

1--Application

Peristaltic pumping systems force water through a filter by a peristaltic pump, and are recommended for filtering water-sediment samples for the determination of common constituents, nutrients, and trace metals. The availability of backflushing systems enables repeated use of the same filter membrane when filtering heavy sediment-laden waters and makes the use of prefilters unnecessary. Problems of degassing the filtrate, common to pressure and vacuum filtration systems, are avoidable with peristaltic systems.

\section{2--Description}

Peristaltic pumping systems (fig. 19) consist of a plate-type filter holder, surgical silicone, Tygon or other inert tubing, and a peristaltic pump; a reversible pump for backflushing is preferred.

The filter holder consists of two machined acrylic or cast polycarbonate plastic plates about $198 \mathrm{~mm}$ in diameter that are held together by five $1 / 2$ by $21 / 2-i n$. nylon or stainless steel bolts located around the circumference of the unit. A 132-mm diameter silicone-rubber "O" ring sets in a groove in the lower plate to seal the filter holder. A number of concentric grooves approximately $1 \mathrm{~mm}$ wide and $1 \mathrm{~mm}$ deep are machined or cast in the upper and lower plates to permit a layer of the water-sediment sample to spread over the upper surface of the membrane filter. These grooves are interconnected by eight grooves radiating from the center which direct the filtrate to a central collection point. The lower plate is threaded at the center for a $3 / 8-i n$. outlet tube and near the outer edge for three $91 / 2-i n$. long tripod support legs. A 1/4-in. tabulated fitting screws into the upper plate for attaching the silicone-rubber tube from the peristaltic pump. A screw-type or poppet-type valve is located near the outer concentric groove in the upper plate to exhaust trapped air, allowing the water-sediment sample to spread over the entire upper surface of the membrane filter which is supported between two nylon screens.

The peristaltic pump unit consists of a pump head driven by a 12-volt DC, variable speed, reversible motor. The unit operates at 350 revolutions per minute and is capable of pumping approximately $600 \mathrm{~mL}$ per minute.

\section{3--Care and Maintenance}

Peristaltic pumping filter assemblies should be thoroughly cleaned with a nonphosphate laboratory detergent and rinsed with tap water followed by distilled or demineralized water. Porous plastic filter retainer pads and screens should be washed with distilled or demineralized water after each use.

Filter tubing should be inspected before each use for residue accumulation, discoloration, weakness, or other deterioration. Thoroughly clean new tubing before use by soaking overnight in distilled or demineralized water. 

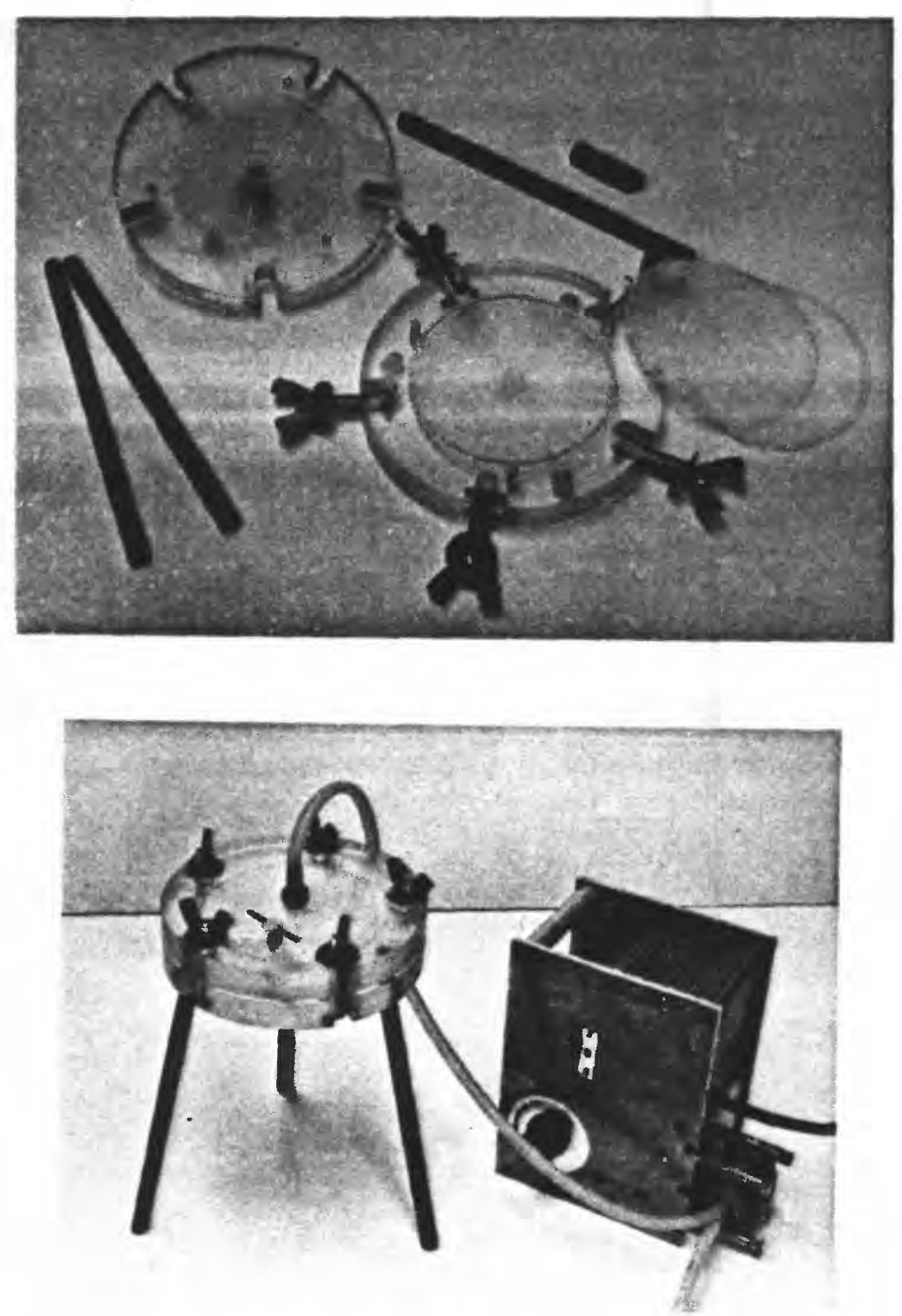

Figure 19. A peristaltic pumping filtration system. 


$$
\text { 1--Equipment }
$$

Most of the filtration systems and filters described above are appropriate for filtering water-sediment samples for the determination of dissolved major constituents and nutrients provided the limitations of each are taken into account and the necessary adjustments made. The preferred equipment for routine field filtration is a plastic, backflushing platefilter holder, 142-mm diameter; 0.45- $\mu \mathrm{m}$ pore-size membrane filters: and a reversible peristaltic pump with lengths of medical grade silicone-rubber tubing.

\section{2--Procedures}

Water-sediment samples usually are filtered for the determination of the dissolved major constituents and nutrients after subsamples required for the determination of their total or total recoverable concentrations are taken.

The filtration system selected needs to be in good condition and physically and chemically clean before use. Check filter holders for damage and replace or repair if not usable; gaskets or 0-rings must be intact. If membrane filter support screens are iron stained, soak in dilute hydrochloric acid (about 10 percent) and rinse with distilled or demineralized water. Filter holders and tubing should be washed with a nonphosphate detergent and rinsed with tap water followed with distilled or demineralized water.

The peristaltic pumping filtration system is preferred for the filtration of water-sediment samples collected for the determination of major inorganic constituents and nutrients.

Place a 142-mm diameter, 0.45- $\mu \mathrm{m}$ pore-size membrane filter between the nylon support screens, set the unit on the lower plate of the filter holder, put the top plate in place, and fasten together by tightening the wing nuts evenly. Attach the silicone-rubber tube from the peristaltic pump and place the other end of the tubing in the water-sediment sample in a churn splitter or other container. Turn the peristaltic pump on and allow the water film to spread over the surface of the membrane filter by opening the exhaust port. After the membrane-filter surface has been wetted, close the exhaust port and waste about $400 \mathrm{~mL}$ of filtrate to rinse the membrane filter and plate-filter assembly. Collect the required volumes of subsamples in the appropriate sample containers and process as described below.

If the membrane filter becomes clogged with particulates, insert the outlet tube of the plate filter into the sample container filled with filtrate. Reverse the direction of the peristaltic pump to backflush or remove the filter cake from the membrane filter. Replace the tube in the water-sediment sample, reverse the direction of the peristaltic pump, and proceed with filtration as above until the required volume of sample is obtained. This backflushing procedure is usually not effective with samples high in clay-sized particles. An alternative procedure is to open the filter holder, insert a new membrane filter, rinse as described above, and then continue the filtration. 
Pressure filtration may be used when small quantities of filtrate are needed for analysis or where repeated filling of the sample reservoir-filter holder is permissible. Place, in sequence, a 47-mm diameter, 0.45- $\mu \mathrm{m}$ poresize membrane filter on the support screen and the Teflon gasket in the lower cap of the filter holder and screw the cap on the filter-holder barrel; the filter holder usually is supported by a condenser clamp on a ring stand. Pour about $200 \mathrm{~mL}$ of the water-sediment sample into the filter-holder barrel and

- screw on the upper cap. Attach the hose from the compressed gas cylinder and open the regulator valve; a pressure of about $101 \mathrm{~b} / \mathrm{in}^{2}$ is sufficient. Rinse the membrane filter by wasting the first 30 to $40 \mathrm{mI}$ of the filtrate. The rinse can be done with distilled water if the sample has high concentrations of sediment that will clog the filter before the required sample volume is processed. However, the preferred alternative for filtering sediment-laden samples is peristaltic pumping filtration. The remaining filtrate is collected in an appropriate sample container. If needed, the procedure is repeated, omitting the rinsing of the membrane filter, until the required volume of filtered sample is obtained. Sample handling and preservation are described below.

Vacuum filtration may be used to filter water-sediment samples collected for the determination of the major inorganic constituents and nutrients, except for those that are affected by the loss of carbon dioxide or oxygen. Water samples with low dissolved oxygen or samples that may be unstable should not be filtered with vacuum filtration.

Place a 47-mn diameter, 0.45- $\mu$ m pore-size membrane filter on the filter support and clamp on the filter funnel. Place the assembly in the filter flask and attach it to the vacuum source. Pour about $50 \mathrm{mI}$ of the water-sediment sample or distilled water into the filter funnel and rinse the membrane filter by applying a vacuum. Swirl the filtrate to rinse the filter flask and discard the filtrate. Fill the filter funnel with the watersediment sample, apply vacuum, and collect the required volume of filtrate. Transfer the filtrate to the appropriate sample containers.

If the membrane filter becomes clogged with particulates, disassemble the filter support - filter funnel assembly and replace the membrane filter. Pour any remaining filtrate in the filter flask into a sample container. Rinse the new membrane filter as described above before filtering the next sample aliquot.

Trace Metals

\section{1--Equipment}

The peristaltic pumping system with a plastic, backflushing platefilter holder: 142-mm, 0.45- $\mu \mathrm{m}$ pore-size membrane filters; and a reversible peristaltic pump with lengths of medical grade silicone-rubber tubing is the only equipment approved for the filtration of water-sediment samples for the determination of trace metals. The pressure filtration system and vacuum or peristaltic pumping systems with metal filter holders are not approved because of possible contamination of the sample from contact with metal parts. Vacuum systems are not recommended because trace metals such as iron and manganese are easily oxidized. For the filtration of water-sediment samples for the determination of aluminum, iron, manganese, and titanium, membrane filters with a $0.1-\mu \mathrm{m}$ pore size are highly recommended for routine studies; they are essential for geochemical studies. 


\section{2--Procedures}

The procedures described above for major inorganic constituents and nutrients are recommended for the filtration of water-sediment samples collected for the determination of dissolved trace metals.

Organic Constituents

$$
\text { 1--Equipment }
$$

Pressure filtration using a stainless-steel barrel filter holder, silver-membrane filters, and either a peristaltic pumping system or clean nitrogen gas for pressure are recommended for the filtration of watersediment samples collected for the determination of dissolved and/or suspended organic constituents.

$$
\text { 2--Procedures }
$$

For filtration of water-sediment samples for the determination of dissolved and/or suspended organic carbon, place, in order, a 47-mm diameter, $0.45-\mu \mathrm{m}$ silver-membrane filter and a Teflon gasket on the support screen in the lower cup of a previously cleaned stainless-steel barrel filter holder. Handle the silver-membrane filter and gasket with forceps only; the cleanest fingers have an oily coating which will contaminate the equipment and sample. Screw the lower cap onto the barrel, supported on a ringstand, and pour the water-sediment sample into the barrel. Screw on the upper cap, attach the pressure hose, apply pressure, and collect $100 \mathrm{~mL}$ of filtrate in a previously prepared glass sample container.

If suspended-organic carbon is to be determined, continue filtration until the filter holder is empty, carefully measuring the total volume of filtrate. Alternatively, a measured volume of water-sediment sample may be poured into the filter holder and then filtered. Disassemble the filter holder and remove the silver-membrane filter with forceps; handle and preserve the filtered sample and silver-membrane filter as described below.

When field filtration of water-sediment samples collected for the determination of other organic constituents is required, the procedure is the same as above. However, because at least $800 \mathrm{~mL}$ of filtered sample is needed for the analysis, repetitive filtrations using several silver-membrane filters are needed. Absolute cleanliness and sample handing and preservation techniques must be observed because of the increased opportunity for contamination.

Radiechemical Constituents

$$
\text { 1--Equipment }
$$

Water-sediment samples collected for the determination of suspended gross alpha and gross beta radioactivity, cesium-137 and ruthenium-106 must be filtered at the National water Quality Laboratory, not in the field. Similarly, laboratory filtration is required when certain methods are used for the determination of dissolved gross alpha radioactivity, radium-226, strontium-90, and uranium (refer to the National Water Quality Laboratory Services Catalog, Feltz and others (eds.), 1985). 
The peristaltic pumping filtration system consists of a plastic, backflushing plate filter holder; $142-\mathrm{mm}, 0.45-\mu \mathrm{m}$ plastic membrane filter, a reversible peristaltic pump, and silicone-rubber tubing is preferred for filtration of water-sediment samples collected for the determination of other dissolved radiochemical constituents.

\section{2--Procedures}

Water-sediment samples for the determination of radiochemical constituents should be filtered using the peristaltic pumping filtration system as described above for major inorganic constituents and nutrients.

\section{Storage. Preservation and Shipping of hater Samples}

\section{Principles and Concepts}

The effort and cost expended in obtaining representative watersediment samples is wasted if the samples deteriorate between the time of collection and analysis. Generally, the shorter the time lapse, the more reliable will be the analytical results. For some constituents and physical properties, immediate analysis in the field is required to obtain reliable results; for other constituents, reliable results can be obtained from properly stored and preserved samples.

The complete preservation of samples is virtually impossible because complete stability of every constituent or physical property can never be achieved. Preservation techniques, can only retard the chemical, physical, or biological changes that inevitably occur after the water-sediment sample is removed from its source. These changes include oxidation, reduction, precipitation, adsorption, ion exchange, coprecipitation, volatilization, gas exchange, cell growth, and cell lysis. Preservation methods generally are intended to: retard or prevent hydrolysis, precipitation, and adsorption; reduce volatility and gas exchange; and retard biological action. These methods include: $\mathrm{pH}$ control, addition of chemicals, refrigeration, sealing of containers and exclusion of air, light control, and choice of proper container.

Before submitting samples to the National Water Quality Laboratory for analysis, consult the Water Quality Laboratory Services Catalog for the current sample volumes, bottle type, and preservation required.

\section{Sample Containers}

\section{Rolyolefin Bottles}

\section{1--Application}

Polyolefin bottles, most commonly polyethylene, are recommended for the storage and shipment of water-sediment and bed-material samples for the determination of common constituents and trace metals. They also are used for the determination of: tannin and lignin in water-sediment samples, oil and grease in bed-material samples, inorganic carbon, and certain biological analysis (Greeson and others, 1977). Polyolefin bottles are not to be used for the storage and shipment of water-sediment and bed-material samples for the determination of organic constituents other than those mentioned above. 


\section{2--Description}

Polyolefin bottles are made of high-molecular weight hydrocarbons which include low- and high-density polyethylene, polyallomer, polypropylene, and polymethylpentene. They are break resistant, nontoxic, noncontaminating, and the only plastic lighter than water. They are resistant to most chemicals at room temperature but are damaged by long exposure to ultraviolet light and certain strong acids. The bottles supplied for storage and shipment of water-sediment samples by the National Water Quality Laboratory are made of linear high-density polyethylene. They are chemically inert, have no known solvent at room temperature, and can be sterilized chemically or with ethylene oxide gas. Because the polymer has minimal branching, the bottles have low permeability and are relatively rigid.

Polyethylene bottles are furnished by the National Water Quality Laboratory in capacities of $125,250,500$, and $1,000 \mathrm{~mL}$. A $250-\mathrm{mL}$ brownpolyethylene bottle is furnished for the storage and shipment of nutrient samples.

\section{Glass Bottles}

\section{1--Application}

Glass bottles are recommended for the storage and shipment of watersediment and bed-material samples for the determination of organic compounds. They also are recommended for the storage and shipment of water-sediment samples for the determination of isotope ratios and chemical oxygen demand. The bottles are made of a borosilicate or flint (soda-lime) glass which has been "aged" to prevent leaching of boron and other contaminants by aggressive water-sediment samples.

\section{2--Description}

Glass bottles used for the storage and shipment of water-sediment and bed-material samples are usually made of flint (soda-lime) glass; the $40 \mathrm{~mL}$ septum bottle and some special containers are made of borosilicate glass. Glass bottles are furnished by the National water Quality Laboratory in capacities of $40,125,250$, and $1,000 \mathrm{~mL}$.

\section{other containers}

Other containers used for the storage and shipment of water-sediment samples include bottles made of Teflon for the determination of low levels of trace metals, and polypropylene for the determination of algal-growth potential; and borosilicate glass for the determination of radon.

\section{Preservatives}

Acids, bases, or metallic salts are added as preservatives to water samples to retain dissolved constituents in solution, prevent loss by volatilization, or arrest biological activity. All preservatives needed for the analysis of water samples are generally available from either the National Water Quality Laboratory or the Water Quality Service Unit in Ocala, Florida. Preparation and packaging of preservatives by district or field offices is not recommended to reduce chances of contamination and to minimize handling of hazardous chemicals. 
Nitric acid is added to water samples for the determination of major cations and trace metals to retain these constituents in solution by preventing precipitation and adsorption on the walls of containers. If the concentration of trace impurities in reagent grade nitric acid exceeds the tolerance for the detection limit of the desired analysis, ultrapure acid, made by distillation of reagent grade acid, must be used.

$$
\text { 2--Availability }
$$

Concentrated, reagent grade nitric acid is available from the National Water Quality Laboratory in sealed 1-or 2-mL borosilicate-glass ampules for routine sample preservation. Ultrapure nitric acid also is available in 1-mL sealed borosilicate-glass ampules for preservation of water samples for lowlevel determination of trace metals.

\section{3--Precautions}

Nitric acid is highly corrosive, is a powerful oxidizing agent, has a moderate fire hazard, and can explode violently on contact with strong reducing agents. It has high acute local and systemic toxicity through body contact, ingestion, or inhalation of furnes which may cause death or permanent injury after very short exposure to small quantities.

Ampules of nitric acid should be opened by wrapping the ampule in a towel or tissue, then snapping off the tip away from the body. The use of rubber or disposable plastic gloves is recommended. Empty the ampule into the sample by tapping it with a pencil or forefinger or by touching the ampule to the inside edge of the bottle. Ampules should be rinsed with large amounts of tap water after emptying and disposed of properly.

Hydrochloric Acid

$$
\text { 1--Application }
$$

Hydrochloric acid is added to water samples for radiochemical determination of dissolved gross beta and gamma activity and radioelements to prevent their precipitation and/or adsorption on the walls of containers.

$$
\text { 2--Availability }
$$

Concentrated, reagent-grade hydrochloric acid is available from the National Water Quality Laboratory in sealed $5-\mathrm{mL}$ borosilicate glass ampules for routine sample preservation.

\section{3--Precautions}

Hydrochloric acid is highly corrosive and has high acute local and systemic toxicity. It may cause death or permanent injury upon body contact, ingestion, or inhalation of fumes. Ampules of hydrochloric acid should be opened by wrapping the ampule in a towel or tissue, then snapping off the tip away from the body. The use of rubber or disposable plastic gloves is recommended. Empty the ampule into the sample by tapping it with a pencil 
or forefinger or by touching the ampule to the inside edge of the bottle. Ampules should be rinsed with large amounts of tap water after emptying, and disposed of properly.

\section{Sulfuric Acid}

$$
\text { 1--Application }
$$

Sulfuric acid is added to water samples for the determination of chemical oxygen-demand and oil and grease to inhibit microbiological degradation of organic material.

$$
\text { 2--Availability }
$$

Concentrated, reagent-grade sulfuric acid is available from the National Water Quality Laboratory in sealed 1-and 2-mL borosilicate-glass ampules for routine sample preservation.

\section{3--Precautions}

Sulfuric acid is highly corrosive, is a powerful oxidizing agent, and can cause charring or ignition of combustible materials upon contact. It reacts with water or steam to produce heat. It has a high acute local toxicity and can cause death or permanent injury through body contact or ingestion.

Ampules of sulfuric acid should be opened by wrapping the ampule in a towel or tissue, then snapping off the tip away from the body. Empty the ampule into the sample by tapping it with a pencil or forefinger or by touching the ampule to the inside edge of the bottle. The use of rubber or disposable plastic gloves is recommended. Ampules should be rinsed with large amounts of tap water after emptying and disposed of properly.

Nitric Acid - Potassium Dichromate

$$
\text { 1--Application }
$$

A solution of $10 \mathrm{~mL}$ concentrated nitric acid and 0.1 gram potassuim dichromate is added to water samples for the determination of mercury to prevent it from reducing to an elemental form and escaping from the sample as mercury vapor.

\section{2--Availability}

Standard solutions of nitric acid - potassuim dichromate are available from the National Water Quality Laboratory in sealed 10-mL borosiliate-glass ampules for routine sample preservation.

$$
\text { 3--Precautions }
$$

Precautions are similar to those for nitric acid discussed above. Sedium Hydroxide

$$
\text { 1--Application }
$$

Sodium hydroxide is added to water samples for the determination of cyanide to prevent conversion to gaseous hydrogen cyanide and subsequent loss. 


\section{2--Availability}

Sodium hydroxide standard solutions are the preferred form for routine sample preservation. The reagent is available from any chemical supply company. It should be stored in a polyethylene bottle with a polypropylene screw cap for use in the field.

\section{3--Precautions}

Sodium hydroxide is a corrosive reagent that has high acute local and systemic toxicity through body contact or ingestion. It can cause death or permanent injury after short exposure to small quantities. The use of rubber or disposable plastic gloves is recommended. Do not pipet sodium hydroxide by mouth.

Cepeer Sulfate - Phosphoric Acid

$$
\text { 1--Application }
$$

Copper sulfate and phosphoric acid are added to water samples for the determination of phenol to inhibit biodegradation and prevent the oxidation of phenols resulting from the precipitation of cupric hydroxide.

$$
\text { 2--Availability }
$$

Standard solutions of copper sulfate - phosphoric acid are available from the Ocala Water Quality Services Unit. Because of the difficulty of their being emptied, ampules of concentrated phosphoric acid usually are not used. Bottle or plunger-type automatic pipetters are recommended.

$$
\text { 3--Precautions }
$$

Copper sulfate has moderately acute local and systemic toxicity, causing reversible changes which disappear after end of exposure. It is reported to cause irritation of skin and conjunctivitis. The use of rubber or disposable plastic gloves is recommended.

Phosphoric acid has moderately acute local and systemic toxicity, causing irritation upon contact. The use of rubber or disposable plastic gloves is recommended. Do not pipet phosphoric acid by mouth.

Mercuric Chloride

$$
\text { 1--Application }
$$

Mercuric chloride is added to water samples for the determination of nitrogen, phosphorus, and isotopic ratios to prevent their change in oxidation state or form by arresting microbiological activity. It is effective for five days, or longer, when samples also are chilled to $4^{\circ} \mathrm{C}$.

$$
\text { 2--Availability }
$$

Mercuric chloride ampules are available from the National water Quality Laboratory for routine nitrogen and phosphorus sample preservation. Each ampule contains $13 \mathrm{mg} \mathrm{HgCl}_{2}$ and $100 \mathrm{mg} \mathrm{NaCl}$ in $1 \mathrm{~mL}$ of deionized water. The addition of one mercuric chloride ampule to $250 \mathrm{~mL}$ of sample results in a concentration of $40 \mathrm{mg}$ of $\mathrm{Hg}^{+2}$ per liter of sample. 
Mercuric chloride tablets are available in a blister pack from the National Water Quality Laboratory for routine isotopic ratio sample preservation. Each tablet contains $13 \mathrm{mg}$ of mercuric chloride and $172 \mathrm{mg}$ of sodium chloride. The addition of one tablet to $250 \mathrm{~mL}$ of sample results in a concentration of $40 \mathrm{mg}$ of $\mathrm{Hg}^{+2}$ per liter of sample.

$$
\text { 3--Precautions }
$$

Mercuric chloride is extremely hazardous and has high acute local and systemic toxicities. Ingestion or inhalation of dusts may cause death or permanent injury after very short exposure to small quantities; the lethal dose for humans is $1.2 \mathrm{~g}$ (about 100 ampules or tablets). Mercuric chloride has moderate chronic local toxicity which may involve both irreversible and reversible physiological changes. The use of rubber or disposable plastic gloves is recommended for handling ampules. Empty ampule into the sample by tapping it with a pencil or forefinger or by touching the ampule to the inside edge of the bottle. Mercuric-chloride tablets should be handled with tweezers. Do not smoke or eat while handling either the tablets or solution; wash hands immediately after use.

Care should be taken to store mercuric chloride ampules separately from acid ampules to avoid mixup. Mercuric chloride tablets should be stored in airtight plastic or glass containers and used only to preserve samples for isotopic ratio.

Used ampules may contain one drop of mercuric chloride solution, about $500 \mu \mathrm{g}$ of mercury. Used ampules should be stored in a leakproof plastic or glass container. Upon return from the field, rinse the ampules with tap water at a rate of ten seconds of rinsing for each ampule to meet EPA discharge limits of $200 \mu \mathrm{g} / \mathrm{L}$.

\section{Zinc Acetate}

$$
\text { 1--Application }
$$

Zinc acetate is added to water samples for the determination of sulfide to prevent its loss from solution by volatilization or precipitation.

$$
\text { 2--Availability }
$$

Reagent grade, crystalline zinc acetate dihydrate is available from the Ocala Water Quality Services Unit.

$$
\text { 3--Precautions }
$$

Zinc acetate is generally of low toxicity but the ordinary precautions in handling chemicals--avoiding ingestion and inhalation of dusts and washing of hands after use--should be observed.

Ammoniacal strentium Chleride

$$
\text { 1--Application }
$$

Ammoniacal strontium chloride is added to water samples for the determination of the stable isotopes of carbon to precipitate the constituents as strontium carbonate, preventing their loss. 
Standard solutions of ammoniacal strontium chloride are not available from the National Water Quality Laboratory or the Ocala Water Quality Services Unit. Prepare a solution by dissolving $453 \mathrm{~g}$ of reagent-grade strontium chloride hexahydrate in $2 \mathrm{~L}$ of concentrated reagent-grade ammonium hydroxide. The salt can be added to the bottle of ammonium hydroxide. Allow the solution to stand undisturbed for two days. Decant the clear solution into glass reagent bottles and seal tightly. The solution is stable for several years if sealed to prevent contamination with atmospheric carbon dioxide.

$$
\text { 3--Precautions }
$$

The relative health hazard from concentrated short-term exposure to ammonium hydroxide by eye contact and inhalation is high. The hazard from skin contact and ingestion is moderate. Avoid inhalation or other body contact. Use caution when opening bottles of the reagent as release of pressure may cause explosive ejection of contents.

Strontium chloride has a moderate toxicity on ingestion or inhalation of dust. The use of rubber or disposable plastic gloves is recommended.

\section{Shipping Containers}

Containers suitable for shipping water-sediment and bed-material samples to the National Water Quality Laboratory include double-walled corrugated paper boxes, reinforced black fiberboard boxes with handles, and picnic-type coolers. All must be of sturdy construction capable of withstanding severe stress and repeated use.

The double-walled corrugated paper box or reinforced black fiberboard box is suitable for shipping samples in polethylene bottles that do not require refrigeration. Picnic-type coolers, particularly those made of highimpact strength polyethylene, are recommended for shipping all types of samples. They are insulated and water-tight and are used to ship and store chilled samples. They will withstand severe treatment and can be used repeatedly. Universal styrofoam packers and 1/8-in. thick soft foam sleeves are available for individually packing 1-L glass bottles to prevent breakage.

\section{Procedures for Groups of Constituents}

Procedures for the storage, preservation, and shipment of watersediment samples for analysis of groups of constituents are described below. All sample bottles must be identified by labeling as to type of treatment and preservation and by station identification number. In addition, labeling by date and time of collection and analytical schedule is desirable. The various sample bottles required for an analytical schedule should be packaged as a unit for shipment and must be accompanied with a properly executed analytical request form. Procedures not described below are given in the Water Quality Laboratory Services Catalog (Feltz and others (eds), 1985).

Major Cations

\section{1--Appropriate Materials}

Acid-rinsed polyethylene bottles and 1- or 2-mL ampules of nitric acid are required for the storage and preservation of samples for the determination of major cations. Samples may be shipped in double-walled corrugated 
paper boxes or reinforced black fiberboard boxes. However, if the analytical schedule includes sample bottles that must be chilled, ship all bottles in a picnic-type cooler.

\section{2--Procedure}

The acid-rinsed polyethylene bottle, usually of 250-mL capacity, is filled to the neck with the filtered or unfiltered sample leaving enough space for the addition of preservative. Open an ampule of nitric acid and pour contents into the sample. One $\mathrm{mL}$ is usually adequate to adjust the $\mathrm{pH}$ of the sample to less than 2. Cap the bottle tightly and mix the contents; the $\mathrm{pH}$ can be checked with pHydrion test paper. Label the tightly capped bottle and pack in the shipping container.

Major Anions

\section{1--Appropriate Materials}

Field-rinsed polyethylene bottles are required for the storage of water samples for determination of major anions. Preservatives are not needed. Samples may be shipped in double-walled corrugated paper boxes or reinforced black fiberboard boxes. However, if the analytical schedule includes sample bottles that must be chilled, ship all bottles in a picnictype cooler.

\section{2--Procedure}

The field-rinsed polyethylene bottle, usually of 250-mL capacity, is filled to the neck with the filtered sample and tightly capped. A separate field-rinsed polyethylene bottle is filled with unfiltered (raw) sample for the determination of alkalinity. Label the bottles and pack in the shipping container.

Nutrients

\section{1--Appropriate Materials}

Field-rinsed, brown polyethylene 250-mI capacity bottles, ampules of mercuric chloride-sodium chloride, and ice are required for the storage and preservation of water samples for determination of nutrients. Nutrient samples should be shipped in a picnic-type cooler because they must be chilled.

$$
\text { 2--Procedure }
$$

The field-rinsed, brown polyethylene bottle is filled to the neck with the filtered or unfiltered sample and one ampule of mercuric chloride-sodium chloride is added. Tightly cap the bottle, shake to mix the preservative, and cool to $4^{\circ} \mathrm{C}$. Label the bottle and pack with ice in the picnic-type cooler.

\section{Irace Metals}

\section{1--Appropriate Materials}

Acid-rinsed polyethylene or Teflon bottles and 1- or 2-mL ampules of nitric acid or $1-\mathrm{mL}$ ampules of ultrapure nitric acid are required for the storage and preservation of water-sediment samples for determination of trace metals. Acid-rinsed 250-mL glass bottles and 10-mL ampules of nitric acidpotassium dichromate are required for the determination of mercury. Samples 
may be shipped in double-walled corrugated paper boxes or reinforced black fiberboard boxes. However, if the analytical schedule includes samples that must be chilled, ship all bottles in a picnic-type cooler.

\section{2--Procedure}

For the determination of trace metals except mercury, an acid-rinsed polyethylene bottle, usually of 1-L capacity, is filled to the neck with the filtered or unfiltered sample, leaving enough space for the addition of preservative. Open an ampule of nitric acid and pour contents into the sample. Two $\mathrm{mL}$ is usually adequate to adjust the $\mathrm{pH}$ of the sample to less than 2. Cap the bottle and mix the contents; the pH can be checked with pHydrion test paper. For low-level determination of trace metals, a 250-mI acid-rinsed Teflon bottle and ultrapure nitric acid are used in place of the polyethylene bottle and reagent grade nitric acid. Label the bottles and pack in the shipping container.

For the determination of mercury, an acid-rinsed 250-mL glass bottle is filled as above. Open an ampule of nitric acid - potassium dichromate and pour the contents into the sample. Cap the bottle and mix the contents. Label the bottles and pack in the shipping container.

\section{erganic constituents}

\section{1--Appropriate Materials}

Glass bottles, baked at $350^{\circ} \mathrm{C}$ for several hours, with Teflon-lined caps or septa, petri dishes, and ice are required for the storage and preservation of water samples for the determination of organic compounds. organic samples are shipped in picnic-type coolers because they must be chilled.

\section{2--Procedure}

A 125-mI capacity glass bottle with Teflon-lined cap is filled with a filtered or unfiltered sample for determination of organic carbon. It should be tightly capped and placed in a 1/8-inch thick soft foam sleeve for shipping. Suspended organic carbon samples are collected on a silver-membrane filter, folded, and placed in a petri dish, labeled, and sealed with plastic tape or placed inside a Whirl-Pak bag. The organic carbon bottles and petri dishes should be labeled and shipped in a picnic-type cooler at $4^{\circ} \mathrm{C}$.

For other organic analyses, a 1-L capacity glass bottle is filled to the neck with the unfiltered sample, leaving little or no air space. The bottle should be tightly capped, labeled, and chilled to $4^{\circ} \mathrm{C}$. Bottles should be inserted into a universal styrofoam packer or a 1/8-inch thick soft foam sleeve and shipped in a picnic-type cooler with ice.

For the determination of volatile-organic compounds three triplicate vials should be collected for each sample. A $40-\mathrm{mL}$ capacity glass vial is filled to the top, leaving a convex meniscus at the mouth. Slide the septum, Teflon lining down; across the mouth of the bottle and cap. If any air bubbles are present after capping, empty and refill the vial. Label and insert the bottle into a 1/8-inch thick soft foam sleeve ( 2 per sleeve) and pack with ice in the shipping container. 
Analyses for radiochemical constituents include gross alpha, gross beta, radium, radon, uranium, tritium, gross gamma, strontium-90, cobalt-60, cesim-137, lead-210 and stable isotopes of oxygen, nitrogen, sulfur, and carbon. A detailed description of all materials needed for sample collection and preservation may be found in the water Quality Laboratory Services Catalog (Feltz and others (eds.), 1985).

\section{1--Appropriate Materials}

Acid-rinsed 1-L polyethylene bottles, 40-ml glass vials with mineral based scintillation cocktail, 1-pint plastic freezer cartons, 3-mL ampules of hydrochloric acid, mercuric chloride tablets, and ammoniacal strontium chloride are used for most constituents. Samples collected in polyethylene bottles may be shipped in double-walled corrugated paper boxes, reinforced black fiberboard boxes, or picnic-type coolers. Samples collected in glass bottles or vials may be shipped in picnic-type coolers or double-walled corrugated paper boxes if properly supported to prevent breakage.

\section{2--Procedure}

For the deternination of gross alpha, gross beta, radium, uranium, gross gamma, and specific radionuclides (strontium-90, cobalt-60, cesium-137, and lead-210), a 1-L acid-rinsed polyethylene bottle is filled to the neck with a filtered or unfiltered sample as required, leaving enough space for addition of preservative. For those constituents requiring acidification, $3 \mathrm{~mL}$ of nitric or hydrochloric acid is added to the sample. Cap the bottle tightly and mix the contents; the $\mathrm{pH}$ of the acidified samples should be less than 2 .

The determination of tritium uses a 1-L polyethylene or glass bottle filled to the neck with an unfiltered sample. For this determination sample bottles should not be rinsed with sample before filling. Cap the bottle tightly.

The determination of radon-222 by the syringe method uses two $20-\mathrm{mL}$ glass vials containing $10 \mathrm{~mL}$ of mineral based scintillation cocktail. Samples for radon analyses cannot be aerated; a churn splitter cannot be used for collection. After rinsing a $10-\mathrm{mL}$ glass syringe several times with sample, slowly withdraw an aliquot of water to avoid developing a vacuum. slowly eject any air bubbles and excess sample until $10 \mathrm{~mL}$ of sample remain in the syringe. Carefully place the tip of the syringe at the bottom of the scintillation cocktail solution. Slowly inject the sample into the solution to prevent any turbulence or air bubbles. Cap the vial tightly and label. Do not place any labels on the sides of the vial because this will interfere with anlaysis.

For the determination of stable isotopes of oxygen, nitrogen, sulfur, and carbon, a 1-L polyethylene or glass bottle with a leak-free top is filled with a filtered or unfiltered sample as required. Some constituents also require preservation by addition of a mercuric-chloride tablet. Samples for carbon determination require addition of a carbon-free reagent for precipitation. The bottle is capped tightly and sealed with tape. For analyses of solid materials, a plastic freezer carton can be used.

All samples need to be labeled and shipped in the appropriate shipping containers. 


\section{Principles and concepts}

As with water samples, the effort and cost expended to collect bedmaterial samples is wasted if the samples deteriorate between the time of collection and analysis. Generally, the shorter the time elapsed, the more reliable will be the analytical results.

The concentration of sorbed chemical constituents on bed-material particles is generally a function of the particulate surface area. Hence, processing bed-material samples to remove the larger particles provides a sample for which the probability for detection and quantification of constituents of interest is enhanced. Individual processed bed-material samples are easier to composite into a single sample when required and are easier to reliably subsample. Bed-material samples are to be sieved through a screen with 2-mm openings in the field prior to shipment to the U.S. Geological Survey National Water Quality Laboratory. Those bed-material samples where the sand fraction $(2.0$ to $0.063 \mathrm{~mm})$ has no iron, manganese, or organic coating need to be sieved through a screen with $0.063-$ mm openings.

The only preservation technique that is used with bed-material samples is chilling to $4^{\circ} \mathrm{C}$ to retard any chemical or biological changes that may occur before analysis.

\section{Sieving}

\section{Equipment and Aoplications}

Sieves approved for processing bed-material samples (fig. 20) are made of metal or plastic polymers. U.S.A. standard sieves are made of brass or stainless steel and are $8 \mathrm{in.}$. in diameter with a depth to the screen of 2 in. and are $27 / 8 \mathrm{in}$. in total height. For $2.0 \mathrm{~mm}$ sieves the permissible variation of the average screen openings is plus or minus 0.070 mm; for $0.063 \mathrm{~mm}$ sieves the permissible variation is plus or minus $0.004 \mathrm{~mm}$. The plain-square mesh screen is soldered in place with solder composed of 99 percent tin and 1 percent lead in both brass and stainless steel sieves. Stainless steel sieves can be obtained with silver-soldered screens on special order. Plastic sieves are made of linear polyethylene about $12-i n$. in diameter with a depth to the screen of $33 / 4$ in. and about. 4 1/4 in. in total height. The screen is made of a polyester mesh welded to the sieve ring. Plastic sieves with $0.063-\mathrm{mm}$ screens are not available commercially. Five and one-half inch diameter PVC sieve rings, designated US SR-72A, B, and C, are available for making sieves.

The rings are $21 / 4$ in. high. Plain-square mesh screen cloth made of nylon, Teflon, or polyethylene is stretched over the rings and held in place with nylon self-locking straps. Similar rings in a variety of diameters can be machined locally from acrylic resin or polyvinyl chloride tubing. A close-fitting pan is used with metal or plastic sieves to collect the sieved -bed material.

Metal sieves are used to process bed-material samples for the determination of major cations, nutrients, chemical oxygen demand, volatile solids, moisture content, radioelements and isotopes, and organic constituents. Plastic screens are used to process bed-material samples for the determination of the trace metals. 


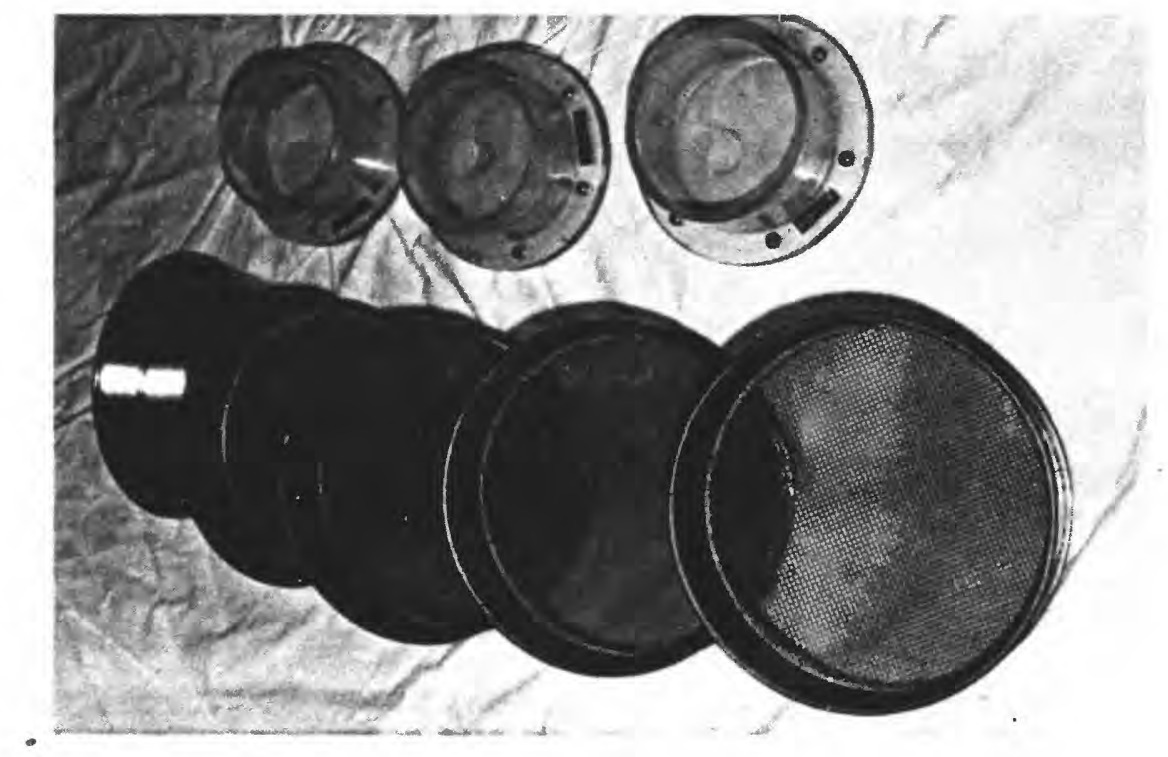

Figure 20. Sieves approved for processing bed-material samples.

\section{Rrecedures}

Samples of bed material are processed for analysis as follows: Sieves and pans should be washed with a nonphosphate detergent, rinsed with tap water followed with distilled or demineralized water, and dried before use. Examine the screens for fine particles clogging the openings. These generally can be removed by gently scrubbing the bottom side of the screen with a stiff-bristled brush or rubbing with the fingers. Do not force particles through the screen as this may enlarge the openings.

Quantitatively transfer the bed-material sample from the sampler to a sieve-pan assembly appropriate to the analysis desired. To avoid overloading a 4.0 - or $8.0-\mathrm{mm}$ sieve can be nested with the $2.0-\mathrm{mm}$ sieve-pan assembly to remove large particles. Shake the sieve-pan assembly from side-to-side until most of the less than $2.0-\mathrm{mm}$ bed material has passed through the screen. The remaining bed material smaller than $2.0 \mathrm{~mm}$ can be washed through the screen with a small amount (not to exceed $100 \mathrm{~mL}$ ) of native water. If further washing is needed, carefully remove the pan, decant the wash water into a chemically clean container, replace the pan, and use the decanted wash water again to wash the bed material.

Remove the pan and thoroughly mix the sieved bed material with a chemically clean metal or plastic spatuia. Transfer a subsample to the appropriate container for shipment. 
Plastic

1--Application

Plastic containers are approved for the storage and shipment of bedmaterial samples that are to be analyzed for physical properties; inorganic constituents including major cations, trace metals, major nutrients, and radioisotopes; and $o i l$ and grease. Bed-material samples collected for the determination of organic compounds are to be stored and shipped in properly cleaned glass bottles.

\section{2--Description}

Plastic containers approved for storage and shipment of bed-material samples are 1-pint polyethylene cartons generally used for storage of frozen foods. The cartons are open-faced boxes about $41 / 4 \mathrm{in.}{ }^{2}$ by $23 / 8 \mathrm{in}$. deep with a tight-fitting, leak-proof cover.

Glass

$$
\text { 1--Application }
$$

Glass bottles are used for the storage and shipment of bed-material samples that are to be analyzed for organic compounds including polychlorinated biphenyls, base/neutral extractable compounds, chlorophenoxy acid herbicides, organochlorine and organophosphorus insecticides, and kepone. Glass bottles can also be used for the storage and shipment of bed-material samples to be analyzed for inorganic constituents.

$$
\text { 2--Description }
$$

Glass bottles approved for the storage and shipment of bed-material samples are 1-L wide-mouth flint-glass bottles that are encased in a universal styrofoam packer or a $1 / 8$-inch thick soft foam sleeve to prevent breakage. The bottles, available from the National Water Quality Laboratory, have been cleaned and baked at about $350^{\circ} \mathrm{C}$ for several hours to remove contaminants.

\section{Sample Preservation and Shipment}

Bed-material samples collected for the determination of organic compounds, cyanide, major nutrients, chemical oxygen demand, and volatile solids are preserved by immediately chilling to $4^{\circ} \mathrm{C}$. Bed-material samples collected for the determination of physical properties and other inorganic constituents require no preservation.

Plastic and glass containers should be carefully filled with the required amount of sieved bed-material sample. No particles should adhere to the container opening that might prevent a tight seal. A clean cover is pressed on the plastic container with enough pressure to firmly seat it; the container is then sealed with plastic-electrical tape stretching the tape slightly as it is applied. A Teflon-lined phenolic cap is screwed tightly on the glass container. Although not required, the container can be sealed with plastic-electrical tape. 
Plastic containers that don't require chilling can be shipped to the National Water Quality Laboratory in a double-walled corrugated paper box or a reinforced black fiberboard box with enough packing material to prevent shifting or deformation of the containers. Plastic containers requiring chilling need to be packed in ice in a picnic-type cooler for shipment. Glass containers are first placed in universal styrofoam packers or foam sleeves and then packed in ice in a picnic-type cooler for shipment.

\section{Procedures for Groups of Constituents}

Physical Properties

$$
\text { 1--Appropriate Materials }
$$

One-pint polyethylene containers, plastic electrical tape, and $2.0 \mathrm{~mm}$ and $0.063 \mathrm{~mm}$ metal or plastic sieves with pans are required for the processing, shipment, and storage of bed-material samples for the determination of physical properties.

\section{2--Procedures}

A minimum of $10 \mathrm{~g}$ of bed material, sieved through a $2.0 \mathrm{~mm}$ screen and well mixed, is transferred to a 1-pint polyethylene container. The container is covered tightly, sealed with plastic-electrical tape, labeled, and packed in the shipping carton. Although not mandatory, it is preferable that bedmaterial samples for analysis of cation-exchange capacity be sieved through a 0.063-mm screen. Bed-material samples for the determination of volatile solids are preserved by chilling to $4^{\circ} \mathrm{C}$ and shipped in ice in a picnic-type cooler; chilling is not required for other physical properties. For the determination of moisture content, water collected with the bed material or that used to wash the sieve needs to be allowed to gravity drain from the bed-material sample before the subsample is transferred to the polyethylene container. However, do not allow the subsample to air dry.

Inerganic Censtituents

\section{1--Appropriate Materials}

One-pint polyethylene containers, plastic-electrical tape, and $2.0-\mathrm{mm}$ and $0.063-\mathrm{mm}$ metal or plastic sieves with pans are required for the processing, shipment, and storage of bed-material samples for the determination of inorganic constituents.

$$
\text { 2--Procedures }
$$

A minimum of $10 \mathrm{~g}$ of bed material, sieved through a $2.0-\mathrm{mm}$ screen and well mixed, is transferred to a 1-pint polyethylene container. The container is covered tightly, sealed with plastic-electrical tape, labeled, and packed in the shipping carton. Bed-material samples that consist largely of silt and clay or contain clean sand are to be sieved through a $0.063-\mathrm{mm}$ screen. Bed-material samples for analysis of trace metals are to be sieved through plastic sieves. Chilling is not required. 


\section{1--Appropriate Materials}

One-liter wide-mouth flint-glass bottles, cleaned and baked by the National Water Quality Laboratory, universal styrofoam packers or. 1/8-inch soft foam sleeves, $2.0-\mathrm{mm}$ metal sieves, and ice are required for the processing, shipment, and storage of bed-material samples for the determination of organic constituents.

\section{2--Procedures}

A minimum of $200 \mathrm{~g}$ of bed material, sieved through a 2.0-mm metal screen and well mixed, is transferred to a 1-L wide-mouth glass bottle taking care to keep the lip of the bottle clean. The bottle is capped tightly, labeled, and immediately chilled to $4^{\circ} \mathrm{C}$. The chilled bottle is placed inside a universal styrofoam packer or a 1/8-in. thick foam sleeve and packed with ice in a picnic-type cooler. For the determination of oil and grease, a minimum of 10 grams of sieved bed material is transferred to a 1-pint polyethylene container. The container is covered tightly, sealed with plastic-electrical tape, labeled, and chilled immediately to $4^{\circ} \mathrm{C}$. The container is packed with ice in a picnic-type cooler.

\section{SELECTED REFERENCES}

Bouma, A.H., and Marshall, N.F., 1964, A method for obtaining and analyzing oceanic sediment samples: Marine Geology, v.2, p. 81-99.

Britton, L.J., and Greeson, P.E., eds., in press, Methods for collection and analysis of aquatic biological and microbiological samples:

U.S. Geological Survey Techniques of Water-Resources Investigations, Book 5, Chapter A4. (Available as U.S. Geological Survey Open-File Report 88-190, 685 p., 1988.)

Colby, B.R., 1963, Fluvial sediments - a summary of source, transportation, deposition, and measurement of sediment discharge: U.S. Geological Survey Bulletin 1181-A, $47 \mathrm{p}$.

Culbertson, D.M., Young, L.E., and Brice, J.C., 1967, Scour and fill in alluvial channels with particular reference to bridge sites: U.S. Geological Survey Open-File Report, 58 p.

Edwards, T.K., and Glysson, G.D., in press, Field methods for measurement of fluvial sediment: U.S. Geological Survey Techniques of WaterResources Investigations, Book 3, Chapter C2. (Available as U.S. Geological Survey Open-File Report 86-531, 118 p., 1988.)

Feltz, H.R., and Culbertson, J.K., 1972, Sampling procedures and problems in determining pesticide residues in the hydrologic environment: Pesticides Monitoring Journal, v.6, no. 3, p. 171-178.

Feltz, H.R., Duncan, S.S., and Zepp, Ann, eds., 1988, 1986-87-88 national water quality laboratory services catalog: U.S. Geologica1 Survey Open-File Report 86-23். 
Feltz, H.R., 1980, Significance of bottom material data in evaluating water quality, in Contaminants and Sediments, Ann Arbor, Ann Arbor Science, v.1, p.271-287.

Garrells, R.M., and Christ, C.L., 1965, Solutions, minerals, and equilibria: New York, Harper and Row, 450 p.

Gilbert, G.K., 1914, The transportation of debris by running water: U.S. Geological Survey Professional Paper 86, 263 p.

Green, R.H., 1979, Sampling design and statistical methods for environmental biologists: New York, John Wiley, 257 p.

Greeson, P.E., Ehlke, T.A., Irwin, G.A., Lium, B.W., and Slack, K.V., eds., 1977, Methods for collection and analysis of aquatic biological and microbiological samples: U.S. Geological Survey Techniques of waterResources Investigations, Book 5, Chapter A4, 332 p.

Greeson, P.E., ed., 1979, A supplement to--Methods for collection and analysis of aquatic biological and microbiological samples: U.S. Geological Survey Open-File Report 79-1279, 92 p.

Grim, R.E., 1968, Clay mineralogy: New York, McGraw-Hill, p. 168-183.

Guy, H.P., Simons, D.B., and Richardson, E.V., 1966, Summary of alluvial channel data from flume experiments, 1956-61: U.S. Geological Survey Professional Paper 462-I, 96 p.

Guy, H.P., 1968, Quality control of adjustment coefficients, in Geological Survey Research 1968: U.S. Geological Survey Professional Paper 600-B, p. B165-B168.

- 1970, Fluvial sediment concepts: U.S. Geological Survey Techniques of Water-Resources Investigations, Book 3, Chapter $\mathrm{Cl}, 55 \mathrm{p}$.

Hem, J.D, 1970, Study and interpretation of the chemical charactertistics of natural water $(2 \mathrm{~d}$ ed.): U.S. Geological Survey Water-Supply Paper 1473, $363 \mathrm{p}$.

1985, Study and interpretation of the chemical characteristics of natural water: U.S. Geological Survey Water-Supply Paper 2254, 263 p.

Hubbell, D.W., and others, 1956, Progress report no. 1, Investigation of some sedimentation characteristics of a sand-bed stream: U.S. Geological Survey Report, 78 p.

Hutchinson, G.E., 1957, A treatise on limnology--Volume 1, Geography, physics, and chemistry: New York, John Wiley, $1015 \mathrm{p}$.

Kennedy, V.C., Zellweger, G.W., and Jones, B.F., 1974, Filter pore-size effects on the analysis of $\mathrm{Al}, \mathrm{Fe}, \mathrm{Mn}$, and $\mathrm{Ti}$ in water: water Resources Research, v. 10, p. 785-790.

Lettenmaier, D.P., 1976, Detection of trends in water-quality data records with dependent observations: Water Resources Research, v. 12, p. 1037-1046. 
Leopold, L.B., Wolman, M.G., and Miller, J.P.,1964, Fluvial processes in geomorphology: W.H. Freeman, San Francisco, Ca., 522 p.

Leopold, L.B., and Maddock, Thomas, Jr., 1953, The hydraulic geometry of stream channels and some physiographic implications: U.S. Geological Survey Professional Paper 252, 57 p.

Mongtomery, H.A.C., and Hart, I.C., 1974, The design of sampling programs for rivers and effluents: Journal Institute Water Pollution Control, v. 33 , p. 77-101.

Mortimer, C.H., 1964, Chemical exchanges between sediment and water in the Great Lakes - speculations on probable regulatory mechanisms: Limnology and Oceanography, v.16, no. 2, p. 387-404.

Reineck, H.E., 1963, Der kastengreifer: Natur und Musik, v.93, p. 103-108.

Robertson, D.E., 1968, Role of contamination in trace element analysis of sea water: Analytical Chemistry, v.40, p. 1067-1072.

Simons, D.B., and Richardson, E.V., 1966, Resistance to flow in alluvial channels: U.S. Geological Survey Professional Paper 462-J, 61 p.

Skougstad, M.W., and Scarboro, G.F., 1968, Water sample filtration unit: Environmental Science and Technology,. v.2, no. 4, p. 298-301.

Smoot, G.F., and Novak, C.E., 1969, Measurement of discharge by the movingboat method: U.S. Geological Survey Techniques of Water-Resources Investigations, Book 3, Chapter A11, 22 p.

Snedecor, G.W., and Cochran, W.G., 1967, Statistical methods, 6th ed: Iowa State University Press, 598 p.

Spencer, D.W., and Mannheim, F.T., 1969, Ash content and composition of milli-pore HA filters: U.S. Geological Survey Professional Paper 650-D, p. D288-D290.

Stevens, H.H., Jr., Lutz, G.A., and Hubbell, D.W., 1980, Collapsible bag suspended-sediment sampler: Journal of the Hydraulics Division, Proceedings of the American Society of Civil Engineers, v.106, no. HY4, April, p. 611-616.

Subcommittee on Sedimentation, Federal Inter-Agency River Basin Committee, 1952, The design of improved types of suspended sediment samplers: Federal Inter-Agency River Basin Committee Reptort No. 6, 103 p. 1961, The single-stage sampler for suspended sediment: Inter-Agency Committee on water Resources Report No. 13, 105 p.

Tourtelot, H.A. and Miesch, A.T., 1975, Sampling designs in environmental geochemistry, Geological Society of America, Special Paper 155.

Twenhofel, W.H., 1950, Principles of sedimentation: New York, McGraw-Hill, p. 199-242. 


\section{SELECTED REFERENCES--COntinued}

Voytek, J.E., Jr., 1983, Considerations in the design and installation of monitoring wells: Ground water Monitoring Review, v.3, no. 1, p. 70-71.

Ward, R.C. and Loftis, J.C., 1976, Establishing statistical design criteria for water quality monitoring systems: review and synthesis: Water Resources Bulletin, v. 22, no. 5, p. 759-767.

Welch, P.S., 1948, Limnological methods: New York, McGraw-Hill, 381 p. 